\title{
AN ECOLOGICAL PERSPECTIVE ON ONLINE COMMUNITIES
}

By

\section{Xiaoqing Wang}

B.A. in International Finance, Fudan University, China, 1999 M.A. in Economics, Central Michigan University, 2001

Submitted to the Graduate Faculty of

Joseph M. Katz Graduate School of Business in partial fulfillment of the requirements for the degree of $\mathrm{PhD}$ in Management Information Systems

University of Pittsburgh 


\title{
UNIVERSITY OF PITTSBURGH
}

\section{JOSEPH M. KATZ GRADUATE SCHOOL OF BUSINESS}

This dissertation was presented

by

\author{
Xiaoqing Wang \\ It was defended on \\ June 25, 2007 \\ and approved by
}

Dennis Galletta, PhD, Professor of Business Administration

Laurie J. Kirsch, PhD, Professor of Business Administration

Robert Kraut, PhD, Herbert A. Simon Professor of Human-Computer Interaction

Richard L. Moreland, PhD, Professor of Psychology

Dissertation Advisor: Brian S. Butler, PhD, Associate Professor of Business Administration 


\title{
AN ECOLOGICAL PERSPECTIVE ON ONLINE COMMUNITIES
}

\author{
Xiaoqing Wang, $\mathrm{PhD}$ \\ University of Pittsburgh, 2007
}

Prior research suggests that members' ongoing participation in a community is influenced by their psychological identification with it, the community's internal structural dynamics, and characteristics of the communication exchanged within the community. However, most of this research has focused on characteristics of the individual members and the community under consideration, taking the existence of the community as a given and giving little attention to the larger context in which the community resides.

This dissertation extends prior research by proposing an ecological perspective when studying community success, taking into account the ecological and structural context of individuals' interaction with an online community. Two empirical studies were conducted to test the impact of context on the ongoing interactions between individuals and communities. The first study develops a theory of online community ecology, focusing on the impact of competition created by other communities in the same niche. Analysis of a longitudinal sample of 241 Usenet newsgroups over 64 months implies that both internal characteristics and external context affect communities' capability to retain members. Specifically, competition - the extent to which a community shares content with other communities and the extent to which the community's members also participate in other communities - represents an external threat that leads to a lower likelihood of members to return in the following time 
period.

The second study builds on the first to explore the impact of contextual factors on individual members' ongoing participation decisions in online communities. Applying social exchange theory, I propose to treat individuals' interaction with online communities as a series of social exchanges. In addition to the ecological context, individuals' prior exchanges with an online community are also expected to shape the ways they make decisions about ongoing interaction. A research model based on social exchange theory is proposed and tested, with participation data of 43,758 individuals in seven Usenet newsgroups. The results suggest that an individual's level of current participation, the prior exchange history with the online community, and the availability of other alternative communities all play a role in the individual's continuance decision. 


\section{TABLE OF CONTENTS}

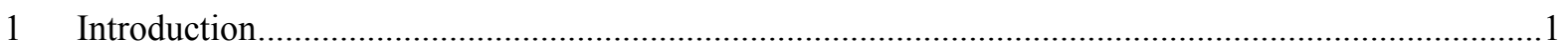

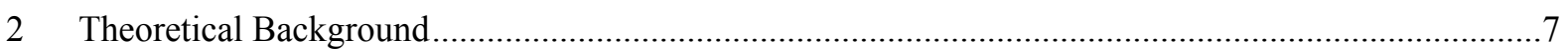

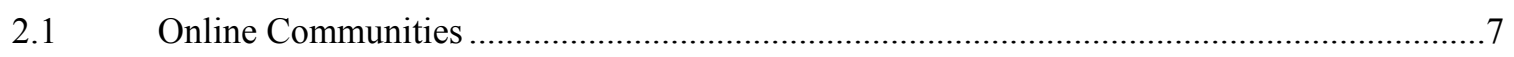

2.2 Member Retention in Online Communities ......................................................................

2.3 Review of Extant Online Community Research .................................................................. 11

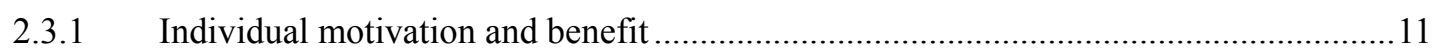

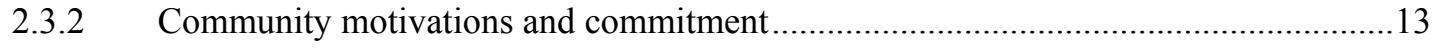

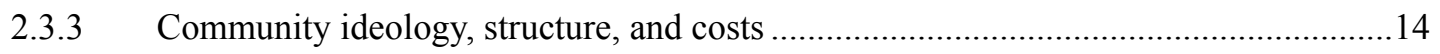

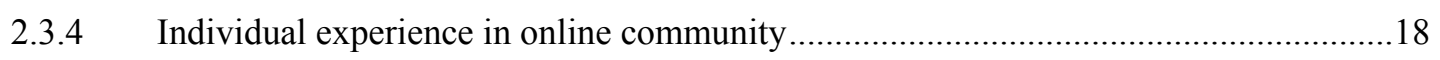

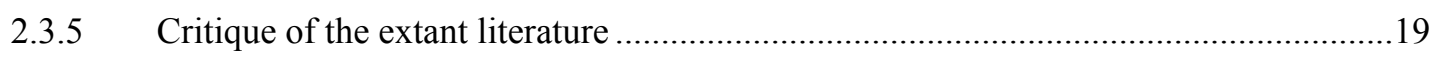

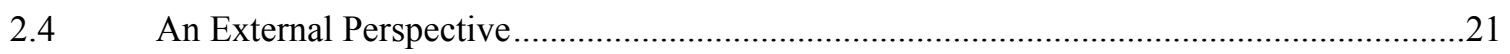

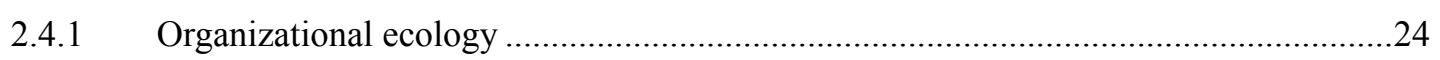

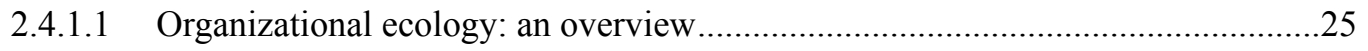

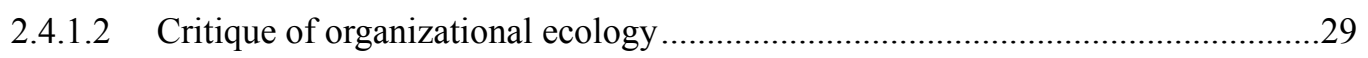

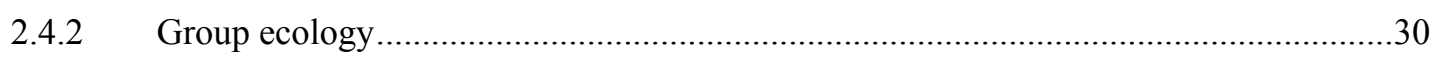

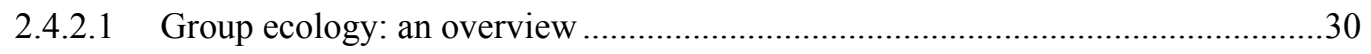

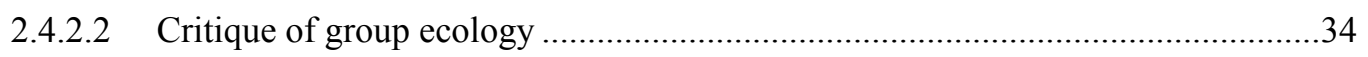

2.4.3 Building a theory of online community ecology .........................................................

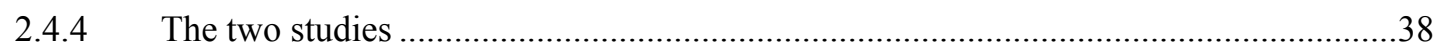

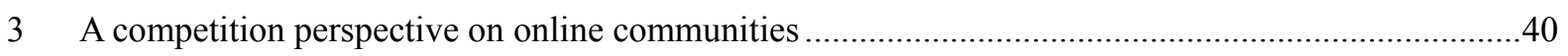

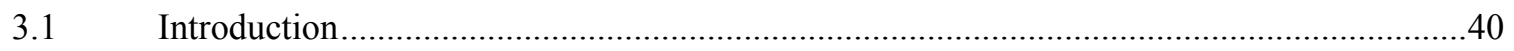

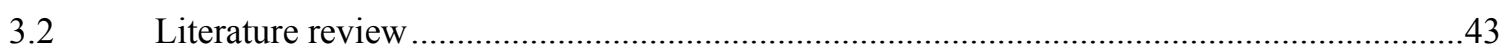

3.2.1 Online Community Member Retention...............................................................43

3.2.2 Commitment, Information Overload, and Ecological Competition ...............................44

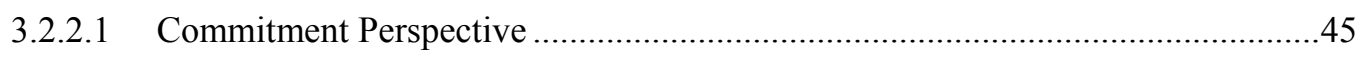

3.2.2.2 Information Overload Perspective …………..................................................... 47

3.2.2.3 Ecological Competition Perspective ................................................................48

3.2.2.4 Interactions between Ecological Context and Community Characteristics............54

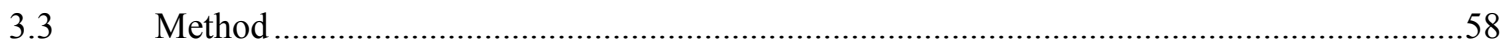

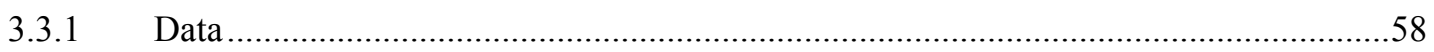

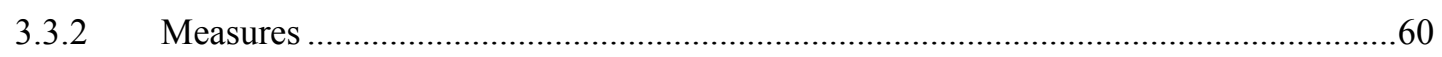

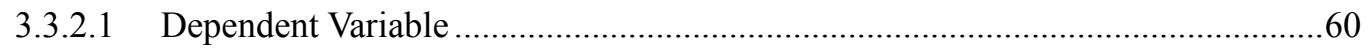

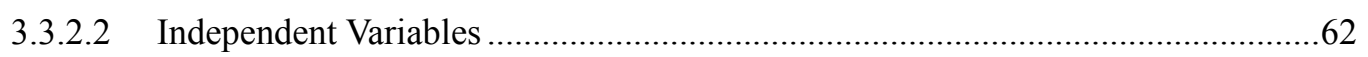

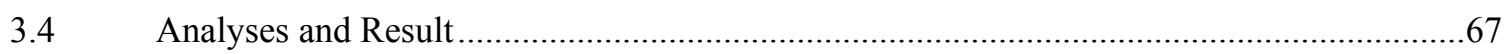

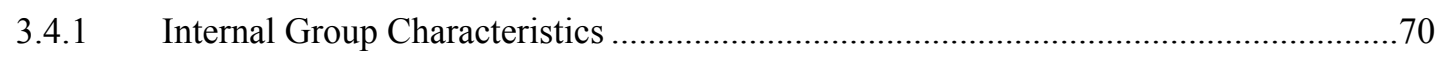

3.4.2 Extent of Competition................................................................................................ 70

3.4.3 Interaction between internal characteristics and extent of competition .........................74

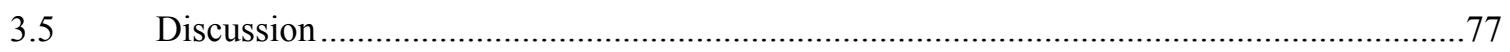




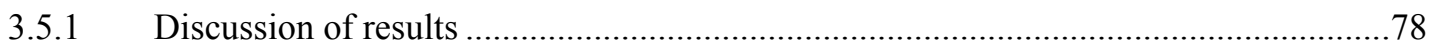

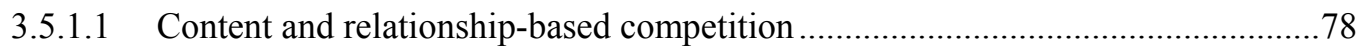

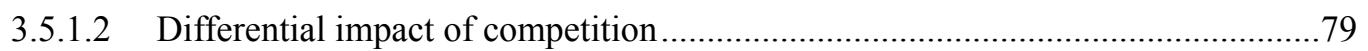

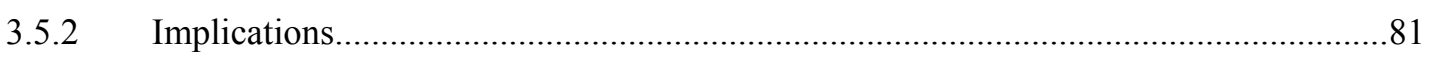

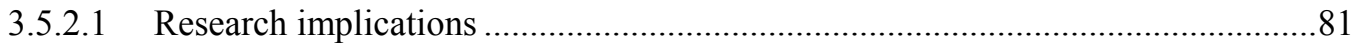

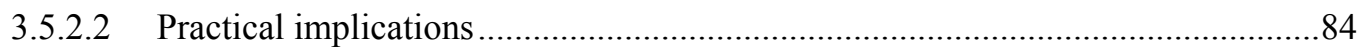

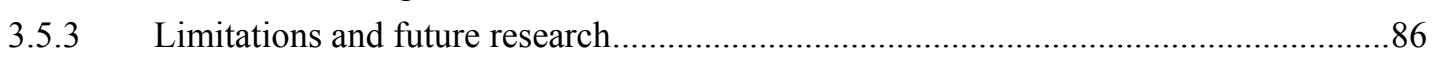

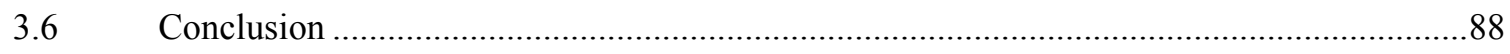

4 Contribution in context: online community participation as contextualized social exchange ...............89

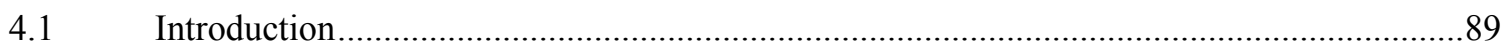

4.2 Online Community Participation as Contextualized Social Exchange ..................................91

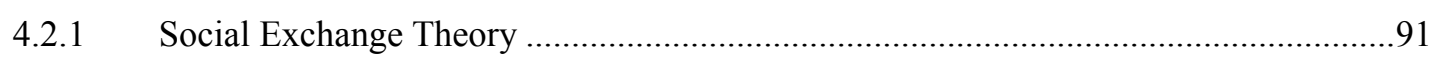

4.2.2 Online community participation as social exchange ...................................................94

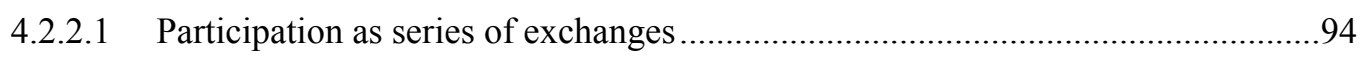

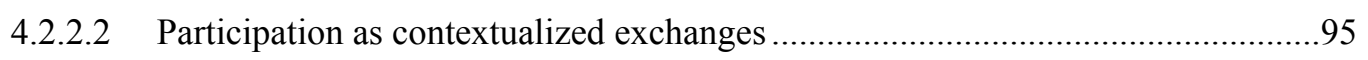

4.2.3 Current participation, prior participation, alternatives and ongoing participation ........96

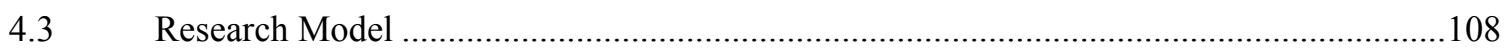

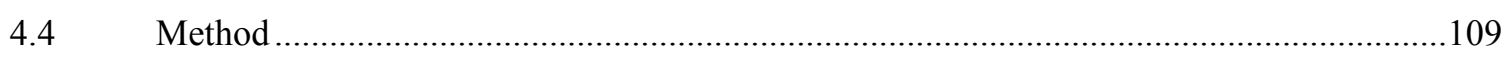

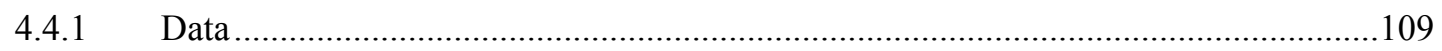

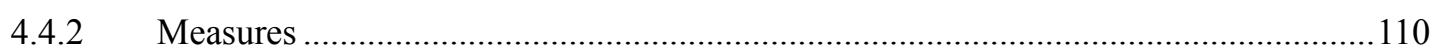

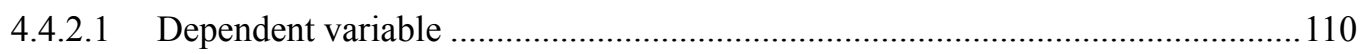

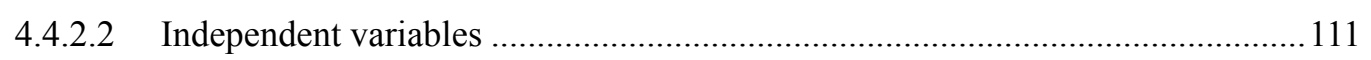

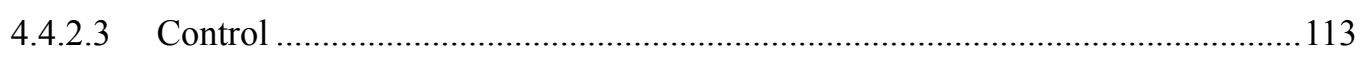

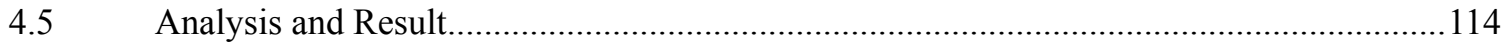

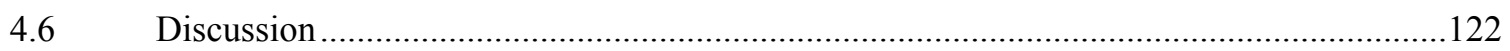

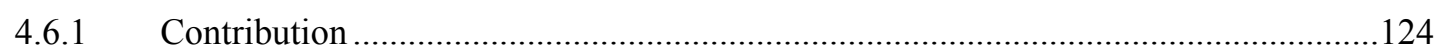

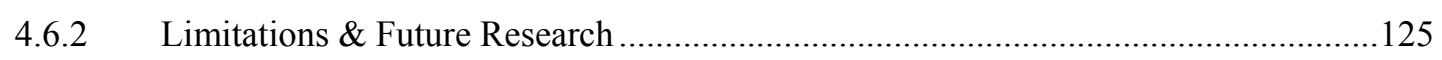

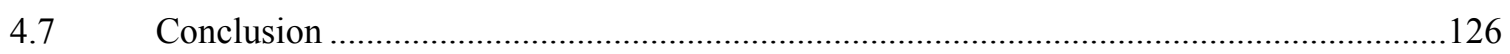

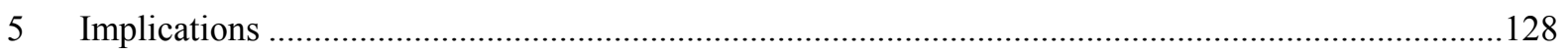

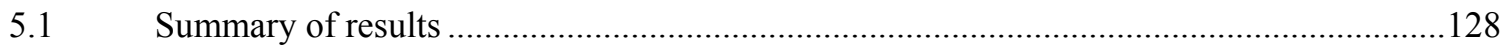

5.1.1 Online community competition and member retention..............................................129

5.1.2 Individual participation as contextualized social exchange .......................................129

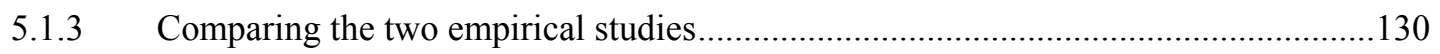

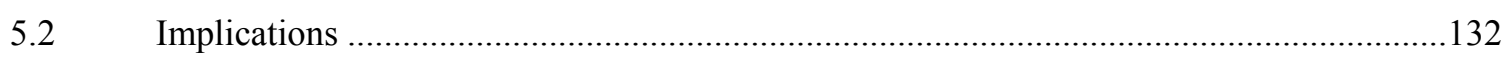

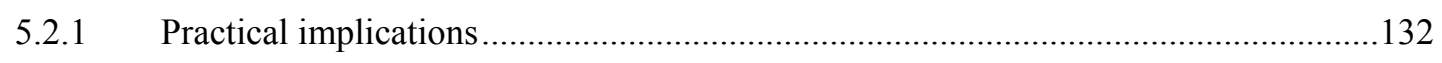

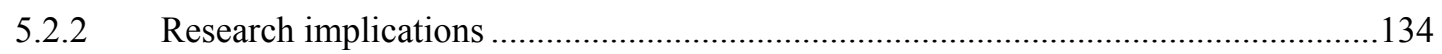

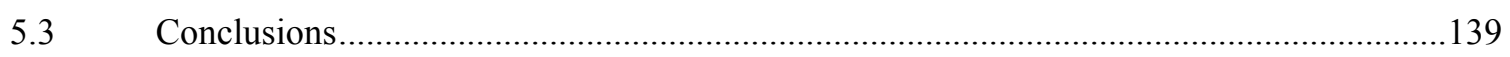

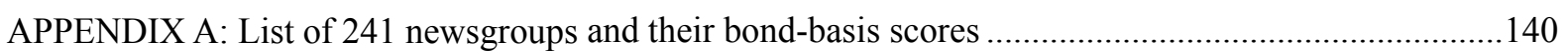

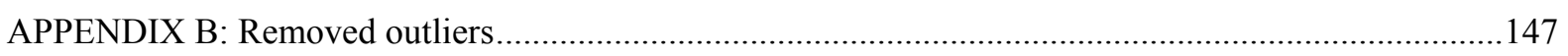

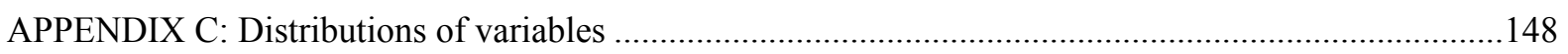

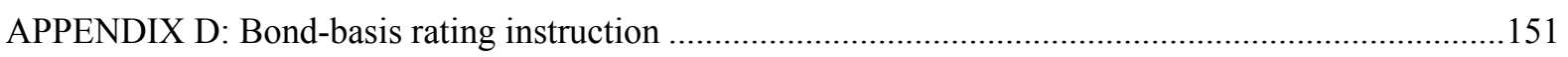

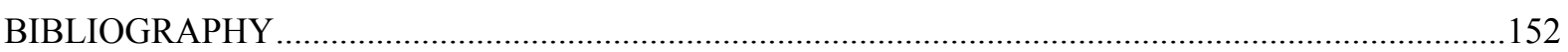




\section{LIST OF TABLES}

Table 1: Comparing Streams of Literature on Online Communities....................................................

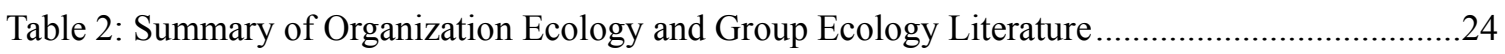

Table 3: Competition Theories in Organizational Ecology and Group Ecology.....................................33

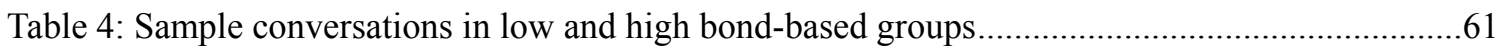

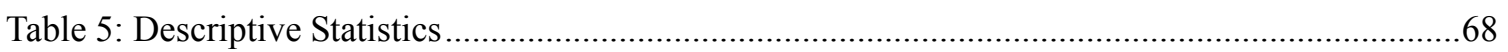

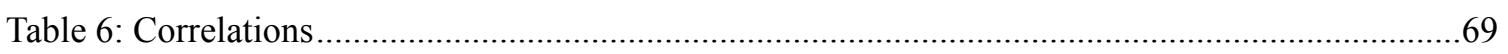

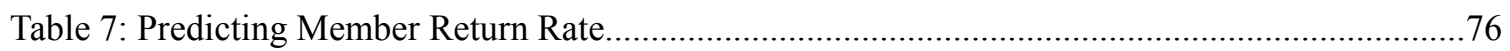

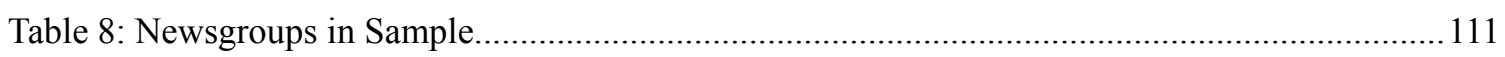

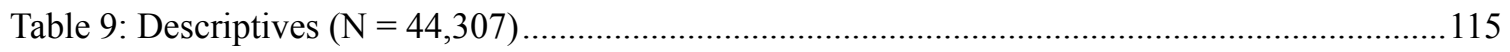

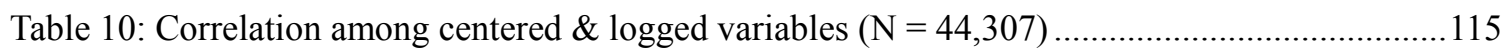

Table 11: Predicting Individuals' Ongoing Participation in Online Communities ...............................121

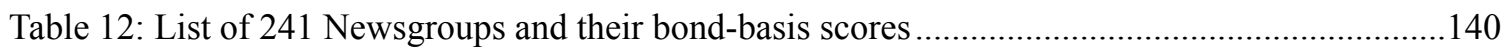

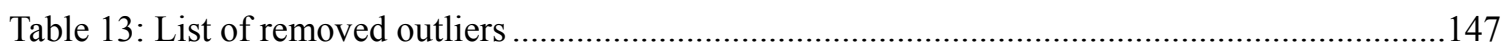




\section{LIST OF FIGURES}

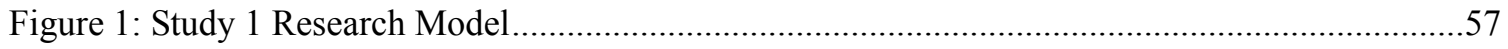

Figure 2: Curvilinear Relationship Between Content Membership and Return Rate .............................73

Figure 3: Curvilinear Relationship between Membership Competition and Return Rate.......................73

Figure 4: Interaction between Cross-posting Groups and Post Per Poster on Return Rate.....................75

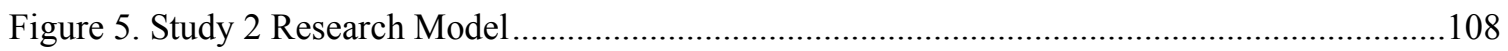

Figure 6: K-M Estimates of Survival and Hazard Functions ..........................................................117

Figure 7: Distribution of variables and the effects of $\log$ transformation ..........................................150 


\section{ACKNOWLEDGEMENT}

My first day in the $\mathrm{PhD}$ program, a senior student told us during orientation: the most important thing surviving the $\mathrm{PhD}$ program is perseverance, and nothing else is more important. Five years later, when I am close to the end of the dissertation process, I finally grasp the true meaning of that. However, I do not think perseverance alone is enough. The people around me have offered tremendous help, love and support and given me the strength to get through. I simply would not have made it without them.

First, I would like to thank Brian Butler, my dissertation chair and academic advisor, for being supportive and encouraging during the whole process. Brian taught me how to approach difficulties: he was never discouraged no matter what kind of problems I encountered and always helped me find a solution. Special thank goes to Bob Kraut, who provided great resources and guidance. My experience working with Bob has been invaluable. Thanks also to the rest of the committee members: Laurie Kirsch, who always provided feedback in a timely manner and gave me the much needed encouragement; Richard Moreland and Dennis Galletta, who asked interesting questions and gave constructive comments.

This dissertation would not have been possible without my family and friends. I thank my mom for always caring when I need it but also pushing me to work hard. I am grateful to those friends who have become my family away from home, for sharing many important moments of 
life with me. I would also like to take this chance to thank all people who love me and support me throughout the years, who make my dissertation years much more enjoyable and sometimes, bearable.

A huge thanks to Carrie Woods in the doctoral office for taking care of everything and eliminating problems in magical ways. Thank you, Carrie, for being patient and making life so much easier. Last but not least, I thank my colleagues, Scott Boss, Enrique $\mathrm{Mu}$, Patrick Bateman, Rachel Chang, Jacqueline Pike, and Ilana Diamond for providing moral support over the years. 


\section{INTRODUCTION}

Recent years have seen exponential growth of online communities ${ }^{1}$ in different forms. Started in 2005, YouTube has become the dominant video sharing website on the Internet. More than 500,000 registered users are sharing over 45 terabytes of videos on YouTube by 2006. In the single month of August 2006, the number of videos on the site grew 20\%, from 5.1 to 6.1 million (Gomes 2006). Usenet, one of the oldest electronic communication infrastructures, has over 190,000 newsgroups worldwide with 48 million participants (Turner et al. 2005). Second life, a 3-D virtual world opened to the public since 2003, now has 6,240,591 virtual residents owning and building 'virtual lives' within. In the Gartner Symposium/ITxpo 2007, Gartner analysts suggest that "over $80 \%$ of the active Internet users (and Fortune 500 enterprises) will have a virtual life online by the end of 2011" (Gartner 2007). There are many more examples including MySpace, Flickr, Epinions, Sourceforge and Wikipedia.

Online communities are virtual spaces that enable groups of similar people to interact online (Preece 2000). The impact of these online communities on our lives can be significant. Individuals participate in online communities to seek information, develop friendships, obtain social support, discuss topics of interest, develop hobbies, and organize cooperative work, just to name a few (Rheingold 2000; Ridings \& Gefen 2004). Technology users are able to find

\footnotetext{
${ }^{1}$ The term "online communities" in this dissertation is a general one, referring to any electronic community infrastructure including "virtual communities" such as Second life.
} 
answers, solve problems, and support each other in online discussion groups (Lakhani \& Hippel 2003). Patients find information about diseases and obtain social support from others in online health support groups (Cummings et al. 2002). Buyers and sellers identify partners and engage in transactions in online trading communities (Boyd 2002). Individuals self-organize and coordinate relief to natural disasters like Hurricane Katrina through online Weblogs (Torrey et al. 2006). Open source software developers coordinate efforts to build free and high quality software applications using online communities (Lee \& Cole 2003; Moon \& Sproull 2000). Across a wide variety of areas, online communities are gaining importance.

Increasingly, online communities are also being used to support business and organizational needs. Some companies build their own discussion groups to provide customer support (Jeppesen \& Frederiksen 2006) and encourage user innovation (von Hippel 2005). For example, a computer-controlled music instrument company sponsored an online user community that enabled its product to be modified and improved by users, saving costs of market research, product development and technical support (Jeppesen \& Frederiksen 2006). Software vendors like Microsoft and IBM maintain Usenet newsgroups, mailing lists, and online forums to provide technical support for users. Electronic communities are implemented within organizations to enable knowledge sharing (Constant et al. 1996; Wasko \& Faraj 2005). Others participate in existing online forums attempting to influence customer purchase decisions (Dellarocas 2006). Moreover, Open Source Software projects such as Linux, Apache and Mozilla successfully use online communities to facilitate coordinated development work among millions of developers and users distributed across the world (Lee \& Cole 2003; 
Mockus et al. 2002). The growing popularity and practical relevance of online community phenomena has made it an area that warrants extensive research to understand the way these online communities work as well as how to utilize them to generate business value and improve social lives (Resnick 2001; Wellman 2001).

There has been an increasing body of online community research in recent years. Prior research attempted to understand the phenomenon of online community by examining people's experiences, activities and behaviors online (Butler et al. 2007), comparing and theorizing the differences between online and offline settings (Cummings et al. 2002; Galegher et al. 1998), identifying motivations to participate (Lakhani \& Hippel 2003; Ridings \& Gefen 2004), describing the benefits from participation (Cummings et al. 2002; Sproull et al. 2005), and studying internal group norms, values, and structures that affect individual contributions and group performance (Hertel et al. 2003; Lee \& Cole 2003; Moon \& Sproull 2000; Wasko \& Faraj 2005). These research findings can have important implications for designing, developing and managing online communities of different kinds.

However, existing research only offers a limited view, by focusing on factors and processes internal to a single community. Many studies look at samples of individuals or interactions within a single community (Lakhani \& Hippel 2003; Moon \& Sproull 2000). Others consider larger samples of individuals and communities (Ridings \& Gefen 2004; Wasko \& Faraj 2005; Wasko et al. 2004). While they empirically consider multiple communities, communities are conceptually treated as independent units. In the real world, however, each online community 
is surrounded by and linked to others in many ways. Treating communities as isolated, independent entities is at odds with their highly contextualized, interdependent nature. For instance, an individual can use both Flickr to share photos and YouTube to share videos with family and friends. Many people embed YouTube videos in their blogs, sharing their life stories in text along with videos. The ubiquity of online communities also means that similar communities can be subject to competition. MySpace and Facebook, two social networking sites for teenagers and college students, attract so many participants that similar service providers such as Friendster and LiveJournal may suffer from reduced traffic (Kirkland 2007). Flickr, the digital photo sharing website offering community tools such as tagging, blogging and commenting, out-competes other web services providing similar functions. Online communities like YouTube, Myspace and Flickr are not isolated, and communities can be linked in many ways. For instance, there are multiple Usenet newsgroups on breast cancer support, and individuals needing information on breast cancer may investigate in each of them. LinkedIn and MySpace may share participants as a result of individuals frequently engaging in multiple online communities. Individuals may gain knowledge of the other community through their involvement within one. The many other communities around a community and the connections between them can have important implications to their survival and success. Does the context of interrelationships among communities affect the viability of each community? What types of connections exist between online communities, and how do they differ? How do individuals choose to participate in, or move to, one community versus another? If we only focus on internal community structure and communication characteristics, the answers to the above questions will remain unknown. 
Furthermore, the current empirical research has an event focus. Empirical examinations of online communities tend to study single, static participation events (e.g. Lakhani \& von Hippel 2003, Wasko \& Faraj 2000), treating individual participations as isolated events independent of each other. However, some theoretical work suggests that online communities represent networks of social relationship (Wellman 2001), and that relationship is important for building sustainable online communities (Wasko et al. 2004). An individual's ongoing exchanges with a community, therefore, plays an important role in each participation decision in that each decision is dependent on prior history of exchanges in the community. Focusing on single participation events undermines our ability to explain individuals' long-term interactions with online communities. For instance, we cannot explain how and why an individual's behavior pattern in a community changes, and when an individual decides to leave a community.

Together, these two limitations in existing research suggest that the contexts of online communities, both the presence of other communities and the long-term historical context of participation within a community, are important, yet under-studied factors. The goal of this dissertation, therefore, is to begin a program of research that fills these gaps by paying more attention to context. A theory of online community ecology, which focuses on the competition aspect of the external context, is proposed to study the impact of the competitive relationships among online communities on one key indicator of community viability: community member retention. Moreover, a model predicting individuals' long-term interactions in online communities is proposed, treating participation decisions as a series of social exchanges 
between individuals and their communities. Empirical studies are conducted to examine both the impact of ecological context for an online community and the historical context for individual continuance decisions.

The structure of this dissertation is as follows: Chapter 2 reviews the relevant literatures and suggests a theory of online community ecology. Chapter 3 builds the online community ecology theory and develops a theoretical model based on the theory. The model is empirically tested to examine the impact of ecological competition on community member retention. Chapter 4 applies social exchange theory, examining the interplay of both prior participation and ecological competitions on individuals' ongoing participation decisions in online communities. Chapter 5 summarizes the overall findings in the two empirical studies, discusses the implications of the findings for research and practice, and concludes with a discussion of possible directions for future research. 


\section{THEORETICAL BACKGROUND}

\subsection{ONLINE COMMUNITIES}

Online community has been defined in many ways. Preece (2000) suggested that an online community consists of four key factors: people who interact socially; a shared purpose that provides a reason for the community, policies that guide people's interactions; and computer systems to support and mediate these social interactions. Ridings and Gefen (2004) defined virtual communities as "groups of people with common interests and practices that communicate regularly and for some duration in an organized way over the Internet through a common location or mechanism". Rheingold (2000) suggested that experience in online communities is getting together and doing everything in virtual cyberspace. Technical perspectives on online communities often focus on the supporting technology, such as bulletin boards, Usenet newsgroups, or web-based forums (Stanoevska-Slabeva \& Schmid 2001).

All of these definitions characterize communities in terms of groups of people with common interests or purposes, their regular interaction, and use of electronic communication technology. In this work, I will use a minimalist definition of online community to refer to any electronic community infrastructure that supports groups of individuals to interact and exchange for a common purpose. This definition covers a broad range of community types, including information exchange, technical support, social support, and hobby groups, and also allows 
for variation in technical infrastructure. Although online communities may have different natures, purposes, and be built on different technologies, it is not the focus of this dissertation to provide a comprehensive online community typology. Choosing a minimalist definition allows this work to focus on building a theory which is potentially generalizable to many types of communities while recognizing that not all communities are the same.

The increasing popularity of online communities as a way to connect people and create business value has made it an exciting area for research, attracting researchers from multiple disciplines such as Organizational Behavior, Communication, Information Systems, Human-Computer Interaction, Sociology, and Psychology. While the following literature review focuses on studies of online communities by information systems researchers, it also draws on studies from other disciplines where relevant.

\subsection{Member Retention in Online Communities}

Online communities vary in their ability to survive and sustain activities over time. There are extremely successful communities such as Craigslist, the online bulletin board (http://craigslist.org), the Apache server project (http://httpd.apache.org/), and Flicker, the online photo sharing community (http://www.flickr.com/), which have attracted millions of visitors and contributors. On the other hand, many other communities fail to elicit enough activity to attract members (Ling et al. 2005). Most SourceForge open source software 
development projects have only one developer (Healy \& Schussman 2003). More than half of listservs do not have traffic (Butler 2001). Prior research suggests that online communities' ability to sustain activities is largely determined by their ability to attract and retain members (Butler 2001). Because online communities rely on members' voluntary participation to provide resources and benefits, members are key resources that are central to community viability. Particularly, because many online communities do not have organizational sponsors or formal incentive mechanisms, their survival and growth depend completely on the voluntary participation and contribution of members.

Critical mass theory also suggests that communities need a minimum level of contributors to sustain themselves (Markus 1987). Thus, communities seeking to sustain themselves over time need to not only retain existing members, but also attract new ones. Current literature often does not distinguish between the two, while putting a focus on motivating contribution from either new or existing members. Although much of online community research has studied the motivation for and benefits of contributing (Lakhani \& Hippel 2003; Ridings \& Gefen 2004; Sproull et al. 2005), providing implications on how to attract members to online communities, little has examined what underlies their willingness to stay and contribute continuously (Bateman et al. 2006). Membership retention, however, is as important, if not more important than, new member attraction. From a utility perspective, if members of a community tend to stay for a long period of time, it signals the effectiveness of the community in fulfilling members' needs and the ability of the community to achieve its own functions. Moreover, from a behavioral point of view, the members who repeatedly participate will be more likely to be 
the people in a community who shape the identity and norms within the community and influence the behaviors of other members (Kim 2000). These regulars are particularly important for community viability because they often contribute the majority of the content, and help developing and maintaining the community identity (Crowston \& Howison 2006; Kim 2000). Therefore, an online community's ability to retain members is likely to be critical for community sustainability.

Nevertheless, retaining members is particularly challenging in online communities, because there is little organizational incentive and low normative pressure for members to stay. This is reflected in the fact that most online community participants are one-time visitors. In Usenet, the oldest and largest online discussion infrastructure, about $73 \%$ of authors who post in a month do not post again (Arguello et al. 2006). Low member retention and the resulting high turnover in online communities reduce the benefits that a community can get from returning members' knowledge and contribution, and thus undermine its ability to provide benefits to its members. Thus, an objective of this dissertation is to understand what influences membership retention in online communities and how to increase a community's capability to attract returning participants. 


\subsection{REVIEW OF EXTANT ONLINE COMMUNITY RESEARCH}

Most online community research that seeks to explain online community membership dynamics take an internal perspective, attributing member behaviors and patterns to factors and processes within the boundary of a community. Loosely defined, there are four types of explanations that have contributed to the understanding of who comes to and who stays in a community: studies of individual motivation and benefits, individual commitment or attachment to a group, group structures and norms that facilitate contribution, and the impact of group interaction on members' decisions to stay or leave. In the following sections, key arguments and findings associated with each explanation are summarized.

\subsubsection{Individual motivation and benefit}

This line of research has focused on identifying individual motivations to participate and their individual gains from participation. Theories from multiple disciplines have been drawn from to answer the key question: what is it about individuals that makes them likely to participate or contribute voluntarily to online communities? Studies have argued that contribution to online community suffers from the public goods dilemma (Connelly \& Thorn 1990; Kollock \& Smith 1996), and therefore understanding the drivers of individual contribution in online communities can help promoting collaborative efforts. Public goods theory suggests that individuals contribute when they perceive benefits higher than costs (Olsen 1965; Ostrom 
1990). Contributors to online communities often receive direct rewards from participation (Lerner \& Tirole 2002), personal benefits from the collective output of the communities (von Hippel 2005; von Hippel \& von Krogh 2003; Wasko \& Faraj 2000), or emotional, attitudinal and health improvement as a result of online interaction (Sharf 1997; Shaw et al. 2000; Sproull et al. 2005). At the same time, individuals with high efficacy are more likely to help others or contribute to public goods, because their cost of participation is low (Hertel et al. 2003; Wasko \& Faraj 2005). Psychology theories of pro-social behavior complement the pure extrinsic incentives suggested by economic theories with intrinsic, altruistic ones (Constant et al. 1996; Sproull et al. 2005), arguing that people help strangers because they enjoy doing so. Moreover, social exchange theory implies that people also expect social rewards from their work, therefore they will likely contribute if they perceive intangible benefits like visibility, self-esteem and reputation (Constant et al. 1996; Wasko \& Faraj 2005).

This research treats individual participation and contribution as an independent, one-time event for the individual. Prior history in the group, relationship or future behaviors are not given any consideration. For this reason, most research in this category is on the individual level, and the methodology tends to be cross-sectional. Community benefits and organizational citizenship behaviors are mentioned occasionally, but usually combined with private motivational variables and not given explicit attention. 


\subsubsection{Community motivations and commitment}

A second line of online community research is also concerned with why individuals participate, but with an emphasis on the organizational or group level benefits instead of personal, private benefits, paying special attention to the relationship between the individuals and their communities (Bateman et al 2006, Blanchard \& Markus 2004). This research describes how individuals are motivated to help others and the larger community, establish identifications with communities and other members, and develop psychological attachment and commitment to communities. For example, organizational motivation theory was used to argue that positive perception of an organization can provide incentives for organizational citizenship behaviors such as helping the larger organization, achieving organizational goal, etc., and these incentives can be stronger than individual incentives (Constant et al. 1996). Organizational commitment theory suggests three bases for people to stay in an online community: affective, normative and continuance commitment (Meyer \& Allen 1991), which outlined different reasons for people to stay in communities. These bases were found to promote different participation behaviors (Bateman et al. 2006). Also, sense of virtual community, feelings of "membership, influence, need fulfillment and emotional connection" was proposed as a precursor of community behaviors, including providing support for others, identifying with the community and developing trust towards other members (Blanchard \& Markus 2004). 
This research highlighted the link between the individuals and the communities, attributing individuals' behaviors to their perceptions of and relationships with the communities over time. This research is still mostly done at the individual level because the focus is on individuals' perceptions. However, it takes a more process-oriented approach than the research on motivation and benefits as it treats contribution as an ongoing process, dependent on prior experience and affecting future behavior.

\subsubsection{Community ideology, structure, and costs}

In contrast to the previous two areas, the third line of research focuses on the communities rather than the individuals, examining community-level factors and processes that encourage participation and facilitate pro-social behavior, such as community norms, values, beliefs, role

structure, trust, size and type. Research in this category often attributes people's behavior to the internal environment and structure of the community, assuming that online communities can become self-sustaining if they are set up properly (Baym 2000). For instance, it was suggested that community ideology and culture will strengthen trust in online communities, reinforce commitment, and increase likelihood of group effectiveness (Stewart \& Gosain 2001). Role structure and member composition within a community was also believed to influence group performance (Giuri et al. 2004; Mockus et al. 2002; Moon \& Sproull 2000). Size and volume of a community, interestingly, were found to have both positive and negative impacts on community viability (Butler 2001; Jones et al. 2004). 
This research is also concerned with the relationship between the individuals and the community, but the focus is on how the community can shape individual behaviors. The role of the community is highlighted, while the individuals are downplayed. As a result, the unit of analysis for this research is often the community rather than the individual. However, because the community culture, pattern, ideology and structure emerge out of member interactions and in turn constrain local behaviors, a few empirical research operationalized these group level factors at the individual level, for example, as an individual's perception of group identity and perceived organization climate (Bock et al. 2005). 
Table 1: Comparing Streams of Literature on Online Communities

\begin{tabular}{|c|c|c|c|c|}
\hline & Theory Base & Research Q. & Key findings & References \\
\hline $\begin{array}{l}\text { Individual } \\
\text { Motivations } \\
\text { \& Benefits }\end{array}$ & $\begin{array}{l}\text { A. Extrinsic motivation: } \\
\text { people expect certain } \\
\text { outcome and value from } \\
\text { participation. } \\
\text { B. Intrinsic motivation: } \\
\text { Participation is inherently } \\
\text { interesting, fun, or } \\
\text { self-fulfilling. } \\
\text { C. Utility: people participate } \\
\text { when benefits (direct and } \\
\text { in direct) are great and } \\
\text { costs are low (capable of } \\
\text { helping). }\end{array}$ & $\begin{array}{l}\text { Why do people } \\
\text { participate in or } \\
\text { contribute to online } \\
\text { communities, } \\
\text { despite the lack of } \\
\text { compensation and } \\
\text { high risk of } \\
\text { failure? } \\
\text { Unit: Individual }\end{array}$ & $\begin{array}{l}\text { A. Extrinsic motivations include: } \\
\text { information \& personal needs, } \\
\text { reward, reputation, } \\
\text { recognition. } \\
\text { B. Intrinsic motivations include: } \\
\text { Altruism, fun/joy. } \\
\text { C. Tangible benefits include: } \\
\text { support (informational, } \\
\text { emotional, and instrumental), } \\
\text { health, satisfaction, visibility, } \\
\text { reward. } \\
\text { D. Intangible benefits include: } \\
\text { learning, relationship, } \\
\text { ownership \& control, } \\
\text { fun/enjoyment, psychological } \\
\text { well-being, reduced } \\
\text { anxiety/depression. } \\
\text { E. Self-efficacy increases } \\
\text { participation } \\
\text { F. Motivations and benefits } \\
\text { depend on the type of } \\
\text { contributors/participants. }\end{array}$ & $\begin{array}{l}\text { Wasko \& Faraj 2000, } 2005 \\
\text { Ridings \& Gefen } 2004 \\
\text { Moon \& Sproull } 2000 \\
\text { Lerner \& Tirole } 2000 \\
\text { Hars \& Ou } 2002 \\
\text { Constant et al } 1996 \\
\text { Sproull et al } 2003 \\
\text { Sharf } 1997 \\
\text { Shaw et al } 2000 \\
\text { Baum } 2004 \\
\text { Winefield et al } 2003 \\
\text { Weis } 2003 \\
\text { Butler et al Forthcoming } \\
\text { Cummings \& Sproull } 2002 \\
\text { Lakhani \& von Hippel } 2003 \\
\text { Kollock \& Smith } 1996 \\
\text { Von Hippel \& von Krogh } \\
2003 \\
\text { Hertel et al } 2003 \\
\text { Fisher et al } 2006\end{array}$ \\
\hline $\begin{array}{l}\text { Community } \\
\text { Motivations } \\
\& \\
\text { Commitment }\end{array}$ & $\begin{array}{l}\text { A. Organizational Motivation: } \\
\text { positive regards for an } \\
\text { organization as substitute } \\
\text { for individual incentives. } \\
\text { B. Organizational } \\
\text { Commitment: three } \\
\text { dimensions (affective, } \\
\text { normative, and switching } \\
\text { cost). Two basis: bond \& } \\
\text { identity. } \\
\text { C. Sense of Community. }\end{array}$ & $\begin{array}{l}\text { Why do people } \\
\text { participate? } \\
\text { Why do people } \\
\text { stay in certain } \\
\text { online } \\
\text { communities? } \\
\text { Unit: Individual or } \\
\text { Group }\end{array}$ & $\begin{array}{l}\text { A. Common organizational } \\
\text { motivators include: } \\
\text { organizational citizenship, } \\
\text { psychological attachment, } \\
\text { sense of community, } \\
\text { generalized reciprocity. } \\
\text { B. Participation is associated } \\
\text { with commitment. } \\
\text { C. Different commitment } \\
\text { dimensions/basis motivate } \\
\text { different community } \\
\text { behaviors. }\end{array}$ & $\begin{array}{l}\text { Gustafson et al } 2001 \\
\text { Wasko \& Faraj } 2005 \\
\text { Wasko \& Faraj } 2000 \\
\text { Constant et al } 1996 \\
\text { Cummings \& Sproull } 2002 \\
\text { Sproull et al } 2003 \\
\text { Hertel et al } 2003 \\
\text { Bateman et al } 2006 \\
\text { Ren \& Kraut } 2006 \\
\text { Blanchard \& Markus } 2004 \\
\text { Roberts } 1998\end{array}$ \\
\hline
\end{tabular}


Table 1 (continued)

\begin{tabular}{|c|c|c|c|c|}
\hline & Theory Base & Research Q. & Key findings & References \\
\hline $\begin{array}{l}\text { Community } \\
\text { Ideology, } \\
\text { Structure, } \\
\text { and Costs }\end{array}$ & $\begin{array}{l}\text { Lacking dominant and } \\
\text { consistent theories. Research is } \\
\text { fragmented. } \\
\text { A. Ideology, org climate. } \\
\text { B. Resourced-based view: } \\
\text { large group provides more } \\
\text { benefits. } \\
\text { C. Advantage of online } \\
\text { environment vs offline. } \\
\text { D. Information load: high cost } \\
\text { of reading/participating } \\
\text { drive people away. } \\
\text { E. Social network }\end{array}$ & $\begin{array}{l}\text { What aspects of } \\
\text { the communities } \\
\text { are associated with } \\
\text { people's likelihood } \\
\text { of participating or } \\
\text { staying? } \\
\text { Unit: Group }\end{array}$ & $\begin{array}{l}\text { A. Community norm, value, } \\
\text { beliefs, trust, role structure, } \\
\text { size, type and community's } \\
\text { structural position all relate to } \\
\text { level of activities and the type } \\
\text { of activities within. } \\
\text { B. High traffic and group size } \\
\text { leads to higher turnover and } \\
\text { shorter message. } \\
\text { C. Group size can have both } \\
\text { positive and negative impact } \\
\text { on member dynamics. }\end{array}$ & $\begin{array}{l}\text { Moon \& Sproull } 2000 \\
\text { Lee \& Cole } 2003 \\
\text { Mockus et al } 2002 \\
\text { Stewart \& Gosain } 2001 \\
\text { Giuri et al } 2004 \\
\text { Wasko \& Faraj } 2000 \\
\text { Galegher et al } 1998 \\
\text { Cummings \& Sproull } 2002 \\
\text { Butler et al Forthcoming } \\
\text { Bock et al 2005 } \\
\text { Jones et al } 2004 \\
\text { Thompson } 2005\end{array}$ \\
\hline $\begin{array}{l}\text { Individual } \\
\text { Experience }\end{array}$ & $\begin{array}{l}\text { Moreland and Levine: group } \\
\text { socialization model }\end{array}$ & $\begin{array}{l}\text { What aspects of } \\
\text { the interactions } \\
\text { within online } \\
\text { communities are } \\
\text { associated with } \\
\text { people's behavior? } \\
\text { Unit: Interaction }\end{array}$ & $\begin{array}{l}\text { Message content, whether a } \\
\text { message is responded to, and } \\
\text { status of repliers lead to higher } \\
\text { likelihood of returning. }\end{array}$ & $\begin{array}{l}\text { Arguello et al } 2006 \\
\text { Galegher et al } 1998 \\
\text { Fisher et al } 2006 \\
\text { Johnson \& Faraj } 2005\end{array}$ \\
\hline
\end{tabular}




\subsubsection{Individual experience in online community}

This category of research conducts micro-level examinations of the individual experience in online communities, addressing how the individual-community interaction affects the process of socialization of individuals into groups, unveiling the processes and mechanisms that influence the success of an interaction and the individual's future behavior in the group (Arguello et al. 2006; Galegher et al. 1998). Distinct from the other lines of research described above, research on individual-community interaction focused on individuals' experiences in online communities, placing more emphasis on the success or failure of specific interaction experiences than on the individual or community characteristics. This type of research can answer important questions like how commitment is developed in online communities and what aspects of interaction encourage future contribution and commitment. However, research on this level is more often found in the communication literature than in the IS field. Yet, because communication research tends to focus on examining the patterns of conversation and how these patterns relate to the success of conversations (Herring 2001), they provide little guidance on how communication success is related to individuals' development of commitment or decisions to stay or leave. Therefore, more research with a focus on relating the interactions within online community with individual and community-level outcomes is needed. Recently, a few studies have started to analyze conversation patterns as a way to reveal structural differences among individuals and groups (Fisher et al. 2006) and understand structural characteristics that motivate participation in online community (Johnson \& Faraj 2005). 


\subsubsection{Critique of the extant literature}

The existing online community literature has identified many reasons why individuals contribute voluntarily in online settings and mechanisms that encourage and facilitate ongoing participation. However, prior research has two main limitations. First, almost all existing studies take an internal approach, paying little attention to the larger context of online communities. Traditional group literature has studied group dynamics in three levels: individual members, groups, and the context within which the groups exist. Individual behaviors and group patterns comprise the internal dynamics of groups, while contextual variables are extrinsic factors that shape and constrain both individual and group level processes (McGrath et al. 2000). Online community research predominately focused on what happens inside the boundary of a community, ignoring the larger context in which communities exist. The missing piece of context in online community research implies that researchers are not considering the existence of other communities that individuals can switch to, and how the relationships between groups affect individual motivations, benefits, commitment, and behaviors. In particular, members' stay or leave decisions may largely depend on the availability of other alternatives and the benefits the alternative communities can provide, and thus online community turnover can be influenced by the presence of other communities in the environment. For example, the growth of MySpace and Fackbook may have caused many people to leave Friendster, which cannot be fully understood using an internal approach. While most existing research explains member contribution in a given, 
isolated community setting, little is known about the impact of external forces on membership dynamics within a community. A notable exception is a recent study on investment-related virtual communities, which found that multiple communities compete with each other for user participation (Gu et al. 2007). Moreover, without knowledge of the context, we would not be able to predict under what conditions benefits, commitments and structure will be sufficient to retain members, and when groups will fail to sustain themselves. For instance, the high turnover in an online IT job hunting community may be due to the high rate of change in the industry, which can only be explained when considering the larger industrial environment of the community. Therefore, an external perspective that explores the factors and dynamics outside of a community may help fill the gap and explain what contributes to communities' different capability to retain members in different settings.

Second, most of the empirical studies, especially those on motivations and benefits, are static in nature. Existing cross-sectional analyses rarely considered whether benefits, commitments and structures will change, what leads to changes, and how group processes, structures, and performance may be affected by these changes. A few exceptions exist, including Butler (2001) and Jones et al (2004), which examined longitudinal data to reveal how group dynamics unfold and how they shape group behaviors and capabilities. Because of the static focus, extant research did not explicitly examine the conditions under which a member continues participating in or leaves a community. It is assumed that members will continuously participate if they receive benefits greater than costs, or their sense of group commitment is strong enough, and the group structure and norm are set up properly. Little is 
known about what contributes to the maintenance and changes in commitment over time. Without longitudinal examinations of individuals' ongoing participation decisions, existing findings based on isolated participation events may be biased towards the individuals who decide to participate. Reasons for people to stop participating will remain unknown. It would be difficult to predict when an individual will be motivated to change from silent participant (reader) to active engagement (poster), or from active participant to a more passive role. Therefore, longitudinal analysis that focuses on individuals' long-term participation in online communities is necessary to address these issues.

The above limitations in the extant online community literature suggest a need for new theories and approaches to study community member retention. The next sections review relevant theories with external perspectives and propose a theory of online community ecology based on the organizational ecology and group ecology literature.

\subsection{An External PERspective}

An external perspective considers the context within which a community exists. Context refers to the environment that affects and constrains the development of groups over time, such as stress, relations with other groups, organizational support, etc. Specifically, the relationships among communities may have impact on decisions of members to stay or leave, and thus can help explain the internal patterns of membership movements. Taking an external perspective, 
we can start to examine how the environmental setting affects the activities, behaviors, and patterns of interaction inside a community, and what aspects of context are related to a community's ability to sustain itself. We can answer questions like: Is context an important factor for community membership turnover? Will groups perform the same in changing environments as in stable ones? Which kinds of groups survive in a given environment? How do individuals behave and make decisions differently in different environments?

Organization studies and group studies have emphasized the role of context in several research areas. Theories that take an external approach include organizational ecology (Hannan \& Freeman 1977), group ecology (Levine \& Moreland 1990; McPherson 1983), industrial organization (van Witteloostuijn 1998), organizational psychology (McGrath et al. 2000), and inter-group relations (Messick \& Mackie 1989). Organizational psychology theories address the impact of organizational environment and organizational support on work teams, which have group goals and formal incentive mechanisms. Online communities, different from work teams, are often voluntary and rarely use formal incentives, which makes organizational psychology theories less applicable. Inter-group relations literature is centered on the group categorization process and how it affects member perceptions and behaviors toward others inside and outside of a group (Messick \& Mackie 1989), paying much less attention to the performance and sustainability of the groups themselves. Industrial organization (IO) theories emphasized how organizations adapt their strategies, activities, and features to react to changes in the environment (van Witteloostuijn 1998). IO typically assumes that decision-makers are rational and have enough control over the organizational activities and strategies, and that firms 
can strategically compete with rivals and adapt their decisions to changes in the environments. Because online communities often consist of a group of voluntary participants, referring to the community 'deciding' in an intentional, strategic way is problematic. As a result, the IO perspective is not a good fit. The organizational ecology literature is a complement to IO theories in that it recognizes both the role of environmental variables on the patterns of organizational forms, activities, and chances of survival and the impact of internal adjustment on an individual organization's sustainability (Bruderer \& Singh 1996; Lomi \& Larsen 1996). Therefore, among the theories with an external perspective, the organizational ecology and the related group ecology literature are the most suitable reference disciplines for understanding group sustainability. The next sections review the organizational ecology and group ecology literatures, and propose a community ecology approach to studying online communities. 
Table 2: Summary of Organization Ecology and Group Ecology Literature

\begin{tabular}{|c|c|c|}
\hline & Organizational Ecology & Group Ecology \\
\hline $\begin{array}{l}\text { Definition of } \\
\text { ecology }\end{array}$ & $\begin{array}{l}\text { Natural environment of organization } \\
\text { populations }\end{array}$ & $\begin{array}{l}\text { Settings that a group occupies (Levine \& Moreland } \\
\text { 1990) }\end{array}$ \\
\hline $\begin{array}{l}\text { Main research } \\
\text { questions }\end{array}$ & $\begin{array}{l}\text { - Why are there so many kinds of } \\
\text { organizations? (Hannan \& Freeman } \\
\text { 1977) } \\
\text { What affects the founding, growth, } \\
\text { decline and death of organizations? }\end{array}$ & $\begin{array}{l}\text { - Model competition of social organizations for } \\
\text { members (McPherson 1983) } \\
\text { - The reciprocal relationship between } \\
\text { inter-group processes and intra-group } \\
\text { dynamics }\end{array}$ \\
\hline Key arguments & $\begin{array}{l}\text { Organizational forms are result of } \\
\text { selection process. } \\
\text { Populations in the same niche } \\
\text { compete for limited resources. } \\
\text { - Survival depends on the fit between } \\
\text { organization forms with the } \\
\text { environment. } \\
\text { Organizations with the ability to } \\
\text { adapt to the environment survive. }\end{array}$ & $\begin{array}{l}\text { Overlap in niche dimensions lead to } \\
\text { competition, and competition affects the } \\
\text { growth rate of the organizations in the } \\
\text { population (McPherson 1983). } \\
\text { Inter-group relations affect the groups' } \\
\text { strategy in recruiting and retaining members. } \\
\text { Strategies further affect inter-group relations. }\end{array}$ \\
\hline Unit & Population or Organization & Categories of groups or groups \\
\hline Weakness & Environmental deterministic & Weak conceptualization of competition \\
\hline
\end{tabular}

\subsubsection{Organizational ecology}

Population ecology in organizations, or organization ecology, was the first to apply natural selection theory to organizations. Beginning with Hannan and Freeman (1977)'s seminal work, organizational ecologists have argued that the relationship between organizations and their embedding natural environments is ecological in nature, in that organizations compete with one another for limited resources in the environment to survive and grow. The environment selects out the organizational forms most suitable to survive in the environmental conditions, 
and eliminates the unsuitable ones. The environment in organizational ecology includes the presence of other organizations and populations, resources that organizations need in order to survive, and the availability of the resources. A population ecology perspective seeks to explain the distribution of organizational forms in different environmental conditions (Carroll \& Hannan 2000; Hannan \& Freeman 1977). In particular, early organizational ecology researchers attribute patterns of organizations to a natural selection process, arguing that organizations tend to have low flexibility to adapt to environmental changes as they grow larger and older (Hannan 1986; Hannan \& Freeman 1977). The environment eliminates the populations of organizations that are not suitable for the environment and selects the best form for survival. Therefore, each of the different environments has a corresponding organizational form that is the most suitable, with different kinds of organizational forms arising in different environmental conditions, often defined by the frequency and nature of changes in the environment or demographic composition in a population. Because the focus is on natural selection, competition is a critical process in the organizational ecology literature. Therefore, this literature review is centered around the role and impact of competition for key resources. The main research question for organizational ecologists is: what environmental conditions affect the rate that organizations found, grow and die?

\subsubsection{Organizational ecology: an overview}

Early organizational ecology research focuses on studying the founding and mortality rates of populations, downplaying the ability of organizations to adapt (Amburgey \& Rao 1996). An organization's ability to survive is argued to depend on organizational age and size (P'eli et al. 
1994). They argue that established firms have developed capabilities to exploit resources in the environment, and are more experienced at competing for resources than newcomers. Therefore, there is a 'liability of newness' (Stinchcombe 1965), which means that newer organizations in an industry have higher risks of dying than older, more established ones. The likelihood of dying is highest at the point of founding and decreases with growing age of the organization. Similarly, large firms have access to more resources, and therefore they have higher survival chances than small firms with scarce resources. Several empirical research confirmed that new and small organizations die faster than old and large ones (Barron et al. 1994).

Later research recognizes that organizations have the ability to change in reaction to environmental turbulence, and therefore start to incorporate both adaptation and selection processes in theoretical developments (Bruderer \& Singh 1996; Singh 1990). Since then, organizational ecology studies have migrated from focusing entirely on the determinants of founding and mortality rate to examining determinants of change in organizational forms (Amburgey \& Rao 1996). Studies have found that both selection and adaptation processes exist in the evolution of organizations. A longitudinal examination of the gasoline retail industry shows that management constantly attempt to transform organizations to cope with environmental changes such as changing customer preferences and new competitors, while only the transformations favored by the environment are sustainable (Usher \& Evans 1996). Moreover, organizational changes that disrupt institutional routines increase the risk of failure as well as the likelihood of the same changes occurring in the future, especially for older 
firms (Amburgey et al. 1993).

In later work, organizational ecology theories have been combined with theories in economics and strategic management to examine multi-level organizational processes, providing a richer and more comprehensive framework for understanding the impact of the environment (Baum \& Oliver 1996; Drazin \& Schoonhoven 1996; Lomi \& Larsen 1996). This work seeks to explain the links between processes at different levels: how micro-level organizational behaviors result in industry-level patterns. For example, a computational simulation demonstrates that the impact of population density (number of competitors) on organizational founding and mortality rates is sensitive to variations in the local environment (Lomi \& Larsen 1996). This is further confirmed by empirical results which show that ecological processes work differently at different levels of analysis. For instance, competitive processes are found to operate more strongly in local areas than at higher geographical levels (Baum \& Oliver 1996).

There are two fundamental theories in organizational ecology: competition and niche width theory. Competition theory outlines when and how competition occurs. Because populations need resources in the environment to survive, their survival and growth bring them into competition with other populations that demand similar resources (Baum \& Amburgey 2002; Hannan \& Freeman 1977). When available resources are limited, there is an upper bound on a population's potential to grow. In this situation, the growth of one population will decrease the growth rate of others (Barron et al. 1994; Ingram \& Inman 1996). Research has extended 
the traditional population level arguments to suggest that competition also exists within populations (Baum \& Singh 1994; Singh 1993). When organizations need similar sets of resources to survive, and the amount of resources is not enough to sustain all organizations, they compete with each other. For instance, automobile companies compete for the set of consumers willing to purchase a vehicle. When the automobile market is mature in that there is little excess demand, the growing market share of one company will be accompanied by the decline of others. In sum, organizations that require the same set of limited resources are direct competitors, and natural selection eliminates the weaker competitors. Empirical work has demonstrated that the number of organizations demanding similar resources increases the level of competition (Barnett \& Carroll 1987; Baum \& Mezias 1992), and that the degree of similarity increases the potential for competition (Baum \& Oliver 1996; Podolny et al. 1996).

Concerned with the outcome of competition, niche width theory argues about which organizations will survive the natural selection process. A niche in ecology is defined by the combination of resources that support a population, and each population occupies a unique niche. Survival in the natural selection process depends on the fit of organizational structure with environmental patterns (Hannan \& Freeman 1977). Organizations may take either a generalist or specialist form. Generalists occupy a broad niche, relying on a wide range of resources in the environment, and therefore can endure prolonged environmental changes. Generalists develop excess capacity, and thus are more flexible and able to adapt to changes. Specialists, on the other hand, occupy a narrow niche and exploit the environment to a great extent, which makes them fit well with the environment unless the environment changes. 
Because the specialists invest deeply to a narrow niche, their chances of survival are small in unstable, frequently changing environments. The diversity of organizational forms is often attributed to the different environmental conditions in different market niches (Amburgey \& Rao 1996).

\subsubsection{Critique of organizational ecology}

The organizational ecology theory has long been criticized for being environmentally deterministic, i.e., it emphasizes the role of the environment to select and affect the structure of organizations, while ignoring the impact of internal organizational characteristics and decision makers' attempts to strategically adapt. Early ecology perspectives stand in contrast with an adaptation perspective, which implies that the distribution of different kinds of organizations in the environment is a result of organizations rationally changing their forms and structures to adapt to their different environmental conditions. Organizational ecology theory emphasizes the impact of environmental selection more than the role of organizational adaptation.

Many studies, however, found that organizations do adapt, although their capabilities in learning and adapting differ, and organizations may even attempt to change the environmental conditions to their favor (Bruderer \& Singh 1996). Therefore, many researchers have argued that ecology perspective and adaptation perspective complement each other, in that environmental selection influences organizations' decision to adapt, while the different adaptation strategies adopted by organizations in turn affect the impact of environment 
(Levinthal 1991; Scott 1987). This argument is reflected nicely in the group ecology literature. Group ecology literature, although less developed than organizational ecology, pays more attention to the interaction between contextual variables and internal group dynamics. The group ecology literature is reviewed in the next section.

\subsubsection{Group ecology}

\subsubsection{Group ecology: an overview}

Applications of organizational ecology by group researchers have addressed the importance of interactions between internal and external variables (Levine et al. 1998; McGrath et al. 2000). Group research assumed that groups were able to adjust their strategies, routines and structures to changes in environments (Levine \& Moreland 1990; Staw et al. 1981). Ecology in this research was defined as the context or settings which groups occupy (Levine \& Moreland 1990). A group's environment creates constraints on resource availability and influences the governing structure, norms and behaviors within a group. For example, groups were found to behave more rigidly when placed in adverse environment (Staw et al. 1981).

Group ecology research introduces the concept of social environment, arguing that social environment is as important as the physical environment in affecting and structuring group dynamics and capabilities (Levine \& Moreland 1990). Different from the physical environment, social environment of a group emerges through members' behaviors outside of the group. Individuals can participate in multiple groups or maintain ties with members of 
other groups, creating connections among different groups. Because group structure, norms, and dynamics are affected by the members inside the group, the individuals who appear in multiple places shape the way each group behaves and performs, creating inter-dependencies among them (Levine \& Moreland 1998). For example, children's experience in their family affects their behavior in school. The social environment of a group thus affects the resources, capabilities, and performance of the group, and may also influence internal member behaviors. Similarly, an independent line of research conducted by McPherson and his colleagues proposed that affiliations among organizations are important forces that drive membership changes inside voluntary organizations (McPherson et al. 1992; McPherson 1983). Because of the focus on social environment and greater attention on internal group processes, the research questions sought by group ecology researchers were different from traditional organizational ecology research: they were most concerned with modeling competition of social organizations for members (McPherson 1983), and the reciprocal relationship between inter-group processes and intra-group dynamics (Levine \& Moreland 1990; Levine \& Moreland 1998; Levine et al. 1998; McGrath et al. 2000).

Because of the fragmented nature of group ecology research (many different dependent variables of group outcomes, different internal processes and external relations), only the literature related to competition is reviewed for the purpose of this dissertation. For a more complete review of group ecology see Levine \& Moreland (1990, 1998). Although group ecology offers a more complete conceptualization of the ecological environment and has more accurate assumptions, surprisingly there has been little empirical research on group 
competition. An exception would be McPherson and his colleague's work. Their basic arguments were that groups as social organizations occupy unique niches defined by the characteristics, or dimensions, of a set of resources they require to survive. When groups overlap in their niche dimensions, i.e., more than two groups are in need of a resource of certain characteristics, there will be competition for that resource if the resource is limited (McPherson 1983). This argument is similar to the competition theory in organizational ecology. Because the most important resource for social groups is members, groups often compete with each other for membership. If two or more groups need similar kinds of members, they will likely be in competition (Levine et al. 1998). The consequences of group competition include size of groups (McPherson 1983), turnover (McPherson et al. 1992; McPherson \& Rotolo 1996), and group strategies for attracting and retaining members (Levine \& Moreland 1990; Levine et al. 1998).

Deviating from the traditional organizational ecology literature, group ecology also emphasizes the possibility that members can maintain ties with people in other groups, or belong to more than one group at a time (Levine \& Moreland 1998; Levine et al. 1998; McPherson 1983; Moreland \& McMinn 2002). The external ties and memberships of individuals are argued to affect their internal status and behaviors in the focal group (Moreland \& McMinn 2002). The implication of multiple memberships at the group level is that groups not only compete for membership, but also for the shared members' commitment and willingness to spend time in them (Levine et al. 1998). This is an important extension to organizational ecology: social groups compete for members' limited time, with members' 
time being a special type of resource. Theoretical development in group ecology suggested that when facing competition, groups will adopt different strategies to increase members' level of commitment to the in-group and decrease their commitment to the out-groups (Levine et al. 1998). Although there have been few empirical studies on the impact of group competition, existing research suggests that individuals with many external ties are more likely to leave an organization (Popielarz \& McPherson 1995).

Table 3: Competition Theories in Organizational Ecology and Group Ecology

\begin{tabular}{|c|c|c|}
\hline & Organizational Ecology & Group Ecology \\
\hline $\begin{array}{l}\text { Main } \\
\text { arguments }\end{array}$ & $\begin{array}{l}\text { Competition for limited resources in the } \\
\text { environment constrains the growth opportunity } \\
\text { and therefore leads to higher failure rate, } \\
\text { decline rate, and slower growth rate. }\end{array}$ & $\begin{array}{l}\text { Conflict or competition among groups affects } \\
\text { the strategies to compete or coordinate with } \\
\text { other groups, which in turn attenuate or } \\
\text { intensify conflict and competition among } \\
\text { groups. }\end{array}$ \\
\hline $\begin{array}{l}\text { Theory for } \\
\text { Competition }\end{array}$ & $\begin{array}{l}\text { - Populations compete when they need } \\
\text { similar resources to survive (niche } \\
\text { overlap), and resources are limited in the } \\
\text { environment. } \\
\text { - Competition is a positive function of the } \\
\text { number of organizations (density) in the } \\
\text { population. } \\
\text { The impact of competition depends on } \\
\text { size, age, and the maturity of population. }\end{array}$ & $\begin{array}{l}\text { - Groups compete when more than two types } \\
\text { of organizations sought limited resource in } \\
\text { a given domain (McPherson et al. 2001) } \\
\text { - Groups often compete for membership } \\
\text { (Levine et al. 1998). } \\
\text { - When there are simultaneous } \\
\text { memberships, groups compete for } \\
\text { members' commitment. }\end{array}$ \\
\hline Unit & Population or Organization & Categories of groups or groups \\
\hline Weakness & Narrow definition of environment & $\begin{array}{l}\text { Weak conceptualization of the nature and } \\
\text { consequence of competition }\end{array}$ \\
\hline
\end{tabular}




\subsubsection{Critique of group ecology}

Although group ecology research offers a richer conceptualization of the environment (distinguishing physical and social environments) and pays more attention to the interaction between group factors and environmental constraints (in this case, competition), its conceptualization of competition is less developed than that in organizational ecology literature. It is unclear what determines the extent of competition, and what internal or external factors affect the impact of competition. Moreover, empirical research on group competition is rare ${ }^{2}$.

\subsubsection{Building a theory of online community ecology}

As mentioned earlier, existing online community research takes a relatively narrow internal focus. Therefore, understanding the impact of context on community viability requires that we develop new online community theories. Organizational ecology and group ecology research provide sound theoretical foundations for building a theory that focuses on the nature and impact of an online community's context. Because organizational ecology and group ecology each has its strength and weakness, both literatures were used when developing the theory of online community ecology (see Table 3 for a summary of organizational ecology and group ecology theories). Because competition is a central process in ecology theories, the proposed theory of online community ecology will focus on explaining and predicting the impact of ecological competition among online communities. The key questions the theory attempts to

\footnotetext{
${ }^{2}$ Some empirical research examined inter-group conflicts and how conflicts affect group behaviors and performances. However, these work focus on types and sources of conflicts as well as conflict resolutions, and pay little attention to competition.
} 
answer are: what is the nature of competition among online communities, and how does it influence online community operations and viability?

Based on the organizational ecology theory, competition occurs among organizations when they all require similar resources and the demand for resources exceeds supply in the environment. Competition creates constraints on the growth opportunities for competing organizations, reducing founding and growth rate while increasing mortality rate (Carroll \& Hannan 1989). Online communities rely on resources to survive, just like organizations and groups. The main resource that online communities need is active membership: online communities are composed of individuals who interact in them, and they need individuals' involvement, participation, and contribution to survive and succeed. The niche dimensions for the member resources, thus, are determined by the member characteristics and interests. When multiple online communities need members with similar characteristics and interests, they have overlapping niche dimensions, and ecology theories would suggest that there would be competition among those communities. For example, MySpace and Friendster are both aimed at teenagers and allowed them to connect with friends. Therefore, they are expected to be in competition. MySpace and the comp.access.fr Usenet newsgroup, on the other hand, serve different purposes and different populations, with MySpace presenting individuals and connecting them with friends; and comp.access.fr newsgroup allowing Microsoft Access users from France to get help and support on MS Access. Therefore, there should be little competition between MySpace and comp.access.fr newsgroup. 
The strength of online community competition may be stronger or weaker than offline group or organizational competition. As defined earlier, an online community is an electronic infrastructure that supports groups of individuals to interact and exchange for a common purpose. The electronic nature of online community has mixed implications on how competition affects members' stay or leave decisions. On one hand, the technical infrastructure upon which online communities are built may remove the barriers for participation. Often, anyone interested in an online community can become a member, and can participate any time from any location with Internet connection (Galegher et al. 1998; Lee \& Cole 2003). As a result, there is a larger population of potential members for online communities. A Pew survey in 2001 showed that $84 \%$ of Internet users, or about 90 million Americans, reported to have used an online community (Horrigan 2001). The low constraints on member availability and larger population of potential members might make online competition for members less problematic than offline competition for resources.

On the other hand, technical features in online communities also enable members to join, participate in, and switch groups easily. The barriers to joining and participating in a community are so low that it may be easy to leave a community without bearing much cost. Many online communities only require members to register with some basic information to be able to participate. For example, members of Yahoo! Finance discussion forums need to be Yahoo! registered users, individuals need to sign up for a mailing list to receive list emails, and social networking sites like MSN Space and MySpace require users to have an active account. The registration process is often simple and open to anyone. Switching to another 
community or participating in multiple communities simultaneously is not difficult, and involves little sunk cost. Therefore, the impact of competition online may be greater.

Moreover, most online communities lack formal incentive systems, official rules and policies, or strong normative pressures that prevent members from leaving. Similar to offline voluntary associations, online communities rely on the voluntary participation of members, and do not or cannot penalize members who exit. Although online communities also develop norms, values, identity and culture, rarely are there strong monitoring or reward systems like those often found in formal organizations. This, combined with the low cost of leaving or switching, could aggregate the effects of competition on these communities.

The fact that online communities have more abundant member resources but higher risk of members leaving or switching suggests that the nature and impact of online community competition could be complex. On one hand, the larger membership base might make competition less of an issue online, because the constraint on resources is low. But on the other, membership resources are different from other resources in that it may not be replaceable. Members who are familiar with participating and contributing in an online community can be more valuable and more knowledgeable than newcomers who are still learning about the group. High turnover can cause problems maintaining the purpose and functions of a community, because losing the regular members can lead to loss of some important shared knowledge of the group (Kim 2000). If returning members are the most important resources for an online community, competition may have a greater effect because 
these resources are more limited. Therefore, the exact nature, role, and impact of competition in online communities is not immediately clear. This dissertation aims to empirically test whether competition exists online and modeling how it affects online communities.

\subsubsection{The two studies}

The rest of this dissertation consists of two empirical studies. The goal of the first study is to develop a theory of online community ecology based on theories of organizational ecology and group ecology. In particular, the theory describes the types of competition that are likely to exist online, the conditions for them to emerge, the indications of competition, and their impacts on online communities' short-term member retention capabilities. Then, the theory is tested using a longitudinal sample of 241 Usenet newsgroups over 64 months, from October 1999 to January 2005. The purpose of this study is to demonstrate the importance of ecological competition in explaining online community viability, above and beyond the impact of the internal community characteristics which have been the focus in the existing literature.

The second study builds on the first, to explore the impact of contextual factors on individual members' stay or leave decision in online communities over time. Aiming to understand individuals' ongoing participation decisions, this study has a longer-term focus than the first, treating individuals' participation as series of social exchanges with a community. The second study examines the impact of ecological competition as well as its interaction with individuals' motivation level. Individuals' prior participation history with an online community is 
considered another aspect of the social environment where an interaction takes place, and its impact on individuals' ongoing participation are examined. This study tests the research model using participation data from 43,758 active members in 7 Usenet newsgroups over 64 months. Combined with the first study, the second study provides a more nuanced understanding of how community level ecological competition affects individuals' continuance decisions, while demonstrating the importance of prior exchanges as part of the larger context that individuals face when making continuous participation decisions in online communities. 


\section{A COMPETITION PERSPECTIVE ON ONLINE COMMUNITIES}

\subsection{INTRODUCTION}

Online communities have become an important aspect of business and individual life (Mockus et al. 2002), supporting information, professional, entertainment and social activities (Preece 2000). Online communities are virtual spaces where groups of people can interact for a shared purpose (Preece 2000; Rheingold 2000). Individuals participate in online communities to seek information, develop friendships, obtain social support, discuss hobbies and interests, and organize cooperative work (Rheingold 2000; Ridings \& Gefen 2004). At the same time, businesses increasingly use online community technologies to support and interact with their customers as well as support internal employees. Software vendors maintain Usenet newsgroups, mailing lists, and online forums to provide technical support for developers and users, and enable products to be modified and improved by users, saving costs for market research, product development and technical support (Jeppesen \& Frederiksen 2006). Electronic communities are implemented within organizations to enable knowledge sharing (Constant et al. 1996; Wasko \& Faraj 2005). Across a variety of contexts, online communities are being put in place to support interaction among dispersed individuals. 
A significant amount of research has examined important questions such as why people participate online (Lakhani \& Hippel 2003; Ridings \& Gefen 2004), how online interactions differ from those offline (Cummings et al. 2002; Galegher et al. 1998), what types of activities people engage in online (Butler et al. Forthcoming), what benefits people receive from online participation (Cummings et al. 2002; Sproull et al. 2005), and how internal group norms, values, and structures affect individual contributions and group performance (Hertel et al. 2003; Lee \& Cole 2003; Moon \& Sproull 2000; Wasko \& Faraj 2005). However, most of this research has examined characteristics of a given community or its members, paying little attention to the larger environments within which a community exists and the impact of that environment on community survival. These studies seem to assume that individuals participate in a single community, or that their behaviors in one community are independent of their activities elsewhere. As a result, it remains unclear whether and how communities in different contexts vary in terms of their capabilities for success, and whether existing findings in online communities are dependent on the context.

In many cases, the assumption that communities are isolated is incorrect. Online communities often share content or members with one another, just like offline groups and organizations. Within the Usenet newsgroup hierarchy, for instance, there are often multiple newsgroups covering a topic. A keyword search of 'Microsoft Word' in Google Groups archive yields a result of ten newsgroups with these keywords in the title or group descriptions. Individuals interested in Microsoft Word may need to compare and choose the one(s) most suitable for their needs. Existing members in one of the ten newsgroups may switch from one to another 
because they find the other group more interesting or active. As a result, the ability of a community to attract and retain members is likely to be affected by the presence of other similar communities in the environment.

Multiple online communities sharing members is also common. A member of a cancer support group, for example, might participate in one online group because it provides good information, and another because of attachment to the people in it (Shaw et al. 2000). Because individuals can participate in multiple groups at the same time, members may visit one community less often because they want to spend time in others as well. Therefore, their decisions to stay or leave as well as their extent of participation in a particular community are likely to be affected by other groups that attract their attention. Focusing only on internal community structure and communication characteristics will prevent us from understanding membership changes due to environmental changes.

This paper proposes an ecological view of online communities to complement existing research by taking into account the environments in which communities are embedded. The environments of online communities can include other communities, resource availability, and the relationship among the communities. An ecological view is one that emphasizes the relationship of online communities and their environments, working from the premise that online communities affect, and are affected by, other communities as they compete for member resources. Therefore, as with organizations that exist within a competitive environment, it is important to consider the ecological context when studying online communities and their 
success. This study focuses on how one aspect of community success, the ability to retain members, is affected by the existence of other groups in the environment. The following section discusses factors that may affect this ability. We then propose an ecological perspective to complement prior research.

\subsection{LITERATURE REVIEW}

\subsubsection{Online Community Member Retention}

Members are the key resources for online communities because communities rely on member participation to provide resources and benefits (Butler 2001). Critical mass theory suggests that a community requires a number of contributors above a certain threshold in order to sustain itself (Markus 1987). Similarly, Kim (2000) suggests that a minimal level of activity is critical for communities to attract members. Without enough members to generate activities and contribute meaningful content, an online community will fail to attract members and remain viable. An online community's membership retention capability, therefore, is important for the sustainability of the community. From a utility perspective, if members of a community tend to stay for a long period of time, it signals the effectiveness of the community in fulfilling members' needs, and the ability of the community to achieve its own functions. Moreover, from a behavioral point of view, the members who repeatedly participate will likely be particularly important for community viability because they often contribute the majority of the content and resources to communities, help shape the norms and values within the 
community, and influence the behaviors of other members (Kim 2000).

Nevertheless, retaining members is particularly challenging in online communities because there is often little organizational or normative pressure for members to stay. In fact, most online community participants are one-time visitors. In Usenet, the oldest and largest online discussion infrastructure, about $73 \%$ of authors who post in a month do not post again (Arguello et al. 2006). Thus, it is important to understand what influences a community's capability to retain participants in online communities.

\subsubsection{Commitment, Information Overload, and Ecological Competition}

The majority of the online community research focuses on individuals' motivations to participate in online communities and the benefits they receive from participation (Constant et al. 1996; Lakhani \& Hippel 2003; Wasko \& Faraj 2000). A result of this focus is that most empirical research does not explicitly examine the conditions under which a member stays or leaves a community over time. An underlying assumption is that members will continuously participate if they receive benefits greater than costs. Studies adopting organizational commitment and information overload perspectives are better suited to explain membership turnover over time. A commitment perspective focuses on the psychological attachment to a community that makes members in a community feel positively about it, leading them to stay with the community for a long period of time and continuously contribute to it (Meyer \& Allen 1991; Meyer \& Allen 1997). On the other hand, an information overload perspective 
focuses on the structural characteristics of a community that drive members away over time.

Both perspectives, however, only focus on factors internal to a single community. The impact of factors outside one community is not considered. This paper proposes a third perspective, the ecological competition perspective, to complement existing research with a focus on a community's competitive environment.

\subsubsection{Commitment Perspective}

Research adopting a commitment perspective argues that when group members participate and interact with the group over time, they develop feelings of attachment or belonging, which further lead to commitment to the group (Joyce \& Kraut 2006). Organizational commitment research suggests that when employees are committed, they feel emotionally attached to the organization and want to be part of it, perceive high economic or social cost of losing organization membership, and feel obliged to stay in the organization (Meyer \& Allen 1991; Meyer \& Allen 1997). Individuals with high commitment will thus be less likely to quit their jobs and will have higher job performance (Meyer et al. 2002). The group socialization model suggests that commitment is a function of the benefits individuals get from a group (Moreland \& Levine 2000). If individuals are satisfied with the resources and benefits a group provides, they will perceive continued participation as beneficial and become committed to the group (Butler 2001; Moreland \& Levine 2000). Based on the organizational commitment and group socialization theories, groups within which individuals are highly committed should have low membership turnover, because members are likely to return repeatedly (Joyce \& Kraut 2006). 
Commitment to groups takes different forms. Studies of traditional groups identified two distinct bases for group attachment (Prentice 1994; Sassenberg 2002). Some members are attached to groups because of their relationships with other members. For instance, some college students may participate in their fraternities because they like the people there and enjoy interacting with them. Others are attached because of the topics and content offered in their groups. Most people participating in a group have topic attachment to the group, and the match between their interests and the content in a group affect whether and how long they will stay. Whether they like each other or value each other, however, varies across groups. Therefore, we focus on the bond-basis of groups, which is defined as the extent to which a group's basis for attachment depends on members' interpersonal relationship with each other. In high bond-based groups, members like each other, value each other, and feel similar to each other (Prentice 1994). They frequently refer to each other, provide social or emotional support to other members, value the social interaction with others, and are more tolerant towards off-topic discussions (Ren et al. 2006). Such behaviors help the development of internal ties among members and, in turn, increase the level of commitment among members. In low bond-based groups, on the other hand, attachment to groups mainly come from members' interest in the general topic of the groups. Members do not value the relationships with others (Sassenberg 2002). Empirical research comparing offline groups with different attachment bases found that groups with high bond-basis often have high topic identifications as well (Prentice 1994). Therefore, members in groups with high bond-basis have higher incentives to stay than those in groups with low bond-basis. Studies have found that traditional voluntary 
associations in which individuals have strong internal ties are less likely to lose members than those whose members have many external ties (McPherson et al. 1992). Hence, communities that are more bond-based are expected to be more capable of retaining members:

H1: The degree to which an online community is bond-based is positively associated with its member retention capability.

The level of activity in a group can reflect members' commitment to it. Because commitment is often associated with increased participation (Meyer et al. 2002), the level of contribution in a group represents the motivation, interest, and commitment of the individuals in the group. Contribution efforts can further create a basis of attachment to a group because people tend to increase their commitment to justify their effort (Duck 1998; Festinger 1957). Therefore, a higher level of contribution in a community indicates a community that overall is more motivated and committed, and hence more attractive to members (Lickel et al. 2000). Thus,

H2: Overall level of contribution in an online community is positively associated with its member retention capability.

\subsubsection{Information Overload Perspective}

While a high level of interaction can build high member commitment, the volume and complexity of messages may overwhelm members. Information overload theory argues that individuals have limited information processing capabilities (Jones et al. 2004). Large volumes of messages can make it costly for members to read and sort through available content in order to find the information they value. Highly complex messages in a community can demand more time and energy from members to compose and read (Butler 2001). Messages can get 
especially long and complex in online communities, because the Internet and communication technologies enable easy reference or inclusion of previous messages on the same topic. If a community requires a greater amount of effort from its members, the members are more likely to leave the community in order to maintain a balance between limited capability of and high demand for information processing (Butler 2001; Jones et al. 2004). Therefore, as information overload increases, and with it the costs of participating in a community, higher turnover among members is expected.

H3: Information overload in an online community is negatively associated with its member retention capability.

\subsubsection{Ecological Competition Perspective}

The above two perspectives, group commitment and information overload, focus on factors that are internal to a single community. However, communities do not exist in a vacuum. Each online community exists in a context, where there are other communities, people with different interests, and conditions that affect the survival of the community. Although many studies on groups and affiliations consider one network or group at a time, an ecological perspective suggests that community dynamics cannot be fully understood without taking into account the environment within which the community exists (Levine \& Moreland 1998; McPherson et al. 2001). One important aspect of the environment is the presence of other communities and the relationships with them. Studies of traditional voluntary organizations have found that individuals maintain ties with others within a group, and also with others external to that group, depending on their interests and needs (McPherson et al. 1992). Small group research also suggests that individuals often have multiple group memberships, forming linkages across 
group boundaries (Moreland \& McMinn 2002). Having such external ties and multiple memberships reduces the commitment in a given community and creates forces that may drive members outside, which leads to higher turnover (Cress \& McPherson 1997; McPherson et al. 1992), and groups changing their strategies to attract and retain members (Levine et al. 1998).

An ecological competition perspective on online communities is rooted in organizational ecology theory, which posits that organizations demanding the same set of resources are competitors when resources in the environment are limited (Hannan \& Freeman 1977). The environment includes the presence of other organizations, the resources that organizations need in order to survive, and the availability of resources. When available resources are limited in the environment, there is an upper bound on a population's potential to grow. In this situation, the growth of one population will decrease the growth of others, leading to competition (Barron et al. 1994; Ingram \& Inman 1996). The same is true for organizations within a population (Baum \& Singh 1994; Singh 1993).

Competition theory in the organizational ecology literature specifies the conditions under which competition occurs: when demand of resources in the environment exceeds supply, and similar organizations all require the limited resources. Each organization occupies a unique niche location, determined by the type of resources that the organization needs to survive (Hannan \& Freeman 1977; McPherson 1983; McPherson et al. 2001). Each organization's resource niche is multi-dimensional, depending on the different characteristics of the required resources. When organizations overlap in their niche dimensions, they need similar resources, 
and hence create competitive pressure on one another. Competition occurs among the organizations with overlapping niche dimensions.

Online communities, like organizations and groups, are subject to competition from other communities in overlapping niches. A critical resource that online communities need is members: online communities need member involvement, participation, and contribution to survive and succeed. Therefore, if communities need similar types of participants and the available participants are limited, the ecological approach suggests that there will be competition among those communities.

Earlier, it was mentioned that there are two distinct bases for group attachment: content and relationship. A niche for online communities can be defined in terms of the characteristics, interests, and values of members in a community. Content and relationships represent key elements of an online community that members seek. These bases for attachment describe the values of community members, and thus can also define the niche in which online communities compete. Content-based competition emerges when an online community offers similar content with other communities. Relationship-based competition occurs when an online community shares members with other communities.

\section{Content-based competition}

Individuals can differ on many dimensions, including demographics, interests, values, etc. One obvious way that online communities compete for members is through the topics and content 
that they offer. If multiple communities cover similar topics and offer similar content, they are likely to be vying for the same pool of members interested in those topics and content. In other words, they need the same resource. Individuals interested in the topics and content can compare and choose among the similar communities and select the one most suitable for their needs. For example, when there are many online support groups for Microsoft Access, a user with questions regarding Access can visit any one of the available groups to get their questions answered. As a result, individuals' tendency to stay in one community is lower than when there is no other choice. In addition to sharing a common topic focus, communities may also explicitly share content by allowing the same content to be posted to multiple places. In online communities, content sharing is very easy with the advanced communication and Internet technology. Forwarding a post to another community or posting the same messages to multiple places can be done in a few clicks. Thus, explicit and implicit content similarity with others can occur in many places without community owners being aware of them. Each community's capability to retain members is weakened by the presence of other similar communities in the environment. Therefore, communities that share topics or content pose a threat to each other in a similar way as competitors in a product market.

There are many indicators for content similarity among online communities. Among them, the most direct indicators are the number of content-based competitors and the extent of content overlap. The number of content-based competitors refers to the number of communities offering similar content. Organizational ecology theory suggests that the number of organizations in the same niche increases the intensity of competition (Barron et al. 1994), and 
this competition reduces organizations' ability to survive, and thus leads to higher mortality rates (Carroll \& Hannan 2000) and reduced growth rate (Podolny et al. 1996). In the online environment, the more communities with which a focal community offers similar content, the more options its members have, and the higher the competition. Therefore, the number of online communities offering similar content indicates the number of competitors for the community, which is expected to weaken its ability to retain members.

H4: Number of communities that an online community offers similar content with is negatively associated with its member retention capability.

Communities often have multiple topics that together define their content focuses, and the topics can change over time. As a result, it is rare to see a community's content completely duplicated in other communities. The extent to which a community's content is similar with others indicates the extent to which it competes with others based on content. The ecological model suggests that organizations within a niche, or with overlapping niche dimensions, compete with each other (Baum \& Singh 1994; Hannan \& Freeman 1977). When online communities compete based on overlapping content niche, higher extent of content similarity suggests that a community is subject to higher level of content-based competition, which is expected to reduce the likelihood of community members coming back to the community.

H5: The extent to which an online community offers similar content with others is negatively associated with member retention capability.

Content is not the only basis upon which online communities compete. Individuals also stay in communities for the relationships with other people. In that case, when the same people belong 
to multiple communities at the same time, individuals seeking to maintain relationships with those people have multiple choices as to what communities in which to build the relationships. There will be lower motivation for them to stay in one versus another. Therefore, communities with shared members are relationship-based competitors: they compete for the individuals interested in building relationships with their shared members.

Because some people seek content in online communities and others look for relationships, the same community can be subject to both content and relationship-based competition. However, the bases for the two types of competition are distinct. Communities with different topical foci will have low content-based competition. But they can still share members when individuals are interested in multiple topics, and thus be subject to high relationship-based competition. For instance, many college classmates participate in Facebook to keep in touch, while some of them may also be active members in Flickr. Then, although Facebook and Flickr do not have high content similarity, they can have a high extent of membership overlap.

A community's ability to retain members as active participants is likely to be affected by the presence of other relationship-based competitors. Membership overlap between traditional voluntary associations has been found to reduce a group's capability to retain existing members (Popielarz \& McPherson 1995). As with content-based competition, relationship-based competition can also be represented by two indicators: the number of other online communities that share members with a focal community, and the extent of membership overlap among them. If a community shares members with many others, individuals seeking relationships with 
the shared members have many options to choose from. Therefore, it will be harder for the community to retain members.

H6: The number of communities an online community shares members with is negatively associated with its member retention capability.

The degree to which a community shares its members with others indicates the extent of membership overlap with other communities. This overlap indicates the extent of relationship-based competition that the community faces. When most of a community's members have single membership, the group is less vulnerable to relationship-based competition. When many members also participate elsewhere, the community's stability is at greater risk. Thus, it is expected that,

H7: The extent to which an online community shares members with other communities is negatively associated with its member retention capability.

\subsubsection{Interactions between Ecological Context and Community Characteristics}

Neither internal nor external perspective is sufficient to fully understand online community member dynamics. Contextual settings limit and structure the behaviors and capabilities of groups, while internal strategies and activities differentiate groups in the same environment (McGrath et al. 2000). Internal group dynamics and contextual variables can interact to affect group behaviors, abilities, and performance over time (McGrath et al. 2000). For instance, studies have found that the impact of competition on an organization's performance depends on organizational differences (Baum \& Singh 1994; Singh 1993). Similarly, the impact of internal structure on community stability depends on the extent to which a community is subject to 
competitive pressure (Pettigrew 1967). Therefore, in order to fully understand online communities' sustainability, the interaction between internal and external variables must be considered.

Communities with different bases for attachment may be affected by competition in different ways. In particular, if the basis for competition matches the basis for attachment in a community, the competition directly affects the underlying reason that members participate in the community. When that happens, competition should have the most detrimental effects. In high bond-based communities, there are stronger interpersonal connections between members, and the reason for members to stay is the presence of other people they like. If many other communities share members with a focal community, the members can maintain their ties in other places as well, and thus will hurt the very basis for members to remain in the focal community. If a community's competitors are mostly content-based competitors, it will not be affected as much, because its members care more about relationships with people than the content offered. Therefore, high bond-based communities are expected to be more sensitive to the impact of relationship-based competition than communities that are less bond-based. Similarly, for content-based competition, the number of content-based competitors is expected to reduce a community's ability to retain members to a larger degree in low bond-based groups than in high bond-based groups.

H8a: The number of communities that an online community shares members with has a larger negative impact on its member retention capability when bond-basis of the community is high.

H8b: The number of communities that an online community offers similar content with has a larger negative impact on its member retention capability when bond-basis of the 
community is low.

Level of activity in a community can also influence how it is affected by its competitors.

Highly active communities tend to have highly committed members, and therefore members

will not leave easily for other competitors that offer similar content or relationships.

Furthermore, a community with a high level of contribution offers more resources to

individuals than those with low contribution, making it more attractive for members. Therefore,

the level of contribution in a community is expected to alleviate the impact of competitors on

member turnover:

H9a: The number of communities that an online community offers similar content with has a smaller negative impact on its member retention capability when level of contribution in the community is high.

H9b: The number of communities that an online community shares members with has a smaller negative impact on its member retention capability when level of contribution in the community is high.

The impact of competition on community turnover may also depend on the information overload inside a community (Pettigrew 1967). When the cost of processing information is low in a community, the community faces lower risk of losing members, even when there is competition. However, when communities demand high amounts of effort for members to participate, availability of alternative competitors will be more likely to drive members to other communities that offer similar benefits. Therefore, we expect to see a stronger negative effect of the number of competitors on return rates when information overload is higher.

H10a: The number of communities that an online community offers similar content with has a larger negative impact on its member retention capability when messages in 
the community are long.

H10b: The number of communities that an online community shares members with has a larger negative impact on its member retention capability when messages in the community are long.

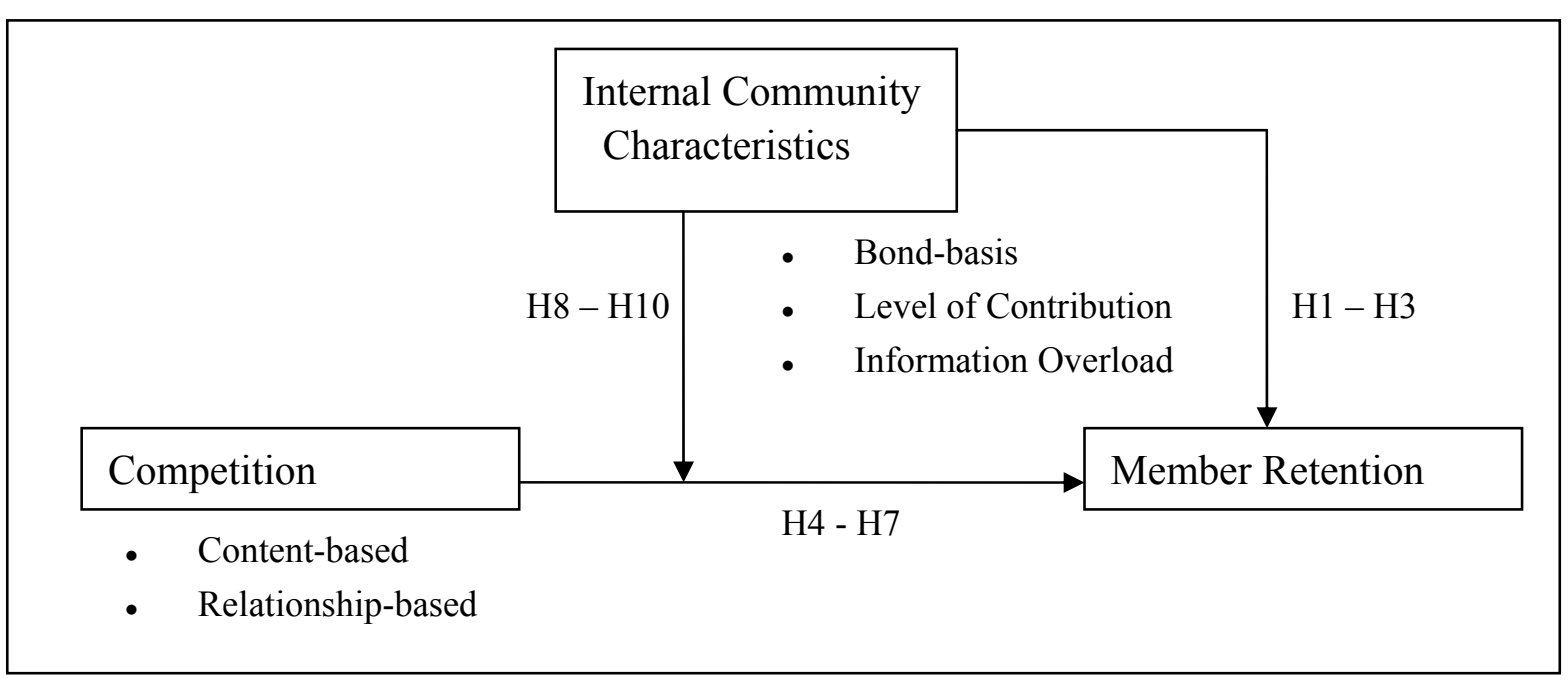

Figure 1: Study 1 Research Model

Figure 1 shows the overall research model. Competition, either content- or relationship-based, is expected to reduce an online community's member retention capability. Internal community characteristics, including the bond-basis of an online community, its overall level of contribution and internal level of information overload, are also expected to affect member retention. Moreover, the internal community characteristics may interact with competition when influencing communities' member retention capability. 


\subsection{METHOD}

\subsubsection{Data}

This study examines the impact of content and relationship-based competition on a community's capability to retain members, above and beyond the impact of internal community characteristics. We use archival data from Usenet newsgroups to test the model. Usenet is a global distributed communication infrastructure that hosts over 189,000 online discussion communities called newsgroups. These newsgroups vary greatly in terms of size, topic, type, internal structure, level of activity, and relation to other newsgroups, thus providing a natural site to test predictions regarding communities' ability to retain members. Topics in Usenet newsgroups cover computers, humanities, entertainment, science, and social or controversial discussions, among many others. The number of newsgroup participants also differs, with some newsgroups attracting a few authors per month, while others have hundreds or thousands of authors. Only a small number of newsgroups are moderated or managed by companies, for instance, the newsgroups run by Microsoft. Within the Usenet system, individuals can participate in multiple newsgroups and post the same messages to several newsgroups simultaneously, i.e., crosspost (Smith 1999). Through joint membership and cross-posting, newsgroups are linked with each other and also compete with each other for members' limited time and energy. 
A stratified random sample of 241 newsgroups was used to test the hypotheses. The sample was selected from the Microsoft Netscan database (Smith 2005). The Netscan system collects information about Usenet newsgroups, the individuals who participate in them, and the messages that are posted in them. From this data it is possible to determine the level of activity in a newsgroup in a certain month, the nature of the messages posted to the newsgroup (message length and timestamp), the number of other newsgroups with which a focal group shares content (i.e. cross-posts), and the number of other newsgroups that members also post to. The sample was selected in several steps. First, a list of 400 newsgroups was randomly selected from the Netscan database, which includes data for 159,356 newsgroups. In order to avoid inactive groups that were mostly spam, only groups with an average of 20 posts per month or more were included in the sample. Next, six researchers unaware of the purpose of the study independently read newsgroup descriptions and random messages in each newsgroup from October 1999 to January 2005 available from Google Groups archive (http://groups.google.com), in order to assess the basis for attachment in each newsgroup. Newsgroups that were mostly spam, announcements, and groups in foreign languages were dropped. Finally, monthly data about the 241 remaining newsgroups and the authors in them from October 1999 to January 2005 was obtained from the Netscan database. The final dataset used in the analysis includes panel data for the 241 newsgroups over 64 months' periods. Because only active contribution leaves a trace in Usenet, the Netscan system does not provide data on lurking behavior, or reading messages without posting. As a result, the data reflects individual contributions, i.e., the messages that authors post to newsgroups. Members of a 
newsgroup are defined as individuals who post messages to the newsgroup ${ }^{3}$. All the behavior measures in this study are based on individuals' active participation in newsgroups.

\subsubsection{Measures}

\subsubsection{Dependent Variable}

Return rate. One indication of a community's ability to retain membership in the short-term is its month-to-month return rate (Jones et al. 2004). In this analysis, returnees were defined as those who posted to a newsgroup in a month and also returned the following month. Thus, return rate for a month was calculated as the percentage of returnees from last month among all active members in the current month. The one-month time-window was chosen because many Usenet participants do not return after one month. Using a wider window variable might obscure the predicted effects, because many of the member returning activities is ignored.

\footnotetext{
${ }^{3}$ In Usenet, there is no strict sense of 'membership', because there is no formal requirement for individuals to become members of a newsgroup. As a result, the majority of participant visit peripherally and silently, and it is difficult for them to develop attachment to a particular newsgroup. Active participation by posting messages to a newsgroup indicates that the participants have additional motivation to engage in a newsgroup, and therefore is a more reasonable proxy for the presence of relationships between individuals and newsgroups in Usenet.
} 
Table 4: Sample conversations in low and high bond-based groups

\begin{tabular}{|c|c|}
\hline Newsgroup Name & Sample Conversation $^{4}$ \\
\hline alt.html.webedit & $\begin{array}{l}\text { From: bobdevrie...@hotmail.com } \\
\text { Hello, } \\
\text { I'm trying to auto refresh my website (every minute my webcam makes a new picture and sends it } \\
\text { to my webspace). But when I use }<\text { META HTTP-EQUIV="REFRESH" CONTENT="20; } \\
\text { URL=home.html"> it doesn't work properly. It doesn't recognize that their is a new picture (with } \\
\text { the same name). Who can help me out? } \\
\text { From: Hywel Jenkins } \\
\text { Try_this in the }<\text { head }>\text { section: } \\
<\text { meta http-equiv="Expires" content="01 Jan 1980 01:01:01 GMT"> } \\
<\text { meta http-equiv="Pragma" content="no-cache"> }\end{array}$ \\
\hline alt.support.depression & $\begin{array}{l}\text { Sometimes i wish i was alone, but then i'm sure i'd have killed myself by now. they're my reason } \\
\text { for staying alive. i do like to be alone and quiet, though. hanging out with some of the cats is just } \\
\text { my speed lately. } \\
\text {-lisa } \\
\text { Yep, me and my } 2 \text { cats. But you have love from and for your family, and that's good (I hope I don't } \\
\text { sound like I'm comparing depressions--that's not what I mean!!) } \\
\text { s... } \\
\text { for waiting rooms and the like, i have my palm computer with me. i've got a couple of games i } \\
\text { like, crossword puzzles, and a book i'm reading all right there with me. especially good for my } \\
\text { neurologist, who's often running a couple of hours late. what drives me nuts is waiting in the } \\
\text { ophthalmologist's office after they've put dilating drops in my eyes. not only do i have to wait, but } \\
\text { i can't really see anything. } \\
\text {-lisa } \\
\text { Sorry Lisa, hopefully you're asleep by now--my NGs were down since around } 9 \text { pm pacific time. } \\
\text { Anyway, just wanted to thank you for your support \& time tonight. I appreciate that you took the } \\
\text { time to reply. Hope you have a good day tomorrow } \\
\text { s... }\end{array}$ \\
\hline
\end{tabular}

\footnotetext{
${ }^{4}$ Message text indicating bond-basis is highlighted in Table 4.
} 


\subsubsection{Independent Variables}

Bond-basis of commitment. The bond-basis of a newsgroup refers to the extent that members of a newsgroup participate because of their relationships with other people in the group, as opposed to general interest in the topic. The bond-basis of each group was assessed by six independent raters based on their evaluations of random messages in each of the 241 newsgroups (drawn from the Google Groups public archive at http://groups.google.com), using a 1 to 7 scale (1: definitely not bond-based -7 : strongly bond-based). The raters were not aware of the hypotheses at the time. They were instructed to read enough random messages in each group to assess the extent to which a group is bond-based. The raters received materials on the definition of bond-basis (see Appendix D), and reviewed examples of high bond-based groups together. They also engaged in discussions on potential indications of high bond-basis in online discussion groups before starting the rating tasks. Then, the raters evaluated whether members appeared to have social relationships with others in each newsgroup by looking for messages containing friendship, support, emotional and/or social elements, such as references to other's names or shared experiences, emotional content, familiarity with other members, etc.

The six researchers achieved a satisfactory level of agreement with a Chronbach's alpha measure of inter-rater reliability of 0.87 . Therefore a bond-basis score was calculated by averaging the individual judges' ratings. Because the bond-basis measure was at the newsgroup level, it did not change over time. Examples of low bond-based groups included comp.lang.c and alt.html.webedit, which often included discussions on technology-related issues and problem solving. On the other hand, the alt.support.depression, alt.support.dissociation, 
alt.recovery and soc.support.pregnancy.loss groups are examples of high bond-based groups. Members in these groups were often more closely acquainted, shared life stories, and provided emotional support for each other. Table 4 presents typical conversations in a low bond-based and a high bond-based group.

Posts per Poster (PPP). Level of contribution in a newsgroup was calculated based on the number of messages in a month divided by the total number of authors posting in the newsgroup in that month. Posts per Poster (PPP) reflects the average per-person contribution in a newsgroup month. In this dataset, an author was defined as someone who posted at least one message to a newsgroup. Therefore, the PPP measure did not include those passive members who only read messages. Because this measure was highly skewed, a log transformation was applied. All log transformations in this analysis are natural log based. Before transforming, all zero values were replaced by 0.1 . Log transformation significantly improves the normality of measures (see Appendix B).

Information Overload. Internal information load was measured by Average Message Length in a newsgroup, calculated as the average number of lines in a message in a newsgroup-month. In earlier work, information overload was measured by both message volume and average message length in the group (Jones et al. 2004). However, in this data, message volume is highly correlated with post per poster, and therefore these two variables cannot be examined together. Therefore, message length is used as the only indicator for information load. Length of messages in a newsgroup was a proxy for the amount of effort required to read and post messages. Because the count of message length includes the quoting of other messages, long 
messages could be a result of replies including earlier messages in a long conversation. However, the average line count measure was not significantly correlated with the number of reply messages or repliers in a group, suggesting that average message length measure was independent of the nature of replies. Moreover, even when parts of a message were quotes of earlier conversations, many readers would read the whole message in order to quickly understand the history of the conversation, instead of finding and reading all the original messages. In that case, message length including quotes would still be a valid indicator of the information load for the reader.

Closer examination of this measure's distribution suggests that the two largest Average Message Length values, 167,719 and 11,671, were more than 50 standard deviations larger than the mean. Thus, these two group-months observations were removed as outliers (see Appendix B). The Message length measure was log transformed because its distribution was highly skewed.

Content and relationship-based competition facing a newsgroup were each measured with two variables. Content-based competition was indicated by the number of cross-posting groups and the percentage of cross-posting messages. Relationship-based competition was indicated by the number of co-member groups and the percentage of members shared with other groups.

Cross-Posting Groups. The number of cross-posting groups measured the number of content-based competitors, i.e., other similar groups that shared content with a focal 
newsgroup. In the Usenet community infrastructure, the same message can be posted to multiple groups with low effort, a behavior called "cross-posting." Each of the cross-posted communities will thus receive a copy of the same message. Cross-posting indicates content similarity among communities on two levels. Concretely, cross-posted messages are common content shared among the different groups and directly contribute to content similarity. More abstractly, cross-posted messages reflect an author's beliefs that the topical foci of the involved groups are similar. Therefore, cross-posting patterns in online communities indicate both the actual and perceived content overlap among them. That is to say, the number of communities that a focal community cross-posts with (cross-posting groups) reflects the number of content-based competitors. The number of cross-posting groups in a group-month was calculated as the monthly count of other unique newsgroups to which local messages were cross-posted. A log transformation was applied to this measure to improve normality (see Appendix C).

Because cross-posting can have ambiguous meanings, representing not only content overlap, but also popularity or size of the group, the same analyses were run using an alternative measure of topic similarity between groups on a subset of the sample. This topic similarity is calculated as the average document frequency between one group and all the other groups assessed, using automated process, which evaluated how frequent words used in one newsgroup appear in other newsgroups. Because the full message content is only available from Jun 2003 - Jul 2005, the analysis using this alternative measure is only conducted for those 25 months. Results show qualitatively similar results, therefore only the results using 
cross-posting are reported.

Cross-posting Rate. Percentage of messages cross-posted with other newsgroups

(\%Cross-posted messages) was used as an indicator of the extent to which a community's content is similar with others in the Usenet environment. This measure was calculated as the number of cross-posting messages divided by the total number of messages posted to the newsgroup in a month. The higher the percentage of cross-posted messages, the more content is explicitly shared with other newsgroups.

Co-Membership Groups. The number of co-member groups represents the amount of competition from relationship-based competitors, i.e., other newsgroups that shared members with a focal group. Two newsgroups share a common author when the same author posted at least one message in both of the newsgroups in a given month. Therefore, the number of co-membership groups was calculated as the number of other newsgroups that share common authors with a focal group in a month.

Because the criteria for co-member group result in large numbers of co-member groups for each newsgroup-month, I also tried to refine the measure to count as co-membership groups only newsgroups that share at least 5 or 10 common authors with a focal newsgroup. Using the alternative measures did not yield qualitatively different results. Thus, the analyses using those measures were not reported in this paper. A log transformation was applied to this measure to enhance normality. 
Membership Overlap Rate. The extent of membership overlap was measured as the percentage of authors in the focal newsgroup who also posted messages to other newsgroups (\%Shared Members). It indicates the degree to which a focal newsgroup competed with other groups in terms of members' time and energy. High percentage of shared members suggests high extent of member similarity between the focal group and all its member competitors.

\subsection{ANALYSES AND RESULT}

The analysis dataset contained measures for 241 groups from October 1999 to January 2005. Not all groups in the dataset are active for all the 64 months, and therefore a few newsgroups have 0 posts in some of the months. Some groups started after October 1999, and thus they have fewer than 64 observations. The final analysis dataset included 14,992 newsgroup-month observations.

Table 5 displays the descriptive statistics for the untransformed measures. In the 241 newsgroups, the return rate ranged from 0 to 1 , with a mean of 0.279 . That is to say, on average, $27.9 \%$ of the authors in a typical newsgroup in a typical month post again in the following month. The low percentage of return rate is consistent with the motivation of this study (i.e., that retaining members is a non-trivial problem). The bond-basis of the sampled newsgroups ranged from 1 to 6.83 , with a mean score of 3.30. On average, an author contributed 4.37 messages in a typical newsgroup-month, with a minimum of 0 messages and a maximum of 70.97 per author. Length of messages in the sample newsgroups varied from 0 to 4,979 lines 
per message, with a mean of 47.41 lines and median of 33 .

Table 5: Descriptive Statistics

\begin{tabular}{|l|l|l|l|l|l|}
\hline Variable & Mean & Median & Min & Max & Std. Dev. \\
\hline Newsgroup-month level & $\mathrm{N}=14,992$ & & & & \\
\hline Return Rate (t) & 0.279 & 0.276 & 0 & 1 & 0.141 \\
\hline Posts Per Author (t-1) & 4.411 & 2.861 & 0 & 70.98 & 4.547 \\
\hline Average Message Length (t-1) & 47.409 & 33.000 & 0 & 4979 & 90.891 \\
\hline \#Cross-posting Groups (t-1) & 46.406 & 26.000 & 0 & 2250 & 112.228 \\
\hline \%Cross-posted Messages (t-1) & 0.286 & 0.181 & 0 & 1 & 0.274 \\
\hline \#Co-membership groups (t-1) & 32358.130 & 30634.500 & 0 & 105305 & 24386.840 \\
\hline \%Shared Member (t-1) & 0.758 & 0.788 & 0.008 & 1 & 0.176 \\
\hline Newsgroup-level & $\mathrm{N}=241$ & & & & \\
\hline Bond-basis & 3.299 & 3 & 1 & 6.83 & \\
\hline
\end{tabular}

There is a medium degree of content sharing among the sampled news groups. A typical newsgroup cross-posted with 26 other newsgroups in a given month, and shared $18.3 \%$ of its messages with other newsgroups. Joint memberships are common in the sampled newsgroups. A typical newsgroup shared members with 32,261 other newsgroups. The percentage of shared members in a newsgroup ranged from $0.9 \%$ to $100 \%$, with a mean of $78.9 \%$. This indicates that online community participants, in particular Usenet participants, often visit multiple places at the same time, which highlight the need for studying consequences of joint membership.

To test the proposed hypotheses, we estimated a longitudinal and multi-level model using the xtmixed procedure in Stata (Rabe-Hesketh \& Skrondal 2005), predicting member return rate in a particular newsgroup-month with the competition indicators as well as the bond-basis of 
a group, level of contribution and information overload. The xtmixed procedure is for estimating multi-level clustered data, which is the nature of this panel dataset, since multiple observations over time are nested within each newsgroup. In particular, the xtmixed procedure allows both fixed and random effects, and provides more flexibility in specifying a model. All the independent variables, except for bond-basis of a group, were lagged for one-month in order to allow examination of the impact of these variables on the return rate in the subsequent month. As a result, the first month's data for each newsgroup was not included in the analyses due to missing values. All the independent variables were centered before creating the interaction terms and running the models. Table 6 shows the correlations among the $\log$ transformed measures used in the analyses. Correlations among the independent variables are not high (mostly smaller than 0.5 ). Multi-collinearity analysis shows that all variance inflation factors (VIF) are below 5, within the generally acceptable levels (Hair et al. 1998). The low VIF suggests that multi-collinearity is not likely to be an issue in this analysis.

Table 6: Correlations

\begin{tabular}{|l|l|l|l|l|l|l|l|l|}
\hline & & 1 & 2 & 3 & 4 & 5 & 6 & 7 \\
\hline 1 & ReturnRate & 1 & & & & & & \\
\hline 2 & Bond-basis & $0.261^{*}$ & 1 & & & & & \\
\hline 3 & Posts Per Author (t-1) & $0.626^{*}$ & $0.325^{*}$ & 1 & & & & \\
\hline 4 & Average Message Length (t-1) & $-0.095^{*}$ & -0.001 & $0.110^{*}$ & 1 & & & \\
\hline 5 & \#Cross-posting Groups (t-1) & $-0.092^{*}$ & $-0.099^{*}$ & $0.258^{*}$ & $0.324^{*}$ & 1 & & \\
\hline 6 & \%Cross-posted Messages (t-1) & $-0.433^{*}$ & $-0.228^{*}$ & $-0.269^{*}$ & $0.326^{*}$ & $0.289^{*}$ & 1 & \\
\hline 7 & \#Co-membership groups (t-1) & $-0.092^{*}$ & 0.013 & $0.159^{*}$ & $0.346^{*}$ & $0.382^{*}$ & $0.034^{*}$ & 1 \\
\hline 8 & $\%$ Shared Member (t-1) & $-0.364^{*}$ & $-0.231^{*}$ & $-0.177^{*}$ & $0.334^{*}$ & $0.310^{*}$ & $0.686^{*}$ & $0.205^{*}$ \\
\hline
\end{tabular}

*: correlation significant at $\mathrm{p}<.05$ 


\subsubsection{Internal Group Characteristics}

Model 1 regressed return rate on just the internal group characteristics (Table 7). All the variables were significant in the expected directions. The bond-basis of a newsgroup was hypothesized to lead to more internal connections and thus higher likelihood of members coming back. The results supported the hypothesis (H1). When the bond-basis of a newsgroup increased by $1 \%$ from the average level, the percentage of returnees in the next month increased by $0.01 \%(\beta=0.0095, \mathrm{p}<0.01)$. Similarly, level of contribution in a newsgroup was hypothesized to reflect the level of motivation and commitment in the group, and thus should be associated with the increasing percentage of returnees. The results found that when Post Per Poster increases by $1 \%$, the return rate increases significantly by $0.09 \%$ $(\beta=0.089, \mathrm{p}<0.001)$, supporting $\mathrm{H} 2$. The information overload hypothesis predicted that long messages would increase the cognitive load on members who read and process the messages in a newsgroup, and thus it would drive people away. We found support for this hypothesis (H3), that each percent increase in the average number of lines in a message significantly reduced the return rate in the following month by $0.03 \%(\beta=-0.025, \mathrm{p}<0.001)$.

\subsubsection{Extent of Competition}

Competition is expected to make it more difficult for newsgroups to retain members. Therefore, newsgroups facing higher competition are expected to have lower return rates. The results largely confirmed the hypotheses. Model 2 added the four competition indicators to the 
regression, and three of the four indicators negatively and significantly predict return rate. A $1 \%$ increase in the number of cross-posting groups from the average level decreased the return rate in the following month by $0.01 \%(\beta=-0.012, \mathrm{p}<.001)$, and each $1 \%$ increase in the percentage of cross-posted messages in a group significantly reduced return rate by $0.09 \%$ ( $\beta=$ $-0.09, \mathrm{p}<.001)$. Therefore, H4 and H5 were supported, confirming the expectation that content-based competition reduces a newsgroup's ability to keep members. Similarly, sharing members with $1 \%$ more newsgroups reduced the percentage of members returning by $0.007 \%$ ( $\beta=-0.007, p<.001)$, confirming H6. Sharing greater proportion of members with other newsgroups decreased return rate, however, the relationship was not significant $(\beta=-0.007$, $\mathrm{p}=.400)$. Therefore, $\mathrm{H} 7$ was not supported.

I also tested for the curvilinear effects of the competition indicators by including squared terms for the four competition measures. In Model 3, the squared terms were added. Three of the four squared terms were significant, suggesting the existence of non-linear relationships. The squared term for number of cross-posting groups was not significantly associated with return rate $(\beta=-0.000, p=0.348)$. The square term for the percentage of cross-posted messages, however, was positive and significant $(\beta=0.076, \mathrm{p}<.001)$. This suggests that as a newsgroup shares more messages with other groups, the negative impact of cross-posting ratio decreases. In other words, the percentage of messages shared with other groups reduces return rate at a decreasing speed (Figure 2). Both of the member overlap measures had a curvilinear relationship with the likelihood of members returning, and their negative impacts on return rate increased as a newsgroup faced higher member-based competition (Figure 3), as 
suggested by the negative coefficients $(\beta=-0.001,-0.126$, respectively, $\mathrm{p}<.001)$. Furthermore, including the squared terms made the coefficient of co-member rate significant. The percentage of shared members in a newsgroup was found to be not significant in Model 2, but it had a significant and negative impact in Model $3(\beta=-0.035, \mathrm{p}<0.001)$. This indicates that sharing a larger proportion of members with other newsgroups does have a negative impact on member retention, although the relationship is non-linear. 


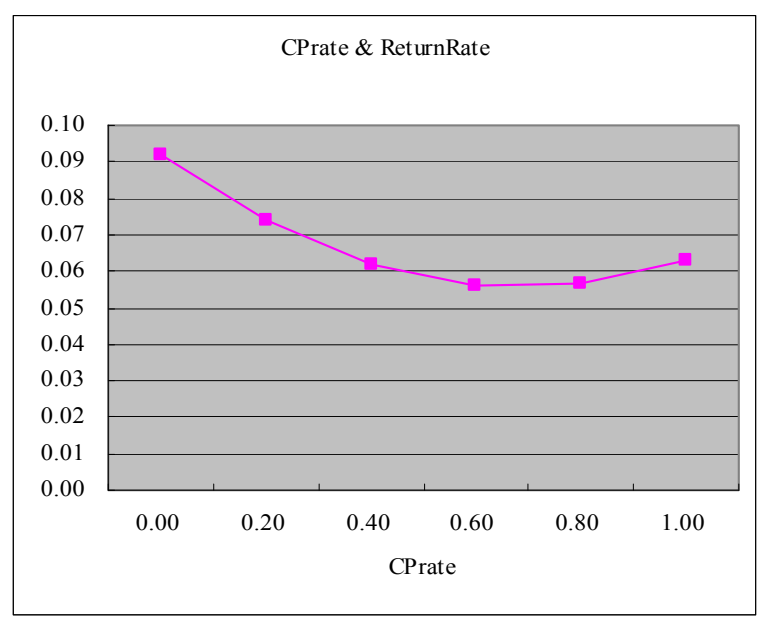

Figure 2: Curvilinear Relationship Between Content Membership and Return Rate
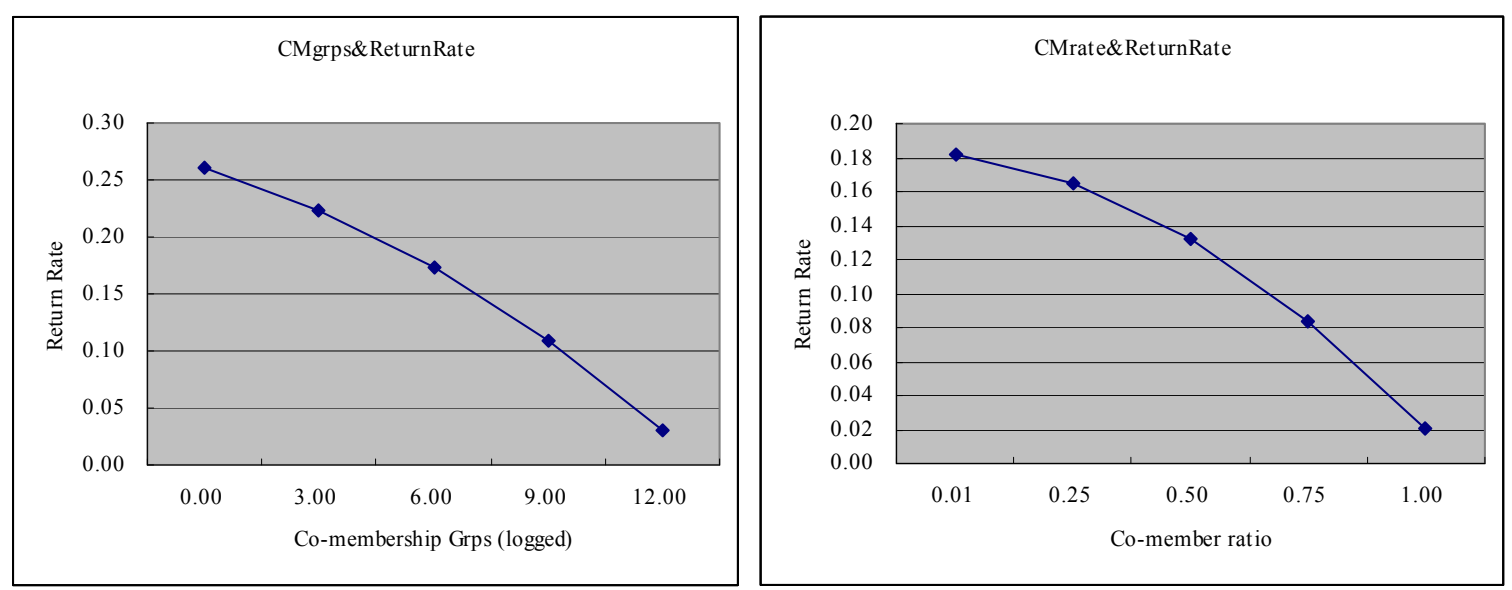

Figure 3: Curvilinear Relationship between Membership Competition and Return Rate 


\subsubsection{Interaction between internal characteristics and extent of competition}

Model 4 tested the effects of interactions between competition indicators and internal group characteristics. Eight interaction terms were added in the model. Multi-collinearity analysis suggested that the squared term for number of co-membership groups and the interaction term between average message length and number of co-membership group were highly correlated with other variables, and thus these two variables were dropped from Model 4, leaving six interaction terms. Adding the interaction terms increased the overall fit of the model, decreasing the AIC from -33928 to $-34020.63^{5}$. As expected, bond-basis of a group was found to interact with the two types of competition differently, supporting H8a and H8b. Although both content-based and member-based competitors reduced a group's ability to retain members, bond-basis of the group alleviated the effect of content-based competitors $(\beta=0.001, p<0.05)$, while it magnified the impact of relationship-based competitors $(\beta=$ $-0.001, \mathrm{p}<0.01)$. When there are many competing similar groups, high bond-based groups are better at retaining members than low bond-basis groups. However, low bond-based groups are better at retaining members than high bond-based groups when facing relationship-based competition.

The level of contribution in a newsgroup was found to magnify the negative impact of content competition on return rate, in contrast to the prediction of $\mathrm{H} 9 \mathrm{a}$. The number of cross-posting groups interacts with the number of post per poster in a group $(\beta=-0.001$,

\footnotetext{
${ }^{5}$ AIC is a criteria for model fit. The smaller the AIC index the better the overall model fit. AIC takes into account of degree of freedoms as it penalize number of variables in the model.
} 
$\mathrm{p}<.001)$ to affect return rate. This result suggested that as the number of content-based competitors in the environment increases, newsgroups with high level of activity are affected more negatively than groups with low contribution per authors. As shown in Figure 4, number of cross-posting groups reduces membership return rate, however, the return rate drops more quickly with highly active groups. Although the interaction between the number of co-membership groups and post per poster is not significant, the coefficient is also negative.

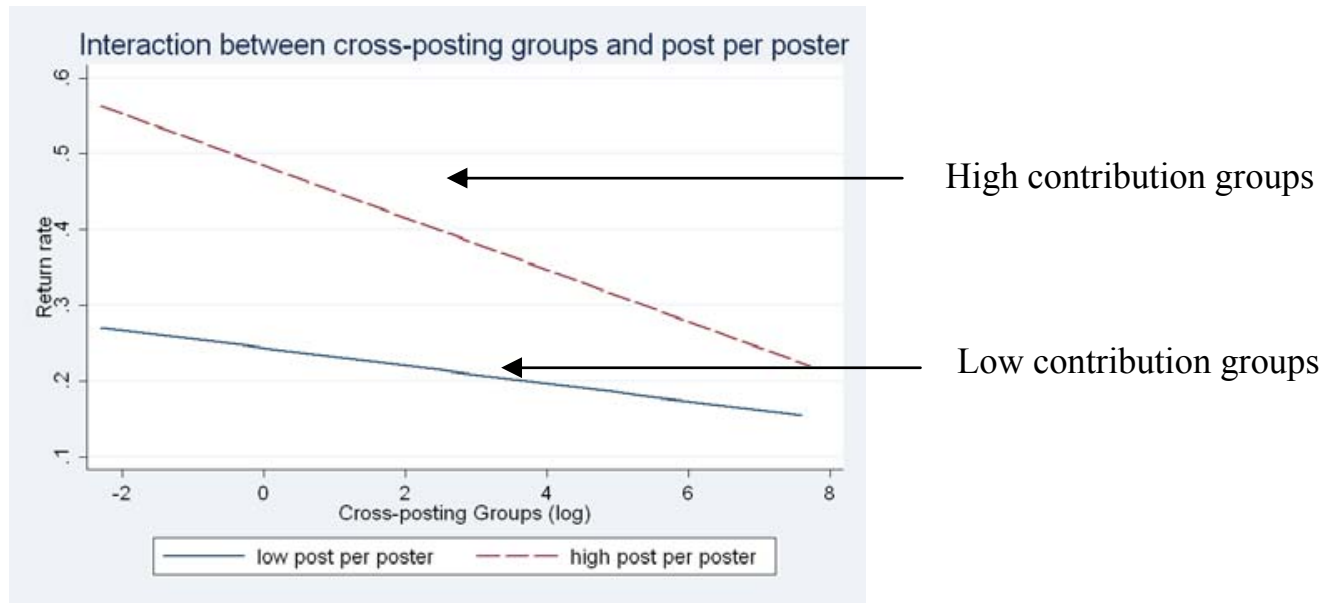

Figure 4: Interaction between Cross-posting Groups and Post Per Poster on Return Rate Average message length in a newsgroup was not found to moderate the impact of competition on the likelihood of members coming back. When the number of cross-posting groups increases, groups with longer messages are affected the same as those with shorter messages. Because of the multi-collinearity problem, the interaction between number of co-membership groups and message length could not be tested. 
Table 7: Predicting Member Return Rate

\begin{tabular}{|c|c|c|c|c|}
\hline & Model 1 & Model 2 & Model 3 & Model 4 \\
\hline & Control & Competition & Square & All \\
\hline \multirow[t]{2}{*}{ Constant } & $0.2784 * * *$ & $0.2784^{* * *}$ & $0.2797 * * *$ & $0.2777 * * *$ \\
\hline & $(0.0049)$ & $(0.0044)$ & $(0.0046)$ & $(0.0046)$ \\
\hline \multirow[t]{2}{*}{ Bond-basis } & $0.0095^{* *}$ & 0.0053 & $0.0059^{*}$ & $0.0064^{*}$ \\
\hline & $(0.0031)$ & $(0.0028)$ & $(0.0028)$ & $(0.0028)$ \\
\hline \multirow[t]{2}{*}{ Average Message Length } & $-0.0254 * * *$ & $-0.0042 * *$ & $-0.0072 * * *$ & $-0.0125 * * *$ \\
\hline & $(0.0012)$ & $(0.0013)$ & $(0.0013)$ & $(0.0014)$ \\
\hline \multirow[t]{2}{*}{ Post Per Poster } & $0.0888^{* * *}$ & $0.0871 * * *$ & $0.0780 * * *$ & $0.0741 * * *$ \\
\hline & $(0.0016)$ & $(0.0015)$ & $(0.0017)$ & $(0.0017)$ \\
\hline \multirow[t]{2}{*}{ \#Cross-posting Groups } & & $-0.0120 * * *$ & $-0.0128 * * *$ & $-0.0126^{* * *}$ \\
\hline & & $(0.0007)$ & $(0.0008)$ & $(0.0009)$ \\
\hline \multirow[t]{2}{*}{$\%$ Cross-posted Messages } & & $-0.0900 * * *$ & $-0.1048 * * *$ & $-0.1137 * * *$ \\
\hline & & $(0.0045)$ & $(0.0066)$ & $(0.0066)$ \\
\hline \multirow[t]{2}{*}{ \#Co-membership Groups } & & $-0.0071^{* * *}$ & $-0.0096^{* * *}$ & $-0.0074 * * *$ \\
\hline & & $(0.0004)$ & $(0.0006)$ & $(0.0004)$ \\
\hline \multirow[t]{2}{*}{ \%Shared Members } & & -0.0069 & $-0.0353 * * *$ & $-0.0287 * *$ \\
\hline & & $(0.0081)$ & $(0.0096)$ & $(0.0097)$ \\
\hline \multirow[t]{2}{*}{ Squared Term of \#Cross-posting Groups } & & & -0.0002 & $0.0006^{* *}$ \\
\hline & & & $(0.0002)$ & $(0.0002)$ \\
\hline \multirow{2}{*}{$\begin{array}{l}\text { Squared Term of \%Cross-posted } \\
\text { Messages }\end{array}$} & & & $0.0758^{* * *}$ & $0.0827 * * *$ \\
\hline & & & $(0.0124)$ & $(0.0127)$ \\
\hline \multirow{2}{*}{$\begin{array}{l}\text { Squared Term of \#Co-membership } \\
\text { Groups }\end{array}$} & & & $-0.0008^{* * *}$ & \\
\hline & & & $(0.0001)$ & \\
\hline \multirow[t]{2}{*}{ Squared Term of \%Shared Members } & & & $-0.1264 * * *$ & $-0.1019 * * *$ \\
\hline & & & $(0.0233)$ & $(0.0239)$ \\
\hline \multirow{2}{*}{$\begin{array}{l}\text { Post Per Poster * \#Co-membership } \\
\text { Groups }\end{array}$} & & & & -0.0003 \\
\hline & & & & $(0.0005)$ \\
\hline \multirow[t]{2}{*}{ Bond-basis * \#Co-membership Groups } & & & & $-0.0007 * *$ \\
\hline & & & & $(0.0003)$ \\
\hline \multirow{2}{*}{$\begin{array}{l}\text { Average Message Length * } \\
\text { \#Cross-posting Groups }\end{array}$} & & & & 0.0001 \\
\hline & & & & $(0.0008)$ \\
\hline \multirow[t]{2}{*}{ Post Per Poster * \#Cross-posting Groups } & & & & $-0.0096 * * *$ \\
\hline & & & & $(0.0009)$ \\
\hline \multirow[t]{2}{*}{ Bond-basis * \#Co-membership Groups } & & & & $0.0011 *$ \\
\hline & & & & $(0.0004)$ \\
\hline Observations & 14992 & 14992 & 14992 & 14992 \\
\hline df & 6 & 10 & 14 & 20 \\
\hline $\mathrm{AIC}$ & -32507.74 & -33828.91 & -33928 & -34020.63 \\
\hline
\end{tabular}

Note: $\mathrm{N}=14992$, Standard errors in parentheses; ${ }^{* * *} \mathrm{p}<0.001,{ }^{* *} \mathrm{p}<0.01,{ }^{*} \mathrm{p}<0.05$ 


\subsection{DISCUSSION}

Prior research suggests that members' psychological identification with a community, internal group dynamics, and information load, all play into their willingness to stay, and hence affects turnover in online communities. This study supplements prior investigations by demonstrating that external forces also affect a community's ability to retain members. This study develops an ecological perspective, taking into account the embedded context of online communities and specifying how this larger context affects internal member dynamics. Such an approach allows a more complete and accurate understanding of the factors which affect membership change beyond the boundary of a community. Specifically, the analyses provide evidences that as expected by the ecological model, the extent of competition has significant impact on retention rates. When groups are in an environment where they share content with other groups (cross-posting) and have a large fraction of their members in many other groups (co-membership), a smaller fraction of people who participated in them in one month return in the next. Although some of the effect sizes seem small, the short-term month-to-month effects can accumulate over time and have significant impacts on community stability. The findings suggest that the presence of other similar groups undermines a group's internal stability, as does the presence of other groups that share members. 


\subsubsection{Discussion of results}

\subsubsection{Content and relationship-based competition}

Consistent with the proposed online community ecology theory, competition from other communities with similar content or shared members reduces a community's capability to retain members. When a community offers similar content with others, it is subject to content-based competition. Both the number of content -based competitors and the extent to which the community's content is similar with others are associated with an increased level of competition, and thus make it more difficult for the community to keep members. This result has important implications because content overlap is commonly seen among online communities. Sometimes, new communities offer similar content as other previously successful groups in order to attract new members, assuming that the existing groups offer timely and interesting topics. For instance, after the success of Facebook and MySpace, other similar social networking websites emerged. Also, in online forums, it is often seen that members of one community leave and start their own group when they are not satisfied with the norms or values in the initial group. The newly established community may have different conventions, but will often cover similar topics. The crossposting feature in some online communities further facilitates content sharing. This result, however, demonstrates that content similarity may have a negative impact on member retention. As the number of communities in a topical niche increases, they all become potentially less viable. Therefore, online community owners and managers may want to re-examine their topical focus and control the level of topical content overlap with others. 
Similarly, when an online community shares members with others, it is subject to relationship-based competition. Both the number of other communities that it shares members with and the extent to which it competes with them increases the competitive pressures it faces, and thus reduces its member retention rate. Individuals often participate in multiple online communities because they can fulfill multiple interests and needs in different places. But the results in this study suggest that this multiple membership can be harmful for the stability of the communities. Therefore, to the degree that online community owners and developers have control, it may be useful to think of ways to reduce, or at least manage, its members' tendency to participate simultaneously elsewhere.

\subsubsection{Differential impact of competition}

The impact of competition was found to be affected by the internal behaviors, patterns, and structure of the communities. Competition was found to have a greater impact when the basis for competition matches the basis for attachment in an online community. Because content-based competition is based on content similarity, it drives people away more so when individuals' link to the community is based primarily on their interest in the topical focus of the community. If people in the community stay around for their personal relationships with each other, the presence of other topically equivalent communities does not have as great an impact. Therefore, content-based competition is more detrimental for online communities with low bond-basis than those with high bond-basis. On the other hand, because members in high bond-basis communities value the social relationships with others, the presence of other communities that these relationships can be sustained in is more disruptive for maintaining 
members' interpersonal ties. Therefore, communities with high bond-basis are more sensitive to relationship-based competition than those with low bond-basis. This distinct interaction pattern for content and member-based competition suggests that the nature and impact of these two types of competition are different.

These results indicate that competition affects different communities in different ways. Therefore, it would be useful for online community owners and managers to know the nature of their communities and accurately assess the bases for their members' involvement. Based on that knowledge, they can evaluate which type of competition is more likely to affect their communities, and monitor that aspect of the larger environment more closely. Also, when the level of particular types of competition in the environment is high, one way to alleviate the impact of competition is to adjust the basis for attachment in the community so that it does not match the type of competition. Previous research in offline groups found that groups can transform from low bond-based groups to high bond-based groups when facing external threats that hurt their group identity (Sassenberg 2002). Our findings suggest that this strategy may also be effective for online communities facing content competition.

Moreover, the impact of content-based competition is found to be higher on communities with high levels of contribution. This is in contrast to what was expected. A possible explanation is that the level of contribution in an online community also represents its members' cost of participation. When the level of member contribution is high, community members need to invest more effort into participating, either by contributing or reading in the 
community. Therefore, the availability of alternative topically equivalent communities may prompt members to switch to other communities that provide similar content benefits but potentially require less effort. Future research should test the validity of this explanation, and explore its implications for the interplay of information costs, competitive context, and membership dynamics in online communities.

\subsubsection{Implications}

\subsubsection{Research implications}

This study contributes to online community research by bringing in an external perspective, calling for more attention to the external environment in which an online community exists. In particular, this paper focuses on the ecological competition among online communities, and examines its impact on communities' member retention capabilities. Based on organizational ecology, it was proposed that competition occurs when multiple organizations need similar resources and the resources in the environment are limited. In online settings, because the Internet removes many geographical and temporal constraints for participation, anyone can participate in any community at any time. Therefore, member resources are potentially abundant. At the same time, it is easy for communities to share content and members, because individuals' participation in multiple online communities involves lower costs than similar offline participation. This means that the demands on member resources are also higher. Therefore, it becomes difficult to determine whether there will be competition or whether competition will play a role in affecting members' decisions. Our results show that in 
spite of the greater access afforded by the Internet, competition does occur among online communities, and it has a significant impact on the communities' internal stability. In the analysis, adding the competition measures increases overall model fit, suggesting that consideration of competition enhances our ability to explain member retention rate. In fact, separate regressions adding the internal community and competition measures in steps suggest that the impact of competition measures has on member return rate is comparable to that of internal community characteristics. Therefore, adding the concept of competition in online community research allows us to have a more complete picture of what affects online community dynamics and viability.

Also, this study proposes a theory of online community ecology and specifies two types of competition that can emerge online. Both types of competition are empirically tested, and their impacts were found to be significant and distinguishable. This provides a foundation for future online community research considering questions regarding an online community's relationship with the larger context. First, researchers interested in individuals' decisions to contribute in online communities can incorporate competition as an influence factor, examining its impact above and beyond the impact of individual characteristics, motivations, experiences, etc. It would be useful to know, for example, what kind of individual is most likely to leave when the level of competition is high, and which kind stays despite the presence of equivalent alternatives. The answer will allow us to better understand the impact of competition on communities' member composition and viability. Future research can also examine which competing community an individual tends to choose to go to when there are 
multiple alternatives, and why. Answers to this question can help community managers make strategic decisions about attracting and retaining members in highly competitive environments.

Online community research focusing on the community or network level dynamics can also consider incorporating competition in their frameworks. We started by taking into account the presence of other similar groups, while other research can examine whether the level of activities, norms and structure in competitive groups play a role in a community's internal dynamics and its viability. In other words, which communities are more successful in competing with others? The number of authors, nature of interactions, and other community characteristics in competing groups may all affect the viability of a community. Also, it will be interesting to investigate other contingency factors that may augment or alleviate the impact of competition. For instance, whether communities with higher quality content and more selective topics are better at retaining members in competitive markets (Hansen \& Haas 2001).

Most prior research has a cross-sectional nature or only examines data in two or three points of time. This study extends existing research by using data over 64 months for each community, taking into account changes that may occur over time, and increasing the generalizability of the findings. Using longitudinal data, this analysis treats online communities as dynamic entities. Another way that future research can extend this work is to examine the impact of competition during different stages in the lifetime of a community, by looking at the 
interaction between time and competition. Both the topics discussed within a community and the members participating in the community change during the life cycle of the community, and the impact of competition may grow stronger or weaker as well. Small group research, for example, treats time as part of the ecological environment, which affects the structure, behavior and dynamics within groups and the ways groups develop (Levine \& Moreland 1998). Studying the interaction between competition and time will allow us to better understand the temporal pattern of online communities' growth and decline, and how those patterns can be attributed to and affected by competition.

\subsubsection{Practical implications}

On one level, the practical message that this study delivers is simple: competition exists online, and it can hurt online communities. Online community owners, managers, and leaders should not underestimate the potential impact of online competition, even if their community is not a for-profit venture. It is important for them to understand the type of competition that exists in their environment and the nature of their own communities in order to accurately assess the impact of competition on their communities.

This paper suggests that online communities seeking to retain members should carefully choose the community features that minimize the level of external competition. A community can shift the topics offered to distance itself from others. Technical features such as message filters, spam detection tools, subgroups structured by topic, time or preference, and search engines can be employed to reduce actual and perceived content overlap with other groups. In 
some cases, policies can be implemented to restrict or constrain the number of communities a member can belong to at the same time. Interestingly, our results suggest that the very technical mechanisms that are often put in place to facilitate online community participation, e.g., cross-posting and open membership, may create competitive tensions among communities and drive people away. Cross-posting reduces the effort of a member to post the same message to multiple groups, facilitating content sharing and allowing members to get maximum benefit from contributing. Open membership makes it easy for members to join new groups and visit multiple groups at the same time. However, both of these features also enable competition, which was found to limit communities' ability to retain active participants. Therefore, online community designers may need to consider these tradeoffs when deciding which features to include in their community infrastructures.

When competition from other groups is unavoidable, as is true in many cases, the results of this study suggest that community managers use different strategies to retain members than when competition is low. This study suggests that adjusting the communities' bases for attachment and controlling the level of contribution may help communities survive in highly competitive environments. Future studies can further examine the effectiveness of these and other strategies communities can use to improve their ability to retain members. 


\subsubsection{Limitations and future research}

The results presented in this paper are limited by the contextual data that is available. The ideal dataset for examining competition would include data on all the potentially competing groups, both online and offline. We do not have information on offline groups that online community participants belong to, or other similar online competitors that are not in Usenet. Although we have comprehensive data within the Usenet infrastructure, which allows us to analyze the impact of the Usenet environment on individual newsgroups, this focus within Usenet limits our power to explain the full effects of competition. In particular, our analysis may underestimate the impact of competition among online communities, because Usenet competition is likely to be only a portion of all competitive forces an online community faces.

This sample contains data on only one type of technical infrastructure: Usenet, and one type of online community: voluntary conversational community. To increase the generalizability of the results, future studies could consider how the ecological competition model plays out for other types of communities like communities of practice, virtual teams, and other technical infrastructures such as Weblogs, Listservs, and Web based forums.

Future studies of competition and online community ecology should also examine other metrics of success. In this paper we found that competition reduces the ability of a community to retain members. However, member retention ability is not the only factor in community success. Success is determined by a community's ability to fulfill members' need 
and achieve its own purposes (Kraut 2003). Member retention is only one of the goals, and may not always be the focus of a community. For communities like Slashdot, which attracts millions of visitors while having much faster member turnover than Usenet newsgroups (Dave et al. 2004), new member attraction and topic maintenance are more critical for their objectives than keeping existing contributors. For online communities at their early stages of development, new member retention may also be a more urgent need than member retention. Similarly, small group research suggested that newcomers can bring innovative ideas to groups and improve group performance (Levine \& Choi 2004; Levine et al. 2003). In open source discussion forums, for example, new members bring in new questions and perspectives, report bugs and contribute to the continuous improvement of the software. In technical support communities, if people get the information they want, some of them will leave. They only come back if their questions remain unanswered or problems unresolved. Hence, in this context, members returning can mean that the community is not fulfilling the members' needs. But even this kind of communities need a core group of contributors who stay for a long period of time to answer questions and help others. For these communities, retaining the right people and building a core is more important than general member retention. Therefore, it is necessary to also examine the impact of external competition on other dimensions of online community success. 


\subsection{CONCLUSION}

Building and sustaining successful online communities can potentially impact many aspects of life: improving individual and social life, creating revenue for businesses, and enabling new forms of political activity. Yet it takes more than building a technical infrastructure to make an online community successful and useful for its members. How a community operates matters, the internal dynamics matter, and so does its external environment. Prior studies often neglect the existence and potential impact of the other communities that combined to form larger networks within which a community resides. This work shows that, within these larger networks, communities compete with each other for member resources. Only by recognizing the impact of potential competing forces, and by understanding how to cope with competition via managing internal dynamics, can community sponsors, managers, and leaders achieve their goals of building viable online communities. 


\section{CONTRIBUTION IN CONTEXT: ONLINE COMMUNITY PARTICIPATION AS CONTEXTUALIZED SOCIAL EXCHANGE}

\subsection{INTRODUCTION}

Successful online communities such as YouTube, MySpace, Wikipedia and Open Source Software communities have raised much interest among practitioners. Online communities are believed to have great potential to generate business value (McAfee 2006; Schindler 2001; Wagner 2007). Recent trends show that many organizations are building online communities to provide user and customer support (Lakhani \& Hippel 2003; Moon \& Sproull 2000), facilitate user innovation (Kern et al. 2006; von Hippel 2005), support information and knowledge exchange (Hof 2005; Wasko et al. 2004), and to build new business functions and models (Wagner 2007). A simple search in Google News with the keyword 'online community' yields thousands of examples of new online communities. Related terms like social computing, Web 2.0, and 'wisdom of crowds' are frequently referred to in the business press (Babcock 2006; Wylie 2007). At the same time, researchers are increasingly interested in the phenomena of online communities. Much of the existing research attempts to understand the social dynamics within these virtual communities, and tackle the challenge of building sustainable and successful online communities (Butler 2001; Wasko et al. 2004). 
Most of the existing online community research focuses primarily on understanding individual motivations to contribute, often treating contributions in online communities as one-time, isolated events (Lakahani et al 2003, Wasko \& Faraj 2000). Empirical studies at the individual, group or interaction level all tend to model individuals' decision to participate as a one time choice, independent of their past or future behaviors in a community (Butler 2001; Wang et al. 2006). The implicit assumption that participations are one-time, isolated choices may be reasonable in some cases, because the level of turnover in these communities is often high. In Usenet, for example, more than $70 \%$ of participants post only one message to a newsgroup and never return again (Arguello et al. 2006). The majority of online community participants stay no longer than a few days. However, for participants who contribute repeatedly in their communities over a long period of time, their decisions may be more complex and should no longer be treated as simple one-time choices. These repeatedly returning participants are also key to the survival and sustainability of a community (Kim 2000), which makes it important to understand their interaction with their communities which involves series of actions that take place over time.

To better understand how individuals engage in extended involvement with online communities in competitive environments, this study applies social exchange theory to model an individual's participation behaviors in an online community over time. Social exchange theory has enjoyed more than 30 years of influence in explaining social behaviors and interaction patterns (Emerson 1976; Homans 1958; Molm 2001), including interpersonal 
relations (Rusbult \& Buunk 1993), interorganizational relations (Cook 1977; Levine \& White 1961), workplace behavior (Farrell \& Rusbult 1992; Rusbult \& Farrell 1983), and group participations (Levine \& Moreland 1990; Levine \& Moreland 1998). Therefore, it serves as an appropriate theoretical lens to describe individuals' ongoing involvement in online communities, which is social by nature. In particular, social exchange theory is combined with an ecological theory of online communities to model series of online community participation in competitive environments.

\subsection{Online Community Participation as Contextualized Social}

\section{EXCHANGE}

\subsubsection{Social Exchange Theory}

Starting from Homans' seminal work, the core of the social exchange theory is the premise that many activities that individuals engage in can be seen as exchanges of resources (Blau 1965; Homans 1958; Molm 2001). Actors, which can be individuals, groups, organizations or networks, all have resources and capabilities that are of value to others. Because not all actors have access to all the resources they need, they will exchange what they have with others who have the resources they want (Levine \& White 1961). Exchange has been defined as 'action that is contingent on rewarding reactions from others' (Blau 1964), and 'behavior whose level or frequency of performance over time is sustained by reinforcing (rewarding) activity from other people' (Emerson 1976). These definitions imply that an exchange should involve both 
sides of a transaction, and should be mutually dependent and rewarding (Emerson 1976). In other words, an initiator of exchange who offers resources to another often expects receiving some reciprocated benefit (Blau 1964; Emerson 1976; Molm 2001). In strict economic sense, the expected reward or benefit are often tangible, such as monetary rewards, information, products, and services. However from a social exchange perspective, the reward can be intangible or intrinsic, including self-satisfaction, reputation, and social recognition from others. Exchanges also involve costs, including the direct cost of executing the exchange and the opportunity cost of foregoing other options. Therefore, an actor's engagement in an exchange involves evaluation of the costs and benefits of alternative exchange options.

Organizational researchers applied social exchange theory in studying inter-organizational relations. Treating organizations as exchange actors, organizational theorists were able to study the formation of inter-organizational relations for different organization functions in different environmental settings. Organizational exchange is defined as 'any voluntary activity between two organizations which has consequences for the realization of their respective goals or objectives' (Levine \& White 1961), and 'voluntary transaction involving the transfer of resources between two or more actors for mutual benefit' (Cook 1977). These definitions loosened the criteria of exchange to include unidirectional transfer of resources, so that it does not require reciprocated transfer of resource (Levine \& White 1961). Moreover, it emphasized that exchange activity must be voluntary and not mandated (Cook 1977). Definition of organizational exchange converges with interpersonal exchange definition in that both suggest that exchange involves multiple actors and be mutually beneficial or 
rewarding.

Originated from different disciplines, including economics, behavior psychology and sociology, social exchange theory has different forms. Some focuses on exchanges as rational choices, assuming that actors consciously assess costs and benefits of alternative exchanges and make rational choices that maximize outcomes. Others treat exchanges as social behaviors, suggesting that actors rely on consequences of past exchanges without cognitively weighing costs and benefits of each alternative (Hall 2003; Molm 2001). However, all forms agree that social exchange involves series of transactions or exchanges that generate obligations to reciprocate (Cropanzano \& Mitchell 2005; Emerson 1976). What distinguishes social exchange theory from economic exchange theory is its emphasis on social relations that develop from series of repeated transactions between the same actors and the social structure within which exchange relationships develop (Molm 2001). Economic exchange theory focuses on the goods and resources being exchanged, and treats actors as interdependent and interchangeable. Each exchange is deemed independent of another. Social exchange theory, on the other hand, pay attention to who the actors are, who they exchange with, and the longitudinal exchange relations between them (Emerson 1976). Moreover, instead of assuming a competitive market where actors are independent, social exchange theory focuses on the exchange structure within which transactions occur and exchange relations emerge.

Dependence structure, exchange network, and power relationship between the actors are central factors that exchange researchers examined that govern the exchange processes and influence the frequency and quality of exchanges (Emerson 1976; Molm 2001; Molm 2003). 


\subsubsection{Online community participation as social exchange}

Participation in online communities often involves multiple individuals, either readers or posters. Each individual, when posting a message to a community, expects some benefits in return, be it information, advice, reputation, self-expression or altruism (Kollock \& Smith 1996; von Hippel \& von Krogh 2003). Also, individuals expect that others in the community will read the message and react in certain ways. The behavior of an individual who posts a message in one community has been found to be contingent on others' reaction to his or her initiation of interaction (Arguello et al. 2006). Therefore, active participation in online communities meets the definition of social exchanges.

\subsubsection{Participation as series of exchanges}

If social exchange theory is applied to study interactions in online communities, its focus on long term repeated transactions has important implications for what is examined. The current body of online community research pays most attention to identifying individual motivations to engage in single contributions to online communities (Constant et al. 1996; Lakhani \& Hippel 2003; Ridings \& Gefen 2004; Wasko \& Faraj 2005). Empirical findings show that individuals have both extrinsic and intrinsic motivations to join or participate in a community (Kankanhalli et al. 2005; Tedjamulia et al. 2005), and they expect both instrumental and social benefits from participation (Constant et al. 1996; von Hippel \& von Krogh 2003). Although this line of research helped much in understanding why individuals spend significant time 
online to share information (Lakhani \& Hippel 2003), exchange knowledge (Wasko \& Faraj 2005), help strangers (Constant et al. 1996; Sproull et al. 2005) and contribute to projects without pay (Lee \& Cole 2003; Mockus et al. 2002), the existing findings shed little light on explaining why people stay in one community versus others, how often they choose to participate, and why they leave. There is only an implicit assumption that individuals leave when their costs of the next interaction exceed the expected benefits of remaining in the community.

Applying social exchange theory to online community research suggests considering individuals' continuance decisions in a community, paying more attention to individuals' ongoing experience, evaluation of experience, and decisions to stay or exit over time. Instead of treating participation and contribution as independent, one-time events, we should focus more on individuals' longer term engagement by examining series of exchange transactions in their online communities over time. Recently, researchers have recognized this limitation and started to emphasize the importance of understanding continuous participation (Tiwana \& Bush 2005). Applying social exchange theory to the study of online community implies a renewed focus on understanding these issues, calling for studies into the nature of the ongoing exchange relationship between individual participants and their online communities.

\subsubsection{Participation as contextualized exchanges}

Social exchange theory also suggests that the context of exchanges is important - the series of participation exchanges are situated in context, and thus context influence and shape online 
community participation behavior. The current online community literature considers only a limited part of the social environment where the interactions between individuals and their online communities take place. Existing research considers the normative pressure in a community (Bateman et al. 2006; Kankanhalli et al. 2005) and the network structure (Wasko \& Faraj 2005), but does not take into account the larger environment outside of the focal community. The impact of the external environment, for instance, the presence of other communities and the connections between communities, on individuals' behavior in a focal community, is unknown. With the increasing number and popularity of online communities, this gap in the literature undermines our ability to explain or predict an individual's decision to continue or discontinue participation in a community. Therefore, a social exchange perspective can extend existing online community research to examine participation as contextualized exchanges and to pay more attention to the effect of context on community dynamics.

\subsubsection{Current participation, prior participation, alternatives and ongoing participation}

Social exchange theory assumes that all actors are self-interest, in that they try to maximize benefit and minimize cost. When the perceived benefits of an exchange have greater value than the costs, an actor will engage in the exchange. An exchange can produce different types of benefits to the actors involved. Because different actors may value different things, social exchange theory does not make assumptions on the types of benefits an exchange offers. What's important is that the actor receiving the benefit deems it valuable. More emphasis is placed on the fact that actors seek to increase benefits and reduce costs when they are selecting 
between alternative outcomes (Molm 2001). Actors' behaviors, therefore, reflect their cost and benefit evaluations. Actors who perceive high benefits of engaging in exchanges will have higher incentive to remain in an exchange relation. Those who spent high effort and incur higher costs in exchange transactions must expect higher benefit for the exchange relationship to be worthwhile (Homans 1958).

The level of participation behavior varies greatly in online communities. A small portion of the participant can contribute to the majority of the content (Butler 2001; Jones et al. 2004), with most of other community members participating peripherally or silently. Taking a social exchange perspective, individuals should engage in exchanges with their online communities when the expected benefits from participating meet or exceed costs (Butler 2001; Kankanhalli et al. 2005). Individuals' participation level should thus reflect their expected benefit from participating at each point of time. The more active individuals are in a community at a given time, the more immediate benefit they should expect in return.

However, because participation is situated in the community context, the level of activities in the community is going to influence individuals' behaviors. As a result, the participation level of the community overall should be taken into account when evaluating the level of participation of an individual at a given time. If an individual participates more heavily than others in the same online community at a given time, it indicates that he or she expects higher benefits from participating than others at that time, either because of high value of participation, high expected benefits, low perceived participation costs or lack of other alternatives. Thus, the 
higher an individual's level of participation at a given time as compared to other participants, the more likely the individual will continue in the community in the immediate future.

Hypothesis 1: Individuals with higher relative level of participation at a given time are less likely to stop participating in an online community.

Social exchange relationships develop in and are influenced by the larger social structure (Emerson 1976; Hall 2003). Social exchange theory pays much attention to the social structure where the exchange occurs, including exchange structure, social norm, structure of social status, and alternative relations (Molm 2001), as well as the impact of social structure on the emerging exchange structure and processes (Kollock 1994; Molm 2001; Molm 2003). The exchange structure, i.e., the dependence structure or power structure among actors, has received much attention from social exchange theorists since Emerson's seminal work (1976). Prior theoretical and empirical work has been done to identify the different types of exchange structure (Molm 2001, Molm 2003), the emergence of the different structures (Kollock 1994), and the different power relations, dependence structure, exchange process and outcomes in different exchange structures (Molm 2003; Takahashi 2000; Yamagishi \& Cook 1993). Exchange structure can be direct or indirect. In direct exchange network, when actor A gives resource to actor B, he or she will receive resource from actor B in return. In indirect or generalized exchange, the benefit that A provides to $\mathrm{B}$ is not directly reciprocated by $\mathrm{B}$, but by another actor $\mathrm{C}$ in the same network. In generalized exchange network, an actor does not know whether his or her provision of resource will be reciprocated and who will reciprocate. Most of the extant social exchange research focuses on direct exchange structure, although generalized exchange behaviors are widely seen, such as helping strangers, reporting crime in a 
neighborhood, and making public donations (Takahashi 2000).

Participation in online community is better characterized as generalized exchange than direct exchange (Fulk et al. 1996a; Molm 2001; Takahashi 2000). Individuals often assume that when they give their resources to others (i.e., invest the time to create and post a message), they will receive something back (i.e., a response or future help) from others. When individuals participate in online communities, the asynchronous nature of the technology infrastructure determines that they often do not get a response, or their expected benefits, immediately. Therefore, an individual attempting to initiate an exchange does not know when the exchange will be reciprocated. Moreover, because each message is posted so that all members of the community can see and respond, there is rarely a fixed dyadic relationship between two individuals. Exchanges are not being reciprocated by specific individuals, but rather by the collection of individuals in the community. A poster does not know whom the response will come from, if it comes at all. In such generalized exchange networks, reciprocity of benefits is indirect (Molm 2001) and the timing for reciprocation is unknown to the exchange initiator (Kollock 1994; Molm et al. 2000).

Uncertainty and risk are expected to be higher in generalized exchange than in direct exchange networks, because the benefit given by an actor is not returned by the recipient, but reciprocated by another actor (Molm 2001; Takahashi 2000). As a result, actors in generalized exchange networks are less dependent on any given actor than on the overall networks, and the risk of any given exchange not being reciprocated is higher than in direct exchanges. Actors 
with lower dependency tend to initiate fewer exchanges (Molm 2001), and thus relationships in generalized exchange networks are more difficult to maintain (Yamagishi \& Cook 1993). In order to be sustainable, generalized exchange networks need mechanisms to reduce uncertainty, either by developing a higher level of trust among actors (Molm et al. 2000), or a higher level of commitment and better relationship (Kollock 1994).

In online communities, the uncertainty of what to expect from any given exchange is also high. Individuals need to learn the norms of interaction and know what to expect from the community through ongoing participation in the community and interaction with other members. Because participation requires effort, higher levels of prior participation suggest higher existing investment in a community. Existing exchange transactions with a community not only provide a basis for individuals to form expectations of the community, reducing uncertainty in such generalized network, but also constitute sunk cost and make it more difficult and costly to leave an exchange relationship (Farrell \& Rusbult 1981; Rusbult \& Farrell 1983). Prior investment in exchange relationships has been shown to significantly influence individuals' intention to continuously use expertise-sharing systems (Tiwana \& Bush 2005), and increase job satisfaction and organizational commitment (Farrell \& Rusbult 1992; Rusbult \& Farrell 1983; Rusbult et al. 1988). Therefore, individuals who have interacted extensively with an online community in the past are less likely to leave than those who have less prior involvement with the community.

Hypothesis 2: Individuals with higher level of prior participation in an online community are less likely to stop participating in the community. 
Another implication of a generalized exchange structure is that an exchange may be uni-directional, i.e., not reciprocated. In direct exchange network, an exchange is completed when an action of providing benefit is reciprocated (Molm 2001). However in generalized exchange network, a transfer of resource to others will not be reciprocated by the benefit receiver. When it is reciprocated by another actor in the network, the initiating actor's behavior is reinforced (Emerson 1976). However, because of the nature of a generalized exchange, it may be difficult to determine which returning transfer reciprocates an initial exchange. Therefore, even when an actor provides benefit to others without receiving benefit in return, the benefit provision behavior is still considered an exchange in generalized exchange networks (Takahashi 2000).

In online communities, when participants post messages to the community, they contribute to the overall content and activity of the community. Other members in the community will see their posting and react in different ways. However, participation in online communities may or may not receive direct responses. When a message poster receives a reply, the reply is a direct reciprocation to the message contributor, whether it is information, solution, or simply emotional encouragement. The exchange initiator has a successful exchange experience with a community when his or her attempt to start conversation receives a response. Successful exchanges with an online community reinforce the message posting behavior and provide direct benefit to the participants. Repeated success in prior exchanges has been found to 
produce positive emotions towards the relationship, which increases individuals' tendency to remain in a relationship despite availability of alternatives (Lawler \& Jeongkoo 1996; Lawler \& Yoon 1993). However, when online community participation is not responded to, the exchange behavior initiated by the poster is not directly reciprocated. Although the non-reciprocated exchange behaviors also accumulate existing investment, they can hurt the existing individual-community relationship by creating an imbalance between the exchange initiators' benefit-cost evaluations. Individuals may be less likely to remain in an exchange relationship if the benefit received does not overweigh the cost. Therefore, it is expected that although level of prior participation, either those that receive response or those that do not, reduces individuals' tendency to leave a community, the level of prior participation that receives responses should have a larger impact on reducing the individuals' tendency to leave than the prior participation that is not responded to. In sum, it is expected that,

Hypothesis 2a: Individuals with higher level of prior participation that receives responses in an online community are less likely to stop participating in the community.

Hypothesis 2b: Individuals with higher level of prior participation that does not receive responses in an online community are less likely to stop participating in the community.

Hypothesis 2c: Prior participation that receives responses has larger impact than prior participation that does not receive responses on individuals' continuance in a community.

Prior participation in a community develops from individuals' activities in a community in the past and shapes future behaviors. Social exchange research argues that individuals do not rationally weigh all benefits and costs each time they engage in an exchange (Molm 2001). Individuals often refer to their prior experience when making decisions. As mentioned earlier, 
social exchange theory differs from economic exchange theory in that it focuses on the longer term exchange relationship that emerge from repeated transactions rather than single exchanges. The underlying premise is that exchanges between the same actors are not inter-dependent, and actors will rely on prior experiences to infer the value of future exchanges. Therefore, prior exchanges not only shape the nature of exchange relationship, but also alter actors' future exchange behaviors. In an exchange relationship between individuals and communities, if individuals do not have enough prior experience to draw from, they may have to rely on conscious assessment of each alternative to make decision of whether a community is worth staying in. The expected benefit of participation would be the most significant factor affecting the individuals' decision. After repeated engagement in the community, individuals' investment in the community accumulates and increases sunk cost, making it increasingly difficult to abandon the exchange relationship (Rusbult \& Farrell 1983). The additional benefit of a single exchange at a given time is likely to matter less after an individual has interacted extensively with a community. Therefore, it is expected that prior participation in a community reduces the impact of individuals' current participation on their tendency to continue or stop participating in a community:

Hypothesis 3: An individual's level of current participation has weaker impact on the ongoing participation decision when the individual has higher level of prior participation in an online community.

If individuals have had many successful exchanges with the community in terms of soliciting responses from the community, their prior participation are more likely to be meaningful interactions that fulfilled their needs. Such interactions contribute to the individuals' 
expectation of the community and add to the investment into the exchange relationship with the community. However, if an individual has contributed much to a community without getting responses, he or she is not receiving direct benefits from participating while continuing bearing the costs. Immediate benefits at a given time may then become a more important factor in an individual's decision to stay or leave a community. Therefore, it is expected that, while the prior participation that receives responses reduces the impact of current participation, prior participation that does not receive responses may increases the impact of current participation on individual's tendency to continue participating.

Hypothesis 3a: An individual's level of current participation has weaker impact on the ongoing participation decision when the individual has higher level of prior participation that receives responses in an online community.

Hypothesis 3b: An individual's level of current participation has stronger impact on the ongoing participation decision when the individual has higher level of prior participation that does not receive responses in an online community.

Regardless of the form of exchange network structure, the larger exchange network can provide alternative sources where an actor can get similar resources from. The availability of such alternative exchange partners gives actors opportunities to exit an existing exchange relationship, and thus power advantage over the existing partner (Molm 2003). The alternative exchange relationships can be connected in different ways (Molm 2001). Most often, alternative relationships are treated as negative influences, in that actors' engaging in one exchange will decrease the frequency and value of other exchange relationships. Such negatively connected relationships are often seen among competitors. Exchange relationships can also be connected in positive ways. An actor's participation in one relationship can 
increase the value of exchanges in others. For instance, a knowledge broker can have multiple relationships with others. Exchanging knowledge in any one relationship may increase the broker's ability to exchange with others. In this case, relationships complement one another.

In online communities, individuals often have many choices as to which communities to participate in, and there is often little or no penalty for leaving a community. Therefore, the alternative online communities, whether positively or negatively connected, may influence an individual's decision to maintain an exchange relationship with a particular community. An individual's participation decision in a community is affected by not only factors internal to the community, but also the costs and benefits of engaging other alternative communities. Social exchange theory assumes that the availability of alternative relationships will change actors' dependence structure, and therefore influence the frequency and outcome of exchanges (Molm 2001). When an actor has alternatives, the actor has more options to choose from, and thus is less dependent on any single exchange relationship. Existing work applying social exchange theory to organizational settings found that presence of alternatives reduces employee commitment and promote employees' quitting behaviors (Farrell \& Rusbult 1992; Rusbult et al. 1988). In general, exchanges are less likely to occur and will occur less frequently when the actor has alternatives.

Based on the earlier study, there are two ways online communities can have alternatives: online communities compete with each other for members when they offer similar content or share members (Wang et al. 2006). Content-based competitors provide similar content and cover 
similar topics. Individuals with particular interests or needs may choose among the available content competitors. When an online community has many content-based competitors, individuals participating in the community have many alternative places to get the content they are interested in. For example, there are multiple technical support communities on Microsoft products, and many online health support groups on breast cancer. When given many choices, the individuals have greater decision power when making participating decisions, and less reason to stay in one. The number of content-based competitors a community faces, therefore, should reduce the likelihood of an individual continuing to participate.

Hypothesis 4: Individuals in an online community with many content-based competitors are more likely to stop participating in the community.

When a community has members who simultaneously participate in multiple communities, it faces relationship-based competition (Wang et al. 2006). That is to say, relationship-based competitors share members who participate in multiple communities. Individuals seeking to develop friendships and ties with the shared members can stay in any one of the communities to achieve their goals. Individuals can maintain ties with people in other groups, or belong to more than one group at a time (Levine \& Moreland 1998; McPherson 1983; Moreland \& McMinn 2002). If a community has many relationship-based competitors in the environment, its members seeking to build and maintain relationships with others have more options to choose from. Therefore, these members are less inclined to stay in one community. Similar to content-based competitor, the presence of relationship-based competitors in the environment is expected to increase individuals' tendency to leave. 
Hypothesis 5: Individuals in an online community with many relationship-based competitors are more likely to stop participating in the community.

Moreover, the availability of alternatives in the environment may influence the impact of current participation. The social environment within which the individual-community exchanges take place governs and influences an individual's decision to engage, continue, or discontinue engaging a community. Recent work applies social exchange theory to study knowledge sharing and examines the impact of social context on electronic knowledge repository usage. It is found that the contextual factors moderate the effects of extrinsic benefits on intention to share knowledge in electronic knowledge repositories (Kankanhalli et al. 2005). Similarly, the availability of alternatives may influence the importance of expected benefit on individuals' participation decision. When there are many alternative communities to choose from, the individual's expected net benefit from a community is not the only factor that determines the decision to remain in the community. When there are other options, an individual has more power in the relationship with a community, and thus the benefit of remaining in the community is less important than when the individual has no other alternative. Therefore, it is expected that,

Hypothesis 6: An individual's level of current participation at a given time has weaker impact on the ongoing participation decision when the community has many other content-based competitors.

Hypothesis 7: An individual's level of current participation at a given time has weaker impact on the ongoing participation decision when the community has many other relationship-based competitors. 


\subsection{RESEARCH MODEL}

The proposed research model applies social exchange theory to explain individuals' ongoing participation in online communities, treating participation as series of exchanges situated in a larger context. This study focuses on the series of individual participation in a community over time and examines the conditions that affect the decision to stay. Figure 5 presents the research model. An individual's level of current participation is expected to reduce his or her likelihood of leaving an online community. An individual's prior participation with a community and availability of alternatives are expected to directly affect the likelihood of an individual to stop participating in the community, while also moderating the impact of current participation.

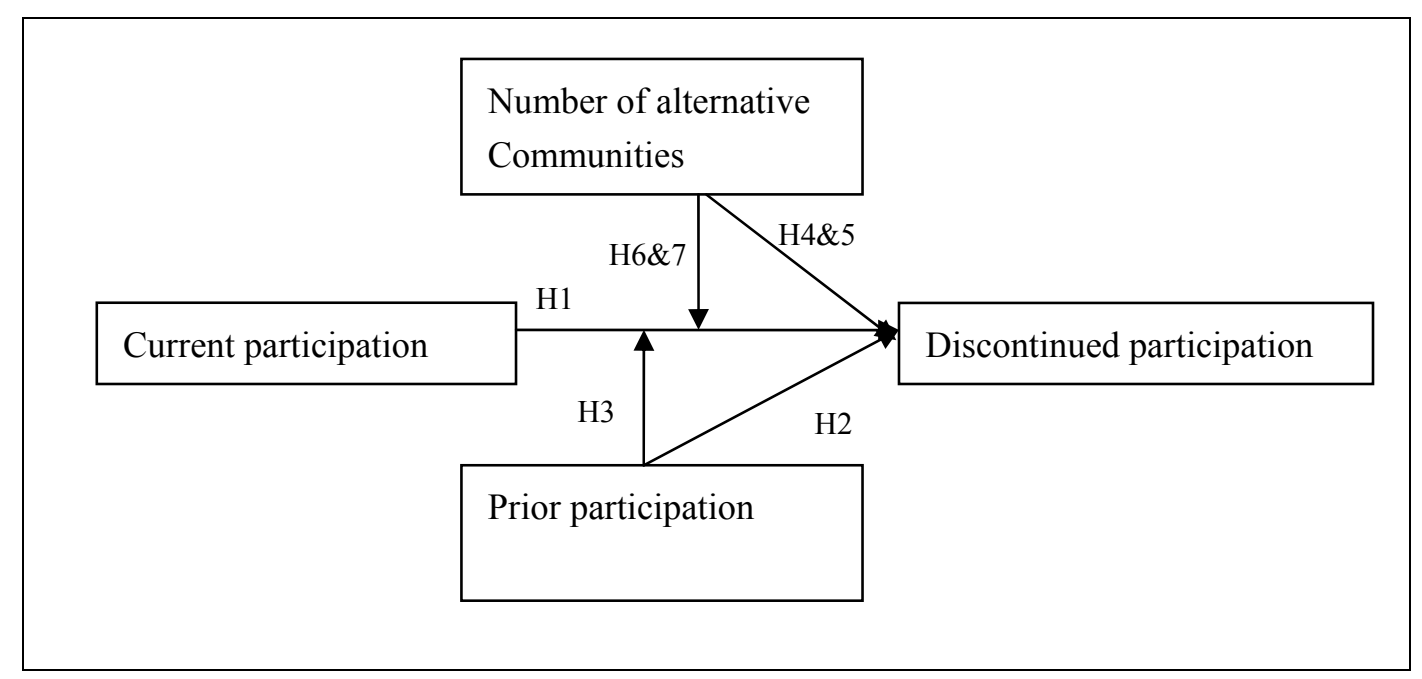

Figure 5. Study 2 Research Model 


\subsection{METHOD}

\subsubsection{Data}

This analysis focuses on individuals' long term relationship with online communities.

Individuals' current participation, prior participation and alternative structure are incorporated when modeling individuals' stay or leave decision in a community. A sample of individuals who posted in one of seven Usenet newsgroups between October 1999 and January 2005 was selected to test the hypotheses. The seven newsgroups were strategically selected so that they included newsgroups with both low and high volume, and newsgroups with different topics and different purposes (Table 8). Data on all the individuals who posted in these seven newsgroups were collected from the Netscan database (Smith 2005). The dataset contains monthly information on the number of messages each individual posted to each newsgroup, time when an individual's first and last messages were posted to a newsgroup, and the individual's participation in other newsgroups during the study time period. Individuals who participated in more than one of the seven newsgroups in the sample can introduce bias because their activities in each newsgroup are not independent of the activities in other newsgroups. Therefore, these individuals were dropped from the sample. As a result, all the remaining individuals in the dataset only participated in one of the seven newsgroups during the study period. They can, however, participate in newsgroups other than the seven in the sample, and thus can still have multiple memberships in the same month. When an individual posts to a newsgroup after a long period of inactivity, it is difficult to assess whether the individual has remained a member the entire time. Based on the frequency of posts in the dataset, individuals 
who were inactive for 9 months or longer before returning were dropped. Moreover, the individuals who left a newsgroup within the first month were dropped from further analysis because their duration in the newsgroup cannot be calculated. The remaining sample consisted of 16,113 unique authors in the 7 Usenet newsgroups over 64 months.

Table 8: Newsgroups in Sample

\begin{tabular}{|l|l|l|}
\hline Newsgroup Name & $\begin{array}{l}\text { Post/month } \\
\text { (median) }\end{array}$ & $\begin{array}{l}\text { Posters/month } \\
\text { (median) }\end{array}$ \\
\hline alt.support.depression & 15027 & 1101 \\
\hline alt.gossip.royalty & 3359 & 215 \\
\hline alt.support.food-allergies & 103 & 50 \\
\hline alt.drugs.pot.cultivation.no-spooks & 56 & 25 \\
\hline comp.lang.c & 11086 & 1845 \\
\hline alt.support.childfree & 8539 & 539 \\
\hline soc.support.depression.misc & 50 & 28 \\
\hline
\end{tabular}

\subsubsection{Measures}

\subsubsection{Dependent variable}

An individual's ongoing participation behavior at each month is measured by a dummy variable Exit, which is 1 if the individual stopped participating in the community in that month, and 0 if the individual continued to participate in any subsequent months. This measure is based on active contribution only. Therefore, a limitation of this dataset is that if an individual continued to read in a newsgroup without actively posting, the individual would be treated as 
having left the community. Examined over time, the Exit dummy indicates how long an individual participates in a newsgroup and reflects the strength of the exchange relationship between the individual and the newsgroup.

Because the dataset ended on January 30,2005 , it is unclear if individuals in the sample returned to post afterwards, i.e., the dataset is right censored. Examination of the data suggests that individuals waited an average of four days between two posts, and $95 \%$ of the authors posted a subsequent message within 94 days. Therefore, the dataset was right-censored for those whose last post is after Oct 18,2004, 94 days before the data end date. That is to say, if an author's last post in a newsgroup appeared after Oct 18, 2004, this individual was treated as having not left the newsgroup before the data end date, because it is possible that their next post occurred after January 30, 2005.

\subsubsection{Independent variables}

Level of current participation is the degree to which an individual's level of participation deviates from the average contribution level in a newsgroup in the prior three months. This measure reflects the individual's current level of behavior, as compared with the other participants in the community. It is calculated as the difference between the number of posts an individual contributes to a newsgroup in the current month and the average number of posts that other individuals contribute to the newsgroup in the past three months, divided by the standard deviation of author participation level in the current month. Because an individual's level of participation in an online community may be affected by the other active 
members' behaviors, the absolute level of activity may not be a true indicator of the author's expected benefit. Therefore, a deviance score from the group average is calculated. A three-month running average is used to indicate the average level of contribution in the recent past to reduce noise due to unusual events. A high value of this measure indicates that the individual expects high benefit from participating in the current month. A low value suggests otherwise.

Prior participation refers to the degree to which an individual has interacted with a newsgroup before a given month, and measures the level and nature of existing investment in the newsgroup. This measure is calculated by summing the total number of posts an individual has contributed to a newsgroup before the current month. When an author attempts to initiate a conversation in a newsgroup, it may or may not receive a response. A message that receives a response is called a start message, while one without a response is called barren. The total numbers of Prior Start and Prior Barren are calculated to examine their separate impacts on individual-newsgroup relationship. The prior participation measures are logged transformed to reduce non-normality.

Number of content-based competitors measures the number of alternative communities that offer similar content as a focal newsgroup. It is calculated as the number of newsgroups that a focal group cross-posts with in a given month. Cross-posting in Usenet refers to the action of posting the same message to multiple newsgroups. Concretely, cross-posted messages are common content shared among the different groups, and directly contribute to content 
similarity. More abstractly, cross-posted messages reflect an author's belief that the topical focuses of the involved groups are similar. Therefore, cross-posting patterns in online communities indicate both the actual and perceived content overlap among them. The number of cross-posting newsgroups, therefore, reflects the number of similar alternatives in the same virtual space. Log transformation is applied to this measure.

Number of relationship-based competitors is calculated as the number of other newsgroups that share participants with the focal newsgroup in a given month. Two newsgroups are treated as sharing a common member when the same author posted at least one message in both of the newsgroups in a given month. The number of relationship-based competitors is constructed by reviewing all members' Usenet activities in a given month, and counting the number of other unique newsgroups the members visit in the same month. Log transformation is applied to this measure to reduce non-normality.

\subsubsection{3 $\underline{\text { Control }}$}

Newsgroup Volume is included in the model to control for size and level of activity in a newsgroup-month. This measure is calculated as the number of messages posted to a newsgroup during each month. Number of messages reflects both the amount of resources available (Butler 2001) and the internal information processing demands (Jones et al 2004) in a newsgroup. Log transformation is applied to this measure to enhance normality. 
Average relationship longevity in a newsgroup represents the overall tendency for members to stay in the community. This control variable serves as an indication of group norm regarding member involvement. The longevity of contribution for each member in a newsgroup (the number of days between the first and last post in the newsgroup) was calculated, and then an average longevity within each newsgroup was calculated to create this measure.

\subsection{ANALYSIS AND RESULT}

The final analysis dataset includes observations for 16,113 unique individuals in seven Usenet newsgroups over 64 months. Each record in the data represents an individual's activity in a given month. Because all individuals in the final sample are active in more than one month, there are multiple records for each individual-newsgroup combination. As a result, the final data has 44,307 observations. Table 9 displays the descriptive statistics for the measures and the correlations among them. In order to control for specific online community characteristics, community size and average longevity of contribution in a newsgroup are included as controls in the analysis. The independent variables were centered before creating interaction terms to reduce multi-collinearity with their associated interaction terms.

Correlations among the independent variables are not high (Table 10). Multi-collinearity analysis shows that all VIF are below 3, well within the generally acceptable levels (Hair et al. 1998). 
Table 9: Descriptives $(\mathrm{N}=44,307)$

\begin{tabular}{|l|r|c|c|c|c|}
\hline Variable & Mean & Median & Std. Dev. & Min & Max \\
\hline 1. Exit & 0.339 & 0 & 0.473 & 0 & 1 \\
\hline 2. Time & 7.390 & 4 & 9.345 & 1 & 63 \\
\hline 3. Current participation & 0.027 & -0.306 & 1.189 & -1.394 & 27.974 \\
\hline 4. Prior participation & 146.035 & 20 & 421.594 & 2 & 8212 \\
\hline 5. Prior starts & 3.717 & 0 & 16.943 & 0 & 528 \\
\hline 6. Prior barrens & 11.859 & 2 & 38.390 & 0 & 868 \\
\hline 7. Content-based competitors & 134.447 & 97 & 230.495 & 0 & 2012 \\
\hline $\begin{array}{l}\text { 8. Relationship-based } \\
\text { competitors }\end{array}$ & 2122.643 & 1981 & 1096.156 & 16 & 8047 \\
\hline
\end{tabular}

Table 10: Correlation among centered \& logged variables $(\mathrm{N}=44,307)$

\begin{tabular}{|l|c|c|c|c|c|c|c|}
\hline Variable & $\mathbf{( 1 )}$ & $\mathbf{( 2 )}$ & $\mathbf{( 3 )}$ & $\mathbf{( 4 )}$ & $\mathbf{( 5 )}$ & $\mathbf{( 6 )}$ & $\mathbf{( 7 )}$ \\
\hline 1. Exit & 1 & & & & & & \\
\hline 2. Time & $-0.258^{*}$ & 1 & & & & & \\
\hline 3. Current participation & $-0.160^{*}$ & 0.007 & 1 & & & & \\
\hline 4. Prior participation & $-0.261^{*}$ & $0.566^{*}$ & $0.437^{*}$ & 1 & & & \\
\hline 5. Prior starts & $-0.215^{*}$ & $0.486^{*}$ & $0.221^{*}$ & $0.643^{*}$ & 1 & & \\
\hline 6. Prior barrens & $-0.230^{*}$ & $0.474^{*}$ & $0.226^{*}$ & $0.668^{*}$ & $0.665^{*}$ & 1 & \\
\hline $\begin{array}{l}\text { 7. Content-based } \\
\text { competitors }\end{array}$ & $0.155^{*}$ & $-0.159^{*}$ & 0.003 & $-0.174^{*}$ & $-0.078^{*}$ & $-0.120^{*}$ & 1 \\
\hline $\begin{array}{l}\text { 8. Relationship-based } \\
\text { competitors }\end{array}$ & $0.217^{*}$ & $-0.207^{*}$ & $-0.031^{*}$ & $-0.283^{*}$ & $-0.127^{*}$ & $-0.273^{*}$ & $0.685^{*}$ \\
\hline
\end{tabular}


Our focus is on the value of the dependent variable, Exit, over time, which indicates an individual's contribution longevity in a newsgroup. Therefore, some individuals have multiple observations in different time periods, and the same individuals' exit decisions across time are interdependent. Traditional OLS regression techniques are not suitable when the dependent variable is not independent among observations. Therefore, survival analysis was applied to test the research model. Survival analysis is often used to study the time between entry to a study and the experience of an event (Singer \& Willett 2003). In survival analysis, the hazard function is defined as the conditional probability that an observation (individual) will experience an event in a particular time period, given that the event has not occurred before. This type of analysis is appropriate here because the dependent variable incorporates time. The model predicts the impact of individuals' current participation level, prior participation, and alternative communities on the risk of leaving a newsgroup in any given month.

The exploratory Kaplan-Meier (K-M) curve estimates the cumulative survival function at the time each event occurs. It is useful for preliminary examination of the data because it produces survival curves that represent the proportion of the study population still surviving at each successive time. The K-M estimates of the survival function (Figure 6) suggest that the median contribution longevity is shorter than 5 months. Most of the newsgroup participants leave the newsgroup early on. Fewer than $10 \%$ of the participants are still actively contributing after 10 months, and fewer than $5 \%$ of them remain after 20 months. As shown from the estimated hazard function on the right hand side of Figure 6, the probability 
of an individual leaving a newsgroup is higher early on. The risk of an individual leaving continues to increase until about month 10 , and then decreases steadily over time. As demonstrated in Figure 6, a Kaplan-Meier survival curve takes into account the effect of time on individuals' tendency to leave a newsgroup.

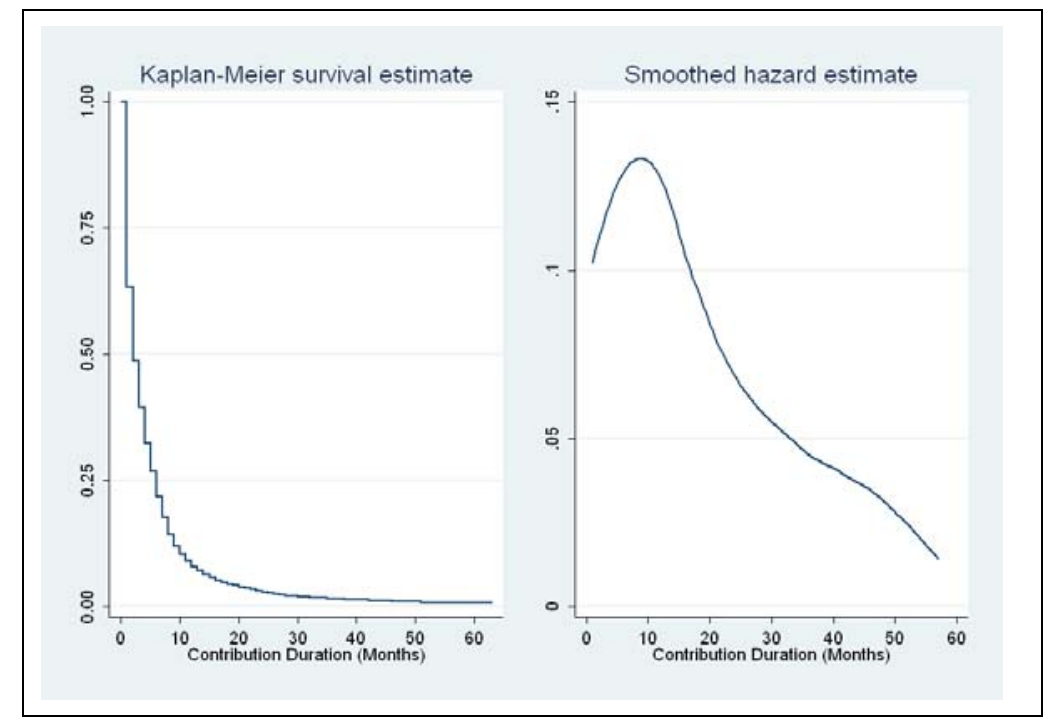

Figure 6: K-M Estimates of Survival and Hazard Functions

Cox regression analysis (or the proportional hazards model) was applied to test the hypotheses. Cox regression allows a comparison of hazard (or survival) functions based on different values of independent variables (Cox 1972, 1984). In other words, Cox regression models the shift of survival curve when the independent variables change. Because the estimation of Cox regression is based on the position of survival curves, time is already taken into account although it is not an explicit independent variable. The hypotheses were tested 
using two models. In Model 1, only the main effects were entered in the regression. Model 2 added the interactions terms. In each model, two separate models were examined with either the overall prior participation as the measure for prior investment or the prior starts and prior barrens as measures for different types of existing investment. Multi-collinearity analysis suggested that the current participation has too high a correlation with its interaction term with relationship-based competitors. Therefore, the interaction term was dropped in Model 2 to eliminate the multi-collinearity problem. Table 11 presents the results of fitting the models. A positive coefficient suggests that an increase of the independent variable increases the likelihood of an individual leaving a newsgroup. A negative coefficient suggests the opposite. The hazard ratio describes the effect of a one-unit difference in the associated predictor on the probability of an individual leaving.

Model 1 examines the main effects. Hypothesis 1 expects that an individual's current level of participation should be negatively associated with his or her tendency to leave a newsgroup. The results support this hypothesis. An individual's level of participation in a given month, as compared with the average level in the same newsgroup in the last three month, reduces the risk of the person leaving the newsgroup $(\beta=-0.205, \mathrm{p}<0.001)$. The hazard ratio of 0.81 indicates that for each percent increase in an individual's level of participation to a newsgroup, the individual's likelihood of leaving in that month drops $19 \%$. Hypothesis 2 expects that individuals with many prior exchanges with a newsgroup will be less likely to leave the newsgroup than those new to the group. The significant and negative coefficient for Prior Participation supports this hypothesis $(\beta=-0.058, \mathrm{p}<0.001)$. The hazard ratio of 0.94 
suggests that for each percent increase in an individual's level of prior participation in a newsgroup, the individual's likelihood of leaving in that month drops $6 \%$. However, in Model 1b, neither Prior Barrens nor Prior Starts is significant and thus the hypotheses H2a, $2 \mathrm{~b}$, and $2 \mathrm{c}$ are not support $(\beta=0.001,0.010$, n.s., respectively).

The number of available alternatives is also a significant factor in an individual's ongoing participation decision. The results suggest that the number of either content- or relationship-based competitors in the environment tends to increase an individual's tendency to leave. Although the coefficient for relationship-based competitors is not significant in Model 1a, it is significant in the predicted direction in all the other three models. Therefore, Hypothesis 4 and 5 are supported. The hazard ratios show that a $1 \%$ increase in the number of content-based or relationship-based alternatives a newsgroup has in a given month is associated with about $8 \%$ increase in the probability of an individual leaving in that month.

Model 2 added the interaction terms. Hypothesis 3 expects that the strength of prior participation reduces the impact of current participation on an individual's decision to leave. As expected, the impact of current participation becomes weaker when the level of prior participation is high $(\beta=0.056, p<0.001)$, confirming hypothesis 3 . Hypotheses $3 \mathrm{a}$ and $3 \mathrm{~b}$ expects that prior barrens and prior starts have differential moderating effect on current participation. The results suggest that while prior starts reduce the impact of current participation $(\beta=0.059, \mathrm{p}<0.001)$, prior barrens do not moderate the effect of current 
participation on individuals' ongoing participation decision $(\beta=-0.019$, n.s. $)$. Therefore, Hypothesis $3 \mathrm{a}$ is supported while $3 \mathrm{~b}$ is not.

Hypothesis 6 and 7 suggest that the availability of competing communities in the environment also moderates how current participation affects the individual-community relationship. It is expected that the number of alternative communities will reduce the impact of current participation. Because the interaction term between current participation and number of relationship-based communities have multi-collinearity issues, hypothesis 7 could not be tested. Hypothesis 6 is not supported by the results. The interaction effect between the number of content competitors and current participation is not significant. 
Table 11: Predicting Individuals' Ongoing Participation in Online Communities

\begin{tabular}{|c|c|c|c|c|c|c|c|c|}
\hline & \multicolumn{2}{|c|}{ Model 1a } & \multicolumn{2}{|c|}{ Model 1b } & \multicolumn{2}{|c|}{ Model 2a } & \multicolumn{2}{|c|}{ Model 2b } \\
\hline & Coef. & $\begin{array}{l}\text { Hazard } \\
\text { Ratio }\end{array}$ & Coef. & $\begin{array}{l}\text { Hazard } \\
\text { Ratio }\end{array}$ & Coef. & $\begin{array}{l}\text { Hazard } \\
\text { Ratio }\end{array}$ & Coef. & $\begin{array}{l}\text { Hazard } \\
\text { Ratio }\end{array}$ \\
\hline $\begin{array}{l}\text { Current } \\
\text { Participation }\end{array}$ & $\begin{array}{l}-0.205^{* * *} \\
(0.019)\end{array}$ & 0.81 & $\begin{array}{l}-0.287 * * * \\
(0.017)\end{array}$ & 0.75 & $\begin{array}{l}-0.405^{* * *} \\
(0.045)\end{array}$ & 0.67 & $\begin{array}{l}-0.282 * * * \\
(0.039)\end{array}$ & 0.75 \\
\hline Prior Participation & $\begin{array}{l}-0.058^{* * * *} \\
(0.009)\end{array}$ & 0.94 & - & - & $\begin{array}{l}-0.030^{* * *} \\
(0.010)\end{array}$ & 0.97 & - & - \\
\hline Prior Barrens & - & - & $\begin{array}{c}0.001 \\
(0.007) \\
\end{array}$ & 1.00 & - & - & $\begin{array}{l}-0.004 \\
(0.007)\end{array}$ & 1.00 \\
\hline Prior Starts & - & - & $\begin{array}{c}0.010 \\
(0.007) \\
\end{array}$ & 1.01 & - & - & $\begin{array}{l}0.018 * * \\
(0.007)\end{array}$ & 1.02 \\
\hline $\begin{array}{l}\text { Content-based } \\
\text { Competitors }\end{array}$ & $\begin{array}{l}0.079 * * * \\
(0.015)\end{array}$ & 1.08 & $\begin{array}{l}0.072 * * * \\
(0.015)\end{array}$ & 1.07 & $\begin{array}{l}0.084 * * * \\
(0.015)\end{array}$ & 1.09 & $\begin{array}{l}0.075^{* *} \\
(0.017) \\
\end{array}$ & 1.08 \\
\hline $\begin{array}{l}\text { Relationship-based } \\
\text { Competitors }\end{array}$ & $\begin{array}{c}0.077 \\
(0.041)\end{array}$ & 1.08 & $\begin{array}{l}0.085^{*} \\
(0.041)\end{array}$ & 1.09 & $\begin{array}{l}0.084^{*} \\
(0.042)\end{array}$ & 1.09 & $\begin{array}{c}0.089 * \\
(0.0417)\end{array}$ & 1.09 \\
\hline $\begin{array}{l}\text { Current } \\
\text { Participation * Prior } \\
\text { Participation }\end{array}$ & - & - & - & - & $\begin{array}{l}0.056^{* * *} \\
(0.009)\end{array}$ & 1.06 & - & - \\
\hline $\begin{array}{l}\text { Current } \\
\text { Participation * Prior } \\
\text { Barrens }\end{array}$ & - & - & - & - & - & - & $\begin{array}{l}-0.019 \\
(0.011)\end{array}$ & 0.98 \\
\hline $\begin{array}{l}\text { Current } \\
\text { Participation * Prior } \\
\text { Starts }\end{array}$ & - & - & - & - & - & - & $\begin{array}{l}0.059^{* * *} \\
(0.010)\end{array}$ & 1.06 \\
\hline $\begin{array}{l}\text { Current } \\
\text { Participation * } \\
\text { Content-based } \\
\text { Competitors } \\
\end{array}$ & - & - & - & - & $\begin{array}{c}0.013 \\
(0.018)\end{array}$ & 1.01 & $\begin{array}{l}-0.005 \\
(0.022)\end{array}$ & 1.00 \\
\hline $\begin{array}{l}\text { Average } \\
\text { Contribution } \\
\text { Longevity }\end{array}$ & $\begin{array}{l}-0.004^{* * *} \\
(0.000)\end{array}$ & 1.00 & $\begin{array}{l}-0.004 * * * \\
(0.000)\end{array}$ & 1.00 & $\begin{array}{l}-0.004^{* * * *} \\
(0.000)\end{array}$ & 1.00 & $\begin{array}{l}-0.004 * * * \\
(0.000)\end{array}$ & 1.00 \\
\hline Newsgroup Size & $\begin{array}{l}-0.037 \\
(0.024)\end{array}$ & 0.96 & $\begin{array}{l}-0.027 \\
(0.024)\end{array}$ & 0.97 & $\begin{array}{l}-0.036 \\
(0.024)\end{array}$ & 0.96 & $\begin{array}{l}-0.021 \\
(0.024)\end{array}$ & 0.98 \\
\hline Log Likelihood & \multicolumn{2}{|l|}{-129267.5} & \multicolumn{2}{|l|}{-129288.8} & \multicolumn{2}{|l|}{-129250.1} & \multicolumn{2}{|l|}{-129266.2} \\
\hline AIC & \multicolumn{2}{|l|}{258546.9} & \multicolumn{2}{|l|}{258591.6} & \multicolumn{2}{|l|}{258516.2} & \multicolumn{2}{|l|}{258552.3} \\
\hline $\mathrm{p}>$ chi2 & \multicolumn{2}{|l|}{0.000} & \multicolumn{2}{|l|}{0.000} & \multicolumn{2}{|l|}{0.000} & \multicolumn{2}{|l|}{0.000} \\
\hline
\end{tabular}

Note: ${ }^{*} \mathrm{p}<0.05 ; * * \mathrm{p}<0.01, * * * \mathrm{p}<0.001$;

Efron method for ties; Standard deviation in parenthesis. 


\subsection{DISCUSSION}

The results of this study demonstrate how an individual's ongoing participation in an online community is influenced by both individual and environmental factors. Individual's current level of participation, as an indicator of expected benefit from participation, is found to matter for the continuance decision, consistent with existing online community research. Prior participation within a community is found to reduce the likelihood of an individual to continue participate. This result seems to be consistent with the argument in social exchange theory that prior investment will incur greater cost of leaving a relationship and thus will increase commitment and reduce turnover (Rusbult \& Farrell 1983; Rusbult et al. 1988). However, the different types of prior exchanges have different impacts, as indicated by the non-significant effect of prior starts and prior barrens. It seems like that the effect of prior participation on individuals' ongoing participation is mainly due to their prior replies to other community messages. Post-hoc analysis adding prior replies as another measure of prior participation in Model $1 \mathrm{~b}$ confirmed this speculation. Individuals who contribute many replies to the community in the past are less likely to leave. Together, these results suggest that not all types of participation in online community increase individuals' level of existing investment. Future studies should examine the nuances in different types of participation behaviors and the underlying mechanisms through which they have different effects.

Examination of the interaction between prior participation and current participation indicates that, when an individual has a strong history of reciprocated exchanges with his or her online 
community, the impact of current participation on continuous relationship is reduced. If an individual has a history of initiating exchanges but are not reciprocated, however, the impact of current participation remains the same. These results reinforce the above discussion that the nature of exchanges in online community can have different impacts on individuals' long term participation. When the exchanges initiated by individuals are reciprocated, individuals can rely partially on the experience in the past when making continuance or exit decisions, and depend less on expectation of immediate benefit. Non-reciprocated prior exchanges, however, do not change the impact of expected benefit at a given time. These results provide some evidence that reciprocated exchanges in the past contribute to individuals' increasing investment in an online community, and individuals rely on past experiences when making decisions to remain in or exit a relationship.

The availability of alternative communities in the environment is found to have significant impact on an individual's ongoing participation decision. Individuals in a community with many content- or relationship-based competitors in the environment are more likely to leave. This is consistent with a competition argument, in that exchange relationships which offer similar benefits allow individuals to choose, and therefore increases their tendency to leave. However, the number of competing communities does not moderate the impact of immediate benefit evaluation. This result suggests that not all contextual factors moderate the impact of individuals' cost and benefit evaluations in exchange decisions. Alternative structure, for one, only has a main effect on individuals' long-term participation decision. 


\subsubsection{Contribution}

This study makes two key contributions to the online community literature. First, it applies social exchange theory to model individuals' ongoing participation decisions in online communities. Second, it combines the social exchange theory and an ecological approach to online communities to model the social environment within which the exchange relationship develops. Applying a social exchange framework may open up new areas of research and new methods of studying existing phenomena. By nature, it calls for a shift from the current focus on single, isolated contributions in an online community to long term, ongoing exchange relationships between the participants and their online communities. This long term perspective will allow online community research to better address the challenge of building sustainable online communities, and to study the dynamics of series of exchanges: how exchange relationship between individuals and their communities is formed, maintained and changed over time (Molm 2001). Moreover, issues like trust and conflict can be better understood as inherent in the ongoing participation process.

The emphasis on social environment also has implications for research. In particular, the prior participation history in a community and the availability of other communities were under-studied in the existing literature. The results of this study confirm the importance of these two factors. There are also other environmental factors that can play significant roles in individuals' continuous participation decisions in online communities. For instance, there has been increasing interest in studying the network structure of electronic network of practices and how structure affects characteristics of exchanges (Johnson \& Faraj 2005; Wasko et al. 
2004). Social exchange theory provides a suitable theoretical foundation to explain how and why network structure governs the ongoing exchange relationships, and how the characteristics of the structure emerge and change (Blau 1965; Emerson 1976). Furthermore, the technical infrastructure for exchanges, the boundary structure between exchange relationships, group norms and identity in the community are all interesting environmental factors that can be examined using a social exchange lens (Hall 2003).

This study suggests that focusing on individuals' series of participation in online communities can be one way to address the challenge of building sustainable online communities. Designers can make salient the environmental factors that are important for individuals' continuance decisions. For example, the comparison of an individual's contribution with other participants can be highlighted, especially when the individual first starts to participate in a community. Features displaying an individual's level of prior participation in a community can be made visible. Also, if a community faces competition with many other communities, the designer can implement mechanisms that downplay the visibility of other linked communities.

\subsubsection{Limitations \& Future Research}

As in all empirical research, this study has its limitations. First of all, caution must be taken when generalizing the results of this study to other contexts. Because this study only examines seven Usenet newsgroups, future research is needed to apply the same analysis to a larger sample and to different types of online communities. Second, this analysis is based on active 
contribution, and reading behaviors are not taken into account. Therefore, the measure of ongoing participation is a narrow one. Future research should incorporate reading behavior as a form of exchange when modeling individual-community relationship (e.g. Bateman, Gray \& Butler 2006). Last but not least, this study examines continuous participation decision as a simple, dichotomous one. The connection among alternative communities implies that an individual's decision to participate in a community may be more complex. An individual's decision can involve not only staying or leaving a particular community, but also whether to participate in other alternative communities. For example, the choice of a participant at a given time can include staying in the focal community, switching to another community, or participating in multiple communities at the same time. Future work can extend this study to consider more complex dependent variables when studying individuals' ongoing participation in online communities.

\subsection{CONCLUSION}

Building sustainable online communities has great potential, but is also difficult.

Community-based products and services like YouTube, Second Life and Epinions.com are attracting interests from both practitioners and researchers. New online communities are built every day, and managers in organizations are looking for new ways to capitalize on the potential of online communities. Much online community research attempts to provide advice to practitioners by studying human behaviors in online communities. Building on existing research, this paper examines series of participation in online communities as social exchanges 
between individuals and their communities. The result of this study demonstrates the importance of building ongoing exchange relationships and considering the social environment of participation. By focusing on the social environment, online community designers can gain more leverage in shaping participants' behaviors in their communities. 


\section{IMPLICATIONS}

\subsection{SUMMARY OFRESULTS}

The majority of the online community research to-date focuses on individual or community variables, paying little attention to the larger context within which a community is embedded, or the environment where an interaction takes place. This dissertation extends existing research by proposing an ecological perspective to online communities, demonstrating the importance of both ecological and historical context on the ongoing interactions between individuals and communities. Ecological context matters because it creates competitive pressure on communities, and historical context matters because it shapes the ways individuals make decisions about ongoing participation within communities. The findings of the two empirical studies contribute to our knowledge of the impact of having similar or related online communities in the environment, and allowing better understanding of individual's ongoing behaviors in these communities. In this chapter, I summarize the findings from the two empirical studies, discuss the implications of these results for IS research, and provide some ideas for future research. 


\subsubsection{Online community competition and member retention}

The first study is aimed at examining the ecological context, in particular, competitive relationships among online communities. It was expected that competition emerges when online communities offer similar content or share members, and that a high level of competition reduces online communities' capability to retain members. The results are consistent with the predictions that content similarity and joint membership are two sources of competition. Specifically, the number of competitors as well as the extent to which they compete reduces the ability of a community to retain members in the short run. Moreover, the impact of ecological competition on a community's viability is dependent on the nature and characteristics of the community. Both types of competition were found to have a stronger effect when the basis for competition matched with the basis of attachment in the community. Content-based competition has a stronger effect when the level of contribution in a community is high. Taken together, results of the two studies provide empirical evidences for the basic premises and key implications of an ecological approach to online communities. They also indicate that incorporating such a perspective provides useful explanatory power above and beyond that provided by the individual and community level factors considered in the existing work.

\subsubsection{Individual participation as contextualized social exchange}

The goal of the second study is to build on the first study and examine both ecological and historical factors that contribute to an individual's decision to continue participate in an online 
community. Based on the social exchange theory, individuals' prior engagement in their online communities was expected to be a significant factor in determining their continuance decisions, as well as the available alternatives in the ecological environment. Consistent with the expectations, the analyses showed that an individual's expectation of current benefit, prior investment in a community, and availability of alternatives all contributed to the continuance decision over time. The results of the second study further demonstrate that the prior investment has both direct and interacting effects on individuals' ongoing exchange relationships with online communities.

\subsubsection{Comparing the two empirical studies}

Conceptually, both empirical studies are concerned with the same dependent variable: member retention. The first study empirically examines a community's ability to retain participants in the short run, while the second one studies factors affecting individuals' decisions to continue active participation. Nevertheless, both studies examine the same concept of online community sustainability: member retention. This focus is different from the majority of existing online community research that emphasizes single contribution events. Both studies also examine the impact of contextual factors on member retention. The presence of other similar and related communities is proposed as being as important as, if not more important than, individual or community characteristics. This ecological approach contributes to the existing online community research by providing a broader view of the phenomenon and better ability to explain individual behaviors and community viability in context. 
The two studies are also distinct in several ways. First of all, they focus on different aspects of member retention. The first study focuses on any community's month-to-month turnover rate, with the assumption that a monthly turnover rate is one indication of community viability. As a result, this study is conducted at the community level. The second study examines an individual's ongoing participation with a community over time, treating participation events as social exchanges between individuals and communities. Therefore, the second study is at the individual level, and allows closer examinations of individuals' continuance decisions. Because of the different research focuses, the two studies place different weights on the roles of context and time. In the first study, ecological context is the central construct being conceptualized and examined. The goal is to understand the impact of ecological competition on online communities' short-term member retention capability, controlling for time and other community characteristics. The second study, however, has a focus on long-term relationship. Therefore, context is one factor that can influence individuals' decision, and equal emphasis is given to the individual benefit expectation, existing investment, and ecological context. Time is explicitly modeled in this study: the impact of independent variables was examined over time. 


\subsection{IMPLICATIONS}

\subsubsection{Practical implications}

Online communities are still a rapidly developing phenomenon. New applications of online communities to business context are seen every day. Businesses like Cisco are using Second Life as a tool for communicating with employees, customers, and business partners (Wagner 2007). New ventures such as Threadless.com have enjoyed a billion-dollar revenue stream derived from building businesses based on communities of customers who design and refine their own designs (Ogawa \& Piller 2006). Social networking sites not only provide products and services that help family and friends keep in touch (e.g. Facebook. Blogger and MySpace), but also provide opportunities for people to find jobs (e.g. LinkedIn) and relationships (e.g. Google's Orkurt). There is high interest in the potential of online community as a platform for innovation, new business opportunities, and as a source of business value for existing firms. Firms interested in investing in online communities, however, need to be able to evaluate the opportunities and risks associated with building, maintaining, and implementing online communities. If not managed well, online communities can become inactive and a waste of resources (Butler 2001), or be misused for purposes different from the owner's original intention. For instance, customers who have negative experiences with a company can vent on its online support forums. Even when successfully implemented, online communities can have unanticipated and sometimes negative implications on organizational functions, for instance, reduced managerial control (McAfee 2006). Therefore, companies need to know when and where online communities are likely to work well, and understand the challenges of 
maintaining sustainable communities.

Online community research can play a major role in business research in the future. In particular, Information Systems research, with its emphasis on the management of new information technology in a business context, is well positioned to study online communities. This dissertation is part of an effort by IS researchers to explain the patterns and behaviors in online communities, explore the similarity and distinctions between the online and offline interactions, and contribute to the IS field by developing new theories about online communities. Findings in this dissertation suggest that, in addition to individual and community characteristics, context is an important factor to consider when making decisions about online communities. Online community designers need to have a good understanding of their communities' ecological environments as well as the social psychological basis for the communities. Some businesses aim to enhance customer experiences in online communities and improve customer retention. For them, it is important to pay special attention to reducing the impact of ecological competition in the environment. Also, this work suggests that community owners should focus more on the type of competition that matches the nature of their communities. For instance, technical support forums that involve mostly question-and-answer interactions should care more about presence of other communities that offer similar content or services. Social networking communities that aim to build long-term connections, on the other hand, should be more alert if the same relationship can be maintained in other communities. No matter the focus, if a community is providing content or building relationships, community owners should be aware that their members' participation activities 

communities can both be effective way to make individuals stay. In sum, this dissertation highlights the significance of context to online community managers, developers, and leaders: both ecological and historical context play important roles in affecting the pattern of member participation in online communities, and thus they should not be ignored when community design decisions are made.

\subsubsection{Research implications}

This dissertation, by focusing on the roles of ecological and historical contexts, suggests some new areas for online community research. Existing research on motivations for online community participation can be extended by taking into account the influence of other communities in the same environments. For instance, when studying individual contribution to corporate knowledge exchange networks, low levels of contribution may be due to the presence of other channels through which individuals can get the information, advice, and contacts they seek. This suggests that alternative knowledge exchange channels (both online and offline) ought to be examined, including personal advice networks within and outside an organization, professional support, online databases, other online discussion forums outside the organization, and other resources like books. Individuals with many alternative knowledge resources may be less likely to participate than those with fewer alternatives. If the prior investment is also taken into account, people with an established history of involvement in one knowledge network may be less inclined to use a new channel than those who have little 
existing involvement.

Research on community sustainability at a more macro level can also benefit from incorporating an ecological approach. With a focus on ecological environment, research may start to consider the structure within one community as well as the community's structural position within a network of communities. For example, ecology theory suggests that the number of organizations in an environment will reduce survival rate only after the market is mature (i.e., there are too many organizations in the same market). Therefore, if a community is in a relatively new market niche, increasing the number of similar communities may have a positive impact on its viability because other communities enhance the legitimacy of the type of community model (Carroll \& Hannan 2000; Hannan 1986).

Moreover, inter-community links other than content and member similarity may have different impacts on community survival. Prior research has found that external affiliations can have positive impacts on group and organization performance. Ancona's work on boundary spanning activities found that team performance is positively associated with external activities (Ancona 1990; Ancona \& Caldwell 1992). Integration and formal affiliation with other organizations were found to increase member satisfaction as well as the structural stability and performance of the organization (Baum \& Oliver 1996; Curtis \& Louis A. Zurcher 1973). Therefore, online communities may be able to build strategic alliances with others to increase their chances of survival, such as including hyperlinks on community websites, offering joint services with other communities, and referring participants to complementary communities, 
especially when the community models are new.

Studies on offline external affiliations focused on the affiliations formed intentionally at the group or organizational level, and found beneficial effects of such alliances. The result of this dissertation, on the other hand, suggests that non-intentional affiliations from shared membership have negative influence on community member dynamics. This may be due to the different nature of online competition from offline ones. Offline competition from a traditional economic or marketing perspective is strategic and intentional. Companies compete for customers using different marketing strategies, adjusting their internal rules, policies and structures. On the other hand, online competition as proposed in this paper is not explicit. Online communities try to distinguish themselves or 'compete' through exploring innovative ways to use technology to connect people. Online competition is an emergent and organic phenomenon, shaped by the participants and the content contributed in different communities. Competition can exist and have an impact even without community builders and managers being aware of it or intentionally making decisions about it. More research can examine the type of connections among online communities, the strength of the connections, and the relationships among these connections to better understand the implications of community context for community development strategies.

Taken together, the results and arguments of this dissertation call into question the single user, single system model which is used in most IS research, and raise important questions about the role of ecological context in other IS phenomena. IS researchers have contributed much to 
understanding the diffusion of IT-related or IT-enabled innovations (Fichman 2000; Fichman 2004). Online communities, as IT-enabled phenomena, themselves warrant examination on the drivers and pattern of their adoption, diffusion, and discontinuance among potential participants. The IS diffusion researchers can examine whether and how traditional information systems and online communities differ in terms of their patterns of diffusion, ways of achieving critical mass (Fulk et al. 1996b), and the impact of competition in different diffusion stages.

An emerging line of research investigates the use of online communities to engage users in various business activities, including innovation, new product development, produce enhancement and product testing (von Hippel 2005). This line of research offers exciting insights on how to capitalize on user participation throughout the complete life cycle of product development and evaluation. Much of this research is exploratory in nature, attempting to observe user behaviors in online communities and propose theories to explain behavioral patterns. This body of research can be augmented by considering users' engagement in online user communities in terms of series of exchanges with the communities. This raises the possibility that successful exchange relationships with online communities may result in increased loyalty to the businesses supporting the communities, or the products the communities are about. Therefore, online communities can not only be new ways to market and support products, but also new mechanisms for building customer relationships. This focus on relationship building implies that the development of trust and norms can be important in customer-oriented online communities. Moreover, an ecological approach suggests that when 
companies choose to be involved in such user communities, they are more likely to succeed if they choose the ones less sensitive to competition in the environment. Investing efforts in relatively unique online communities in terms of topical focus and membership niche may have better outcomes because of the resulting stable participant base. Future research can examine how to maintain trusting environments and develop norms in online communities, as well as the effectiveness of organizational efforts to engage in different online user communities.

Information systems development research can also examine online communities as a mechanism for engaging users in traditional system development processes. Many companies already create online forums where users can discuss the new technologies, ask questions, share experiences, and help one another (e.g. Microsoft MVP program). Open Source Software development even involves distributed users in development of new systems and reporting bugs (Mockus et al. 2002; Moon \& Sproull 2000). Research on in-house development projects or complex, large-scale and distributed system projects can also look into the possibilities of using online communities to involve users, while paying special attention to the impact of ecological environment on the viability of these communities. For example, the presence of other daily tasks and required participation in other organizational projects can reduce users' involvement in system development communities, especially if there are alternative communication channels that serve a similar purpose as the system development communities. Also, long-term, ongoing participation should be recognized and rewarded in online communities to make such online communities sustainable. Future research into 
community-based software development methodologies might also examine how to facilitate the development of individual-community relationships in these intra-organizational online communities, and investigate the impact of such relationships on users' commitment to projects, systems, and to the organizations themselves.

\subsection{CONCLUSIONS}

There are many other ways IS research can incorporate online communities, either as new tools or as new phenomena to which existing theories may apply. At the same time, online communities present a challenge for IS researchers. While online communities are perfect examples of the social-technical phenomena that IS researchers are best suited to study and explain, their divergence from familiar structures of use, system, and activity challenges us to re-examine existing theories and models, and propose new ones. This dissertation contributes to moving the IS research on online communities forward by proposing a new theory on online community ecology, which highlights the importance of both ecological context and long-term participation. While the results of the two empirical studies provide a basis for the new theory, more future work taking this ecological approach is needed to better understand the drivers for sustainable online communities and the value of online communities to different business contexts. 


\section{APPENDIX A: LIST OF 241 NEWSGROUPS AND THEIR BOND-BASIS SCORES}

Table 12: List of 241 Newsgroups and their bond-basis scores

\begin{tabular}{|c|c|c|}
\hline Newsgroup ID & NewsgroupName & Bond-Basis \\
\hline 32 & rec.photo.equipment.misc & 1.50 \\
\hline 127 & rec.games.video.sega & 3.00 \\
\hline 135 & comp.lang.java.help & 2.00 \\
\hline 182 & sci.stat.math & 1.83 \\
\hline 585 & rec.pets.birds & 5.00 \\
\hline 690 & comp.unix.internals & 1.50 \\
\hline 816 & alt.support.depression & 6.80 \\
\hline 908 & rec.arts.comics.dc.lsh & 2.50 \\
\hline 984 & rec.arts.sf.written.robert-jordan & 4.00 \\
\hline 1026 & alt.comp.dcom.modems & 1.50 \\
\hline 1074 & soc.culture.intercultural & 3.00 \\
\hline 1271 & alt.manufacturing.misc & 2.20 \\
\hline 1631 & comp.lang.java.api & 2.00 \\
\hline 1635 & alt.fiftyplus & 5.83 \\
\hline 1977 & alt.games.half-life.tfclassic & 3.00 \\
\hline 2016 & rec.food.veg.cooking & 3.00 \\
\hline 2022 & rec.sport.jetski & 5.50 \\
\hline 2341 & comp.windows.x.kde & 2.00 \\
\hline 2351 & comp.sys.amiga.networking & 2.00 \\
\hline 2390 & sci.lang.japan & 4.00 \\
\hline 2611 & alt.tv.mad-about-you & 3.20 \\
\hline 2771 & rec.arts.movies.people & 3.50 \\
\hline 2793 & rec.crafts.knots & 4.50 \\
\hline 3607 & alt.rec.bicycles.recumbent & 4.00 \\
\hline 3668 & talk.bizarre & 3.67 \\
\hline 3825 & comp.os.ms-windows.nt.admin.security & 1.50 \\
\hline 3890 & alt.support.epilepsy & 6.60 \\
\hline 3925 & talk.politics & 1.50 \\
\hline 4173 & rec.aquaria.misc & 2.00 \\
\hline 4579 & alt.cats.world.domination & 6.00 \\
\hline
\end{tabular}




\begin{tabular}{|c|c|c|}
\hline 4736 & rec.autos.sport.indy & 3.50 \\
\hline 5328 & alt.support.depression.medication & 6.60 \\
\hline 5580 & alt.consciousness & 2.50 \\
\hline 5739 & sci.op-research & 2.00 \\
\hline 5742 & rec.sport.pro-wrestling.fantasy & 2.00 \\
\hline 5833 & rec.arts.theatre.stagecraft & 2.50 \\
\hline 5876 & alt.gossip.royalty & 2.67 \\
\hline 6059 & alt.horology & 3.67 \\
\hline 6136 & comp.infosystems.www.servers.misc & 1.50 \\
\hline 6276 & rec.food.historic & 2.50 \\
\hline 6439 & alt.support.food-allergies & 6.33 \\
\hline 6560 & alt.politics.usa.constitution.gun-rights & 2.50 \\
\hline 6581 & sci.life-extension & 3.00 \\
\hline 6870 & rec.music.artists.bruce-hornsby & 3.00 \\
\hline 7154 & alt.assassination.jfk.uncensored & 3.50 \\
\hline 7159 & rec.scuba.equipment & 1.50 \\
\hline 7187 & alt.recovery.fundamentalism & 4.80 \\
\hline 7265 & comp.lang.c & 1.33 \\
\hline 7367 & alt.fan.keanu-reeves & 3.67 \\
\hline 7383 & alt.comp.periphs.soundcard.sblive & 1.83 \\
\hline 7732 & rec.music.classical.contemporary & 5.00 \\
\hline 7915 & comp.dcom.sdh-sonet & 2.50 \\
\hline 7985 & rec.birds & 4.00 \\
\hline 8055 & alt.fan.inspector-morse & 4.67 \\
\hline 8232 & rec.travel.latin-america & 2.00 \\
\hline 8420 & alt.snail-mail & 2.83 \\
\hline 8866 & rec.arts.tv.uk.emmerdale & 2.00 \\
\hline 8921 & rec.food.drink.beer & 3.50 \\
\hline 8973 & rec.games.diplomacy & 3.00 \\
\hline 8979 & alt.support.parents.with-custody & 6.25 \\
\hline 9030 & rec.arts.books & 2.50 \\
\hline 9038 & comp.sys.sun.apps & 2.00 \\
\hline 9068 & rec.toys.action-figures.discuss & 3.00 \\
\hline 9149 & rec.music.bluenote.blues & 1.00 \\
\hline 9238 & alt.support.childfree & 6.20 \\
\hline 9386 & alt.support.diabetes & 6.60 \\
\hline 9390 & rec.music.folk & 5.00 \\
\hline 9577 & sci.med.cannabis & 3.50 \\
\hline 9716 & rec.sport.swimming & 4.50 \\
\hline 9881 & alt.support.dissociation & 6.83 \\
\hline 10020 & alt.support.kidney-failure & 6.67 \\
\hline 10085 & sci.geo.mineralogy & 3.50 \\
\hline
\end{tabular}




\begin{tabular}{|c|c|c|}
\hline 10676 & rec.knives & 4.50 \\
\hline 10753 & alt.music.jimi.hendrix & 3.17 \\
\hline 10796 & comp.os.geos.programmer & 4.00 \\
\hline 11177 & alt.sci.planetary & 3.50 \\
\hline 11185 & rec.music.industrial & 3.50 \\
\hline 11350 & comp.os.ms-windows.nt & 2.00 \\
\hline 11565 & alt.crazy.people & 4.67 \\
\hline 11861 & rec.aviation.marketplace & 1.50 \\
\hline 11966 & comp.ai.philosophy & 3.50 \\
\hline 11975 & rec.aviation.piloting & 3.50 \\
\hline 12077 & alt.computer.consultants & 2.83 \\
\hline 12110 & rec.games.mahjong & 6.00 \\
\hline 12128 & alt.politics.radical-left & 4.00 \\
\hline 12139 & comp.databases.oracle.tools & 2.00 \\
\hline 12531 & rec.skiing.backcountry & 4.50 \\
\hline 12819 & rec.outdoors.national-parks & 3.50 \\
\hline 12871 & rec.music.makers.synth & 4.50 \\
\hline 12933 & soc.culture.india & 3.00 \\
\hline 13003 & alt.sports.football.pro.miami-dolphins & 2.83 \\
\hline 13062 & alt.politics.economics & 3.50 \\
\hline 13350 & rec.arts.drwho & 4.50 \\
\hline 13379 & rec.autos & 2.50 \\
\hline 13507 & alt.games.nintendo.pokemon.hentai & 3.50 \\
\hline 13564 & alt.tv.friends & 2.00 \\
\hline 13908 & rec.heraldry & 3.00 \\
\hline 14152 & alt.politics.org.cia & 2.50 \\
\hline 14258 & alt.pets.ferrets & 5.60 \\
\hline 14286 & rec.models.rc.land & 4.00 \\
\hline 14323 & rec.autos.sport.nascar.moderated & 4.00 \\
\hline 14330 & rec.sport.football.canadian & 3.50 \\
\hline 14354 & alt.support.social-phobia & 6.50 \\
\hline 14452 & rec.food.chocolate & 2.00 \\
\hline 14600 & alt.support.tourette & 6.60 \\
\hline 14618 & alt.support.inter-cystitis & 6.00 \\
\hline 15284 & alt.politics.nationalism & 2.50 \\
\hline 15392 & alt.music.lyrics & 3.40 \\
\hline 15405 & rec.video.satellite.europe & 3.00 \\
\hline 15448 & alt.psychology.synchronicity & 3.50 \\
\hline 15592 & rec.arts.anime.models & 4.50 \\
\hline 15667 & alt.drugs.pot.cultivation.no-spooks & 2.33 \\
\hline 15704 & comp.protocols.ppp & 2.00 \\
\hline 15888 & alt.rec.hovercraft & 4.50 \\
\hline
\end{tabular}




\begin{tabular}{|c|c|c|}
\hline 16029 & rec.photo.technique.nature & 3.00 \\
\hline 16620 & comp.os.ms-windows.programmer.tools.winsock & 2.50 \\
\hline 16732 & alt.petz & 3.00 \\
\hline 16781 & rec.music.opera & 5.00 \\
\hline 16935 & misc.immigration.canada & 1.83 \\
\hline 17393 & alt.politics.democrats.clinton & 1.50 \\
\hline 17419 & alt.abuse.recovery & 6.33 \\
\hline 17482 & soc.support.depression.misc & 6.40 \\
\hline 17679 & alt.support.asthma & 5.00 \\
\hline 18193 & rec.scouting.issues & 3.00 \\
\hline 18196 & rec.windsurfing & 4.00 \\
\hline 18573 & rec.photo.misc & 2.00 \\
\hline 18720 & rec.radio.amateur.misc & 1.50 \\
\hline 18843 & rec.games.chess.computer & 3.00 \\
\hline 18853 & comp.lang.basic.misc & 1.67 \\
\hline 19006 & alt.recovery & 6.80 \\
\hline 19008 & alt.support.shyness & 6.50 \\
\hline 19133 & rec.drugs.chemistry & 2.00 \\
\hline 19321 & rec.games.miniatures.historical & 3.50 \\
\hline 19506 & alt.nerd.obsessive & 4.33 \\
\hline 19512 & alt.sci.sociology & 4.20 \\
\hline 19685 & alt.music.kraftwerk & 2.17 \\
\hline 19791 & rec.pyrotechnics & 3.50 \\
\hline 19831 & comp.protocols.snmp & 1.67 \\
\hline 20097 & alt.music.bosstones & 3.67 \\
\hline 20335 & rec.aquaria.freshwater & 2.50 \\
\hline 20396 & rec.pets.dogs.breeds & 2.50 \\
\hline 21129 & comp.os.ms-windows & 1.67 \\
\hline 21189 & rec.outdoors.fishing.fly.tying & 5.00 \\
\hline 21251 & comp.text.frame & 2.00 \\
\hline 21644 & alt.psychology.nlp & 4.17 \\
\hline 21657 & rec.boats.racing & 2.50 \\
\hline 21773 & alt.agnosticism & 1.50 \\
\hline 21881 & comp.unix.programmer & 2.83 \\
\hline 22150 & rec.arts.manga & 2.50 \\
\hline 22330 & alt.tv.due-south & 3.00 \\
\hline 22413 & sci.electronics.design & 1.00 \\
\hline 22463 & alt.sys.pdp8 & 2.50 \\
\hline 22552 & rec.music.dylan & 3.00 \\
\hline 22555 & comp.sys.m68k & 1.50 \\
\hline 22609 & alt.mcdonalds & 2.00 \\
\hline 23065 & comp.sys.mac.apps & 2.00 \\
\hline
\end{tabular}




\begin{tabular}{|c|c|c|}
\hline 23467 & rec.sport.snowmobiles & 4.00 \\
\hline 23483 & alt.support.marriage & 6.60 \\
\hline 23563 & sci.physics.computational.fluid-dynamics & 2.00 \\
\hline 23823 & alt.games.final-fantasy.tech-support & 2.00 \\
\hline 23856 & alt.support.impotence & 6.40 \\
\hline 23869 & alt.support.cerebral-palsy & 6.60 \\
\hline 23936 & rec.models.rc.water & 2.00 \\
\hline 24193 & comp.infosystems.www.authoring.site-design & 3.33 \\
\hline 24303 & sci.med.vision & 2.67 \\
\hline 24384 & alt.atheism & 1.50 \\
\hline 24437 & alt.politics.correct & 2.00 \\
\hline 24534 & sci.physics.research & 2.50 \\
\hline 24559 & alt.islam & 2.00 \\
\hline 24697 & comp.software.config-mgmt & 1.67 \\
\hline 24848 & alt.support.rape-survivors & 5.75 \\
\hline 25137 & sci.lang & 3.00 \\
\hline 25185 & rec.music.gdead & 5.83 \\
\hline 25205 & rec.games.roguelike.misc & 2.50 \\
\hline 25497 & alt.politics.usa.misc & 1.50 \\
\hline 25569 & rec.crafts.rubberstamps & 4.50 \\
\hline 25780 & microsoft.public.word.mailmerge.fields & 2.50 \\
\hline 25819 & alt.support.angioplasty & 5.80 \\
\hline 25921 & rec.autos.simulators & 2.50 \\
\hline 26026 & sci.math.num-analysis & 2.00 \\
\hline 26211 & rec.arts.disney.animation & 2.00 \\
\hline 26772 & rec.crafts.textiles.quilting & 5.50 \\
\hline 26831 & rec.motorcycles.tech & 3.00 \\
\hline 26996 & rec.autos.makers.ford.explorer & 1.50 \\
\hline 27135 & alt.comp.hardware.homedesigned & 2.00 \\
\hline 27206 & comp.mail.eudora.mac & 2.50 \\
\hline 27440 & alt.support.mult-sclerosis & 6.75 \\
\hline 27447 & microsoft.public.internet.mail & 2.00 \\
\hline 27466 & rec.bicycles.tech & 1.50 \\
\hline 27474 & soc.singles.moderated & 5.67 \\
\hline 27479 & sci.engr.civil & 2.50 \\
\hline 27563 & soc.support.pregnancy.loss & 6.80 \\
\hline 27651 & alt.support.hepatitis-c & 6.60 \\
\hline 28225 & alt.support.cancer.breast & 6.60 \\
\hline 28340 & rec.games.trading-cards.magic.rules & 2.00 \\
\hline 28486 & alt.rap & 3.67 \\
\hline 28682 & sci.engr.heat-vent-ac & 2.00 \\
\hline 28751 & rec.music.makers.french-horn & 3.00 \\
\hline
\end{tabular}




\begin{tabular}{|c|c|c|}
\hline 28792 & alt.activism.children & 3.50 \\
\hline 29299 & alt.sports.baseball.sea-mariners & 2.83 \\
\hline 29466 & sci.space.tech & 1.50 \\
\hline 29681 & rec.sport.curling & 4.83 \\
\hline 29716 & alt.music.jeff-buckley & 2.50 \\
\hline 29757 & alt.politics.org.nsa & 1.00 \\
\hline 29787 & alt.transgendered & 5.25 \\
\hline 29812 & alt.tv.robotech & 3.00 \\
\hline 29829 & alt.html.webedit & 1.33 \\
\hline 30377 & alt.fan.dennis-miller & 2.67 \\
\hline 30518 & sci.engr.surveying & 1.50 \\
\hline 30585 & rec.sport.unicycling & 5.00 \\
\hline 30606 & rec.audio.tech & 2.50 \\
\hline 30680 & sci.chem.electrochem.battery & 3.00 \\
\hline 30774 & alt.politics.white-power & 4.40 \\
\hline 30960 & rec.music.afro-latin & 6.00 \\
\hline 31006 & alt.sports.basketball.nba.boston-celtics & 3.33 \\
\hline 31217 & alt.support.pco & 6.25 \\
\hline 31227 & alt.comp.periphs.mainboard.elitegroup & 1.83 \\
\hline 31427 & rec.aquaria.freshwater.plants & 3.00 \\
\hline 31486 & comp.dcom.sys.cisco & 1.50 \\
\hline 31538 & rec.aviation.homebuilt & 3.50 \\
\hline 31551 & rec.nude & 3.50 \\
\hline 31970 & microsoft.public.platformsdk.security & 1.50 \\
\hline 36030 & rec.arts.comics.reviews & 1.00 \\
\hline 40048 & alt.support.sex-workers & 5.00 \\
\hline 55884 & alt.bestjobsusa.manufacturing.jobs & 1.83 \\
\hline 91200 & microsoft.public.xml.msxml-webrelease & 1.50 \\
\hline 102307 & microsoft.public.webdesign.html & 2.00 \\
\hline 115788 & alt.video.ptv.replaytv & 1.50 \\
\hline 121242 & comp.arch.embedded.piclist & 1.00 \\
\hline 129525 & alt.tv.powerpuff-girls & 2.40 \\
\hline 135348 & microsoft.public.commerceserver.campaigns_csf & 2.00 \\
\hline 137754 & alt.cellular.bluetooth & 1.50 \\
\hline 138549 & alt.misc.friends & 6.00 \\
\hline 141739 & microsoft.public.sqlserver.dts & 2.00 \\
\hline 144164 & alt.tv.andromeda & 2.50 \\
\hline 145759 & microsoft.public.security & 3.00 \\
\hline 145912 & microsoft.public.exchange2000.clients & 3.00 \\
\hline 174855 & microsoft.public.win32.programmer.directx.video & 2.00 \\
\hline 176240 & alt.2600.hackers.programming & 1.00 \\
\hline 235329 & microsoft.public.smartphone.developer & 1.50 \\
\hline
\end{tabular}




\section{APPENDIX B: REMOVED OUTLIERS}

Table 13: List of removed outliers

\begin{tabular}{|l|l|l|l|l|l|l|}
\hline NewsgroupID & NewsgroupName & Month & Post & Posters & Returnees & $\begin{array}{l}\text { Average } \\
\text { Message } \\
\text { Length }\end{array}$ \\
\hline 17419 & alt.abuse.recovery & Nov-03 & 4545 & 562 & 127 & 11671 \\
\hline 30774 & alt.politics.white-power & Oct-01 & 3355 & 529 & 134 & 167719 \\
\hline
\end{tabular}




\section{APPENDIX C: DISTRIBUTIONS OF VARIABLES}
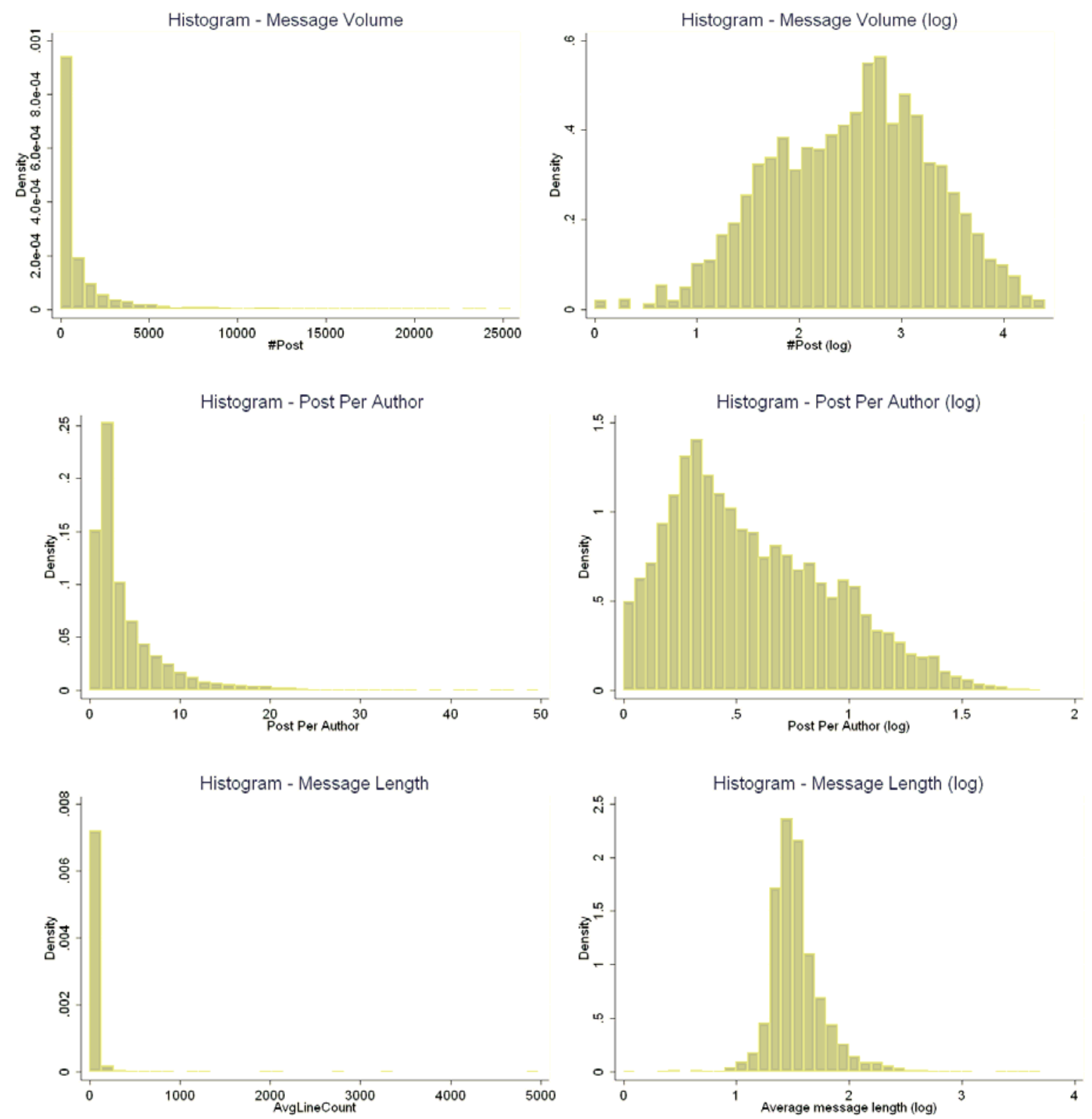

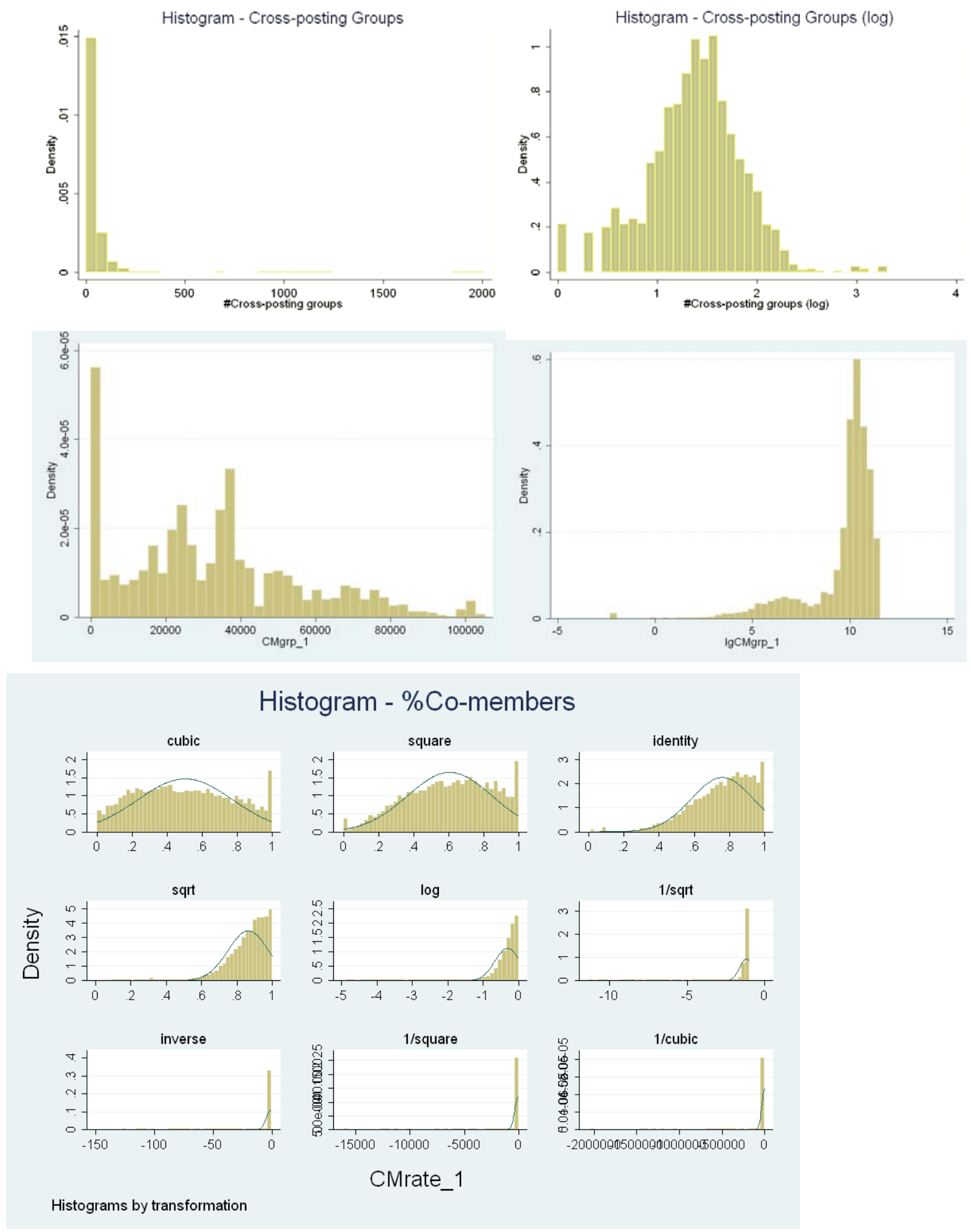


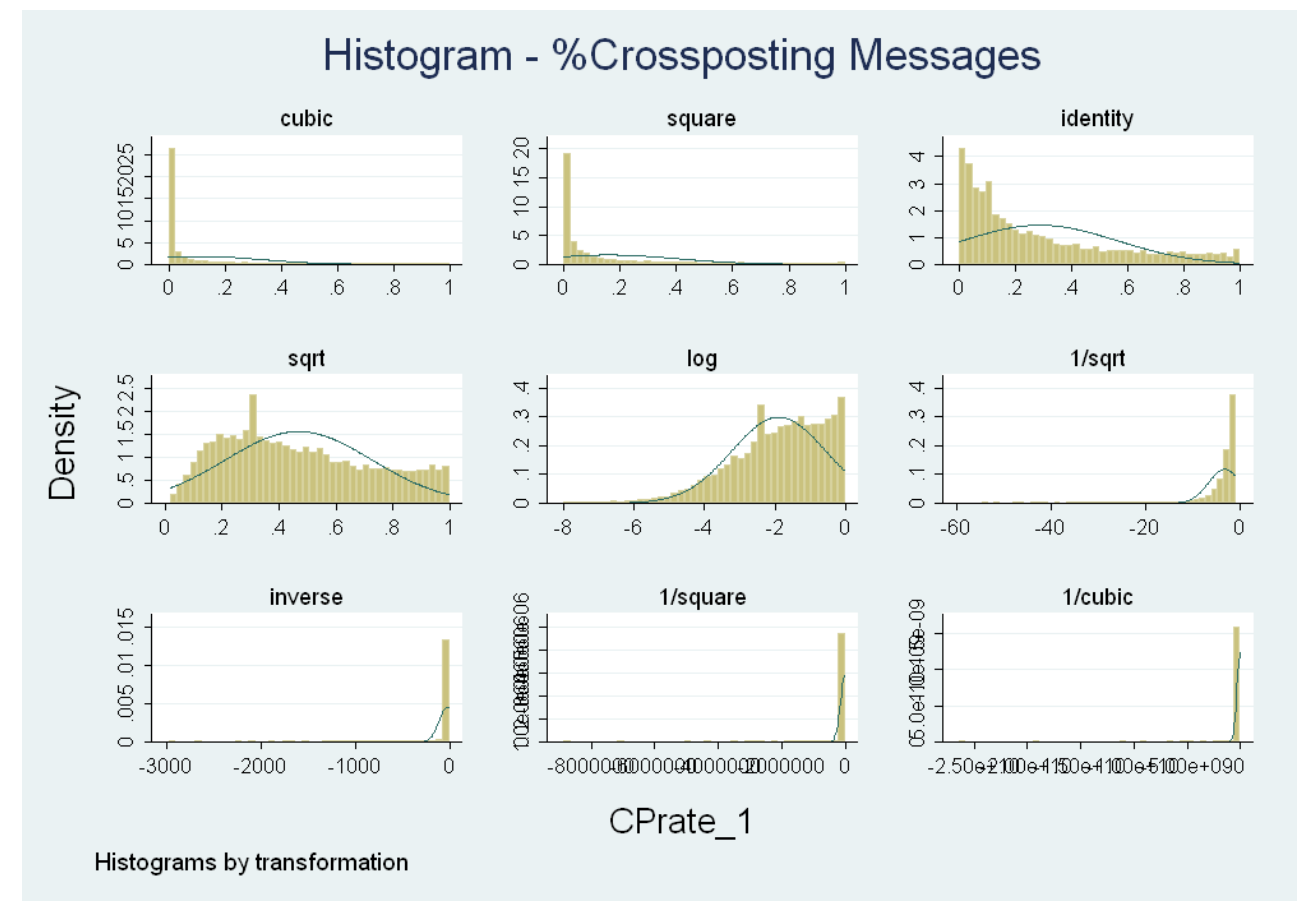

Figure 7: Distribution of variables and the effects of log transformation 


\section{APPENDIX D: BOND-BASIS RATING INSTRUCTION}

\section{How to access the messages through Google Groups:}

1) Go to groups.google.com.

2) Enter the group name into the "Find a group" search field. This should take you to the group's archive page, showing the most recent messages. You can get the group names from the excel file attached.

3) Click on the 'about group' link right underneath the group name at the top of the page. That will take you to the statistics page, showing the message volume every month since 1992. Click on each month's statistics (each number is a link) to see the actual messages within that month.

4) Randomly read messages of the group from Oct 1999 - Feb 2005

\section{Rate the bond and identity levels on a 1-7 point Likert scale:}

\begin{tabular}{|l|l|}
\hline Bond & Identity \\
\hline 1: not a bond group & $1:$ not a identity group \\
\hline 2: most likely not a bond group & $2:$ most likely not a identity group \\
\hline 3: slight evidence of a bond group & 3: slight evidence of a identity group \\
\hline 4: some evidence of a bond group & 4 some evidence of a identity group \\
\hline 5: probably a bond group & 5: probably a identity group \\
\hline 6: most likely a bond group & $6:$ most likely a identity group \\
\hline 7: definitely a bond group & 7: definitely a identity group \\
\hline
\end{tabular}

\section{Definitions:}

Bond groups: members stay in a group because they like other members in the group, for example relation-based groups.

Identity groups: members stay in a group because they like the group as a whole, for example topic groups. 


\section{BIBLIOGRAPHY}

Amburgey, T.L., Kelly, D., and Barnett, W.P. "Resetting The Clock: The Dynamics of Organizational Change and Failure," Administrative Science Quarterly (38:1), Mar 1993, pp 51-73.

Amburgey, T.L., and Rao, H. "Organizational ecology: Past, present, and future directions," Academy of Management Journal (39:5) 1996, p 1265.

Ancona, D.G. "Outward Bound: Strategies for Team Survival in an Organization," The Academy of Management Journal (33:2) 1990, pp 334-365.

Ancona, D.G., and Caldwell, D.F. "Bridging the Boundary: External Activity and Performance in Organizational Teams," Administrative Science Quarterly (37) 1992, pp 634-665.

Arguello, J., Butler, B.S., Joyce, L., Kraut, R., Ling, K.S., Rosé, C., and Wang, X. "Foundations for Successful Individual-Group Interactions in Online Communities," Proceedings of the SIGCHI Conference on Human Factors in Computing Systems, CHI 2006, Montreal, Quebec, Canada, 2006.

Babcock, C. "Demo Report: Internet Consumer Technologies Creeping Into Enterprise Software," in: InformationWeek, 2006.

Barnett, W.P., and Carroll, G.R. "Competition and Mutualism Among Early Telephone Companies," Administrative Science Quarterly (32) 1987, pp 400-421.

Barron, D.N., West, E., and Hannan, M.T. "A Time to Grow and a Time to Die: Growth and Mortality of Credit Unions in New York City, 1914-1990," American Journal of Sociology (100:2) 1994, pp 381-421.

Bateman, P., Butler, B., and Gray, P. "Community Commitment: How Affect, Obligation, and Necessity Drive Online Behaviors," Twenty Seventh International Conference on Information Systems, Milwaukee 2006, 2006.

Baum, J., and Amburgey, T. "Organizational Ecology," in: Companion to Organizations, J.A.C. Baum (ed.), Blackwell Publishers, Ltd, 2002, pp. 304-323.

Baum, J.A.C., and Mezias, S.J. "Localized Competition and Organizational Failure in the Manhattan Hotel Industry, 1898-1990," Administrative Science Quarterly (37) 1992, pp 580-604. 
Baum, J.A.C., and Oliver, C. "Toward an institutional ecology of organizational founding," Academy of Management Journal (39:5) 1996, p 1378.

Baum, J.A.C., and Singh, J.V. "Organizational Niches and the Dynamics of Organizational Mortality," American Journal of Sociology (100:2) 1994, p 346.

Baym, N.K. Tune in, log on: soaps, fandom, and online community Sage Publications, Thousand Oaks, Calif, 2000.

Blanchard, A.L., and Markus, M.L. "The Experienced "Sense" of a Virtual Community: Characteristics and Processes," The Data Base for Advanced Information Systems (35:1) 2004.

Blau, P.M. "Exchange and Power in Social Life," New York: Wiley, 1964.

Blau, P.M. "Exchange and Power in Social Life " The American Journal of Sociology (71:3), Nov 1965, pp 333-334.

Bock, G.W., Zmud, R.W., and Kim, Y.-G. "Behavioral Intention Formation in Knowledge Sharing: Examining the Roles of Extrinsic Motivators, Social-Psychological Forces, and Organizational Climate," MIS Quarterly (29:1), March 2005, pp 87-111.

Boyd, J. "In Community We Trust: Online Security Communication at eBay," Journal of Computer Mediated Communication (7:3), April 2002.

Bruderer, E., and Singh, J.V. "Organizational evolution, learning, and selection: A genetic-algorithm-based model," Academy of Management Journal (39:5) 1996, p 1322.

Butler, B., Sproull, L., Kiesler, S., and Kraut, R. "Community Effort in Online Groups: Who Does the Work and Why?," in: Leadership at a Distance, S. Weisband and L. Atwater (eds.), Lawrence Erlbuam Associates, Mahwah, NJ, 2007.

Butler, B., Sproull, L., Kiesler, S., and Kraut, R. "Community Effort in Online Groups: Who Does the Work and Why?," in: Leadership at a Distance, S. Weisband and L. Atwater (eds.), Lawrence Erlbuam Associates, Mahwah, NJ, Forthcoming.

Butler, B.S. "Membership Size, Communication Activity, and Sustainability: A Resource-Based Model of Online Social Structures," Information Systems Research (12:4), December 2001, pp 346-362.

Carroll, G., and Hannan, M. The Demography of Corporations and Industries Princeton University Press, Princeton, NJ, 2000.

Carroll, G.R., and Hannan, M.T. "Density Delay in the Evolution of Organizational Populations: A Model and Five Empirical Tests," Administrative Science Quarterly (34:3) 1989, p 411. 
Connelly, T., and Thorn, B.K. "Discretionary Databases: Theory, Data, and Implications," in: Organizations and Communication Technology, J. Fulk and C. Steinfield (eds.), Sage Publications, Newbury Park, CA, 1990, pp. 219-233.

Constant, D., Sproull, L., and Kiesler, S. "The Kindness of Strangers: The Usefulness of Electronic Weak Ties for Technical Advice," Organization Science (7:2), March-April 1996, pp 119-135.

Cook, K.S. "Exchange and Power in Networks of Interorganizational Relations," The Sociological Quarterly (18:1) 1977, pp 62-82.

Cress, D.M., and McPherson, J.M. "Competition and Commitment in Voluntary Memberships: the Paradox of Persistence and Participation," Sociological Perspectives (40:1) 1997, pp 61-79.

Cropanzano, R., and Mitchell, M.S. "Social Exchange Theory: An Interdisciplinary Review," Journal of Management (31:6), December 1, 2005 2005, pp 874-900.

Crowston, K., and Howison, J. "Assessing the health of open source communities," Computer (39:5), May 2006, pp 89- 91.

Cummings, J.N., Sproull, L., and Kiesler, S.B. "Beyond Hearing: Where Real-World and Online Support Meet," Group Dynamics: Theory, Research, and Practice (6:1) 2002, pp 78-88.

Curtis, R.L., and Louis A. Zurcher, J. "Stable Resources of Protest Movements: The Multi0Organizational Field," Social Forces (52:1) 1973, pp 53-61.

Dave, K., Wattenberg, M., and Muller, M. "Communities: Flash forums and forumReader: navigating a new kind of large-scale online discussion," Proceedings of the 2004 ACM conference on Computer supported cooperative work, Chicago, IL, 2004, pp. 232 - 241.

Dellarocas, C. "Strategic Manipulation of Internet Opinion Forums: Implications for Consumers and Firms," Management Science (52:10), October 2006, pp 1577-1593.

Drazin, R., and Schoonhoven, C.B. "Community, population, and organization effects on innovation: A multilevel perspective," Academy of Management Journal (39:5) 1996, p 1065.

Duck, S.W. Human relationships (3rd ed.) Sage Publications, Thousand Oaks, CA, 1998.

Emerson, R.M. "Social Exchange Theory," Annual Review of Sociology (2) 1976, pp 335-362

Farrell, D., and Rusbult, C.E. "Exchange variables as predictors of job satisfaction, job commitment, and turnover: The impact of rewards, costs, alternatives, and investments," Organizational Behavior and Human Performance (28) 1981, pp 78-95. 
Farrell, D., and Rusbult, C.E. "Exploring the exit, voice, loyalty, and neglect typology: The influence of job satisfaction, quality of alternatives, and investment size " Journal of Employee Responsibilities and Rights (5:3) 1992, pp 201-218.

Festinger, L. A theory of cognitive dissonance Stanford University Press, 1957.

Fichman, R.G. "The Diffusion and Assimilation of Information Technology Innovations," in: Framing the Domains of IT Management, R.W. Zmud (ed.), Pinnaflex Educational Resources, Inc., Cincinnati, OH, 2000, pp. 105-128.

Fichman, R.G. "Real Options and IT Platform Adoption: Implications for Theory and Practice," Information Systems Research (15:2), June 2004.

Fisher, D., Smith, M., and Welser, H.T. "You Are Who You Talk To: Detecting Roles in Usenet Newsgroups," Proceedings of the 39th Hawaii International Conference on System Sciences, 2006.

Fulk, J., Flanagin, A.J., Kalman, M., Monge, P.R., and Ryan, T. "Connective and communal public goods in interactive communication systems," Communication Theory (6) 1996a, pp 60-87.

Fulk, J., Flanagin, A.J., Kalman, M.E., Monge, P.R., and Ryan, T. "Connective and communal public goods in interactive communication systems," Communication Theory $(6: 1)$ 1996b, pp 60-87.

Galegher, J., Sproull, L., and Kiesler, S. "Legitimacy, authority, and community in electronic support groups," Written Communication (15:4) 1998, pp 493-530.

Giuri, P., Plone, M., Rullani, F., and Torrisi, S. "Skills, Division of Labor and Performance in Collective Inventions. Evidence from the Open Source Software," in: LEM Papers Series 2004/19, Laboratory of Economics and Management (LEM), Sant'Anna School of Advanced Studies, Pisa, Italy, 2004.

Gomes, L. "Will All of Us Get Our 15 Minutes On a YouTube Video?," in: The Wall Street Journal 2006.

Gu, B., Konana, P., Rajagopalan, B., and Chen, H.W.M. "Competition Among Virtual Communities and User Valuation: The Case of Investing-Related Communities," Information Systems Research (18:1) 2007, pp 68-85.

Hair, J.F., Jr. , Anderson, R.E., Tatham, R.L., and Black, W.C. Multivariate data analysis, (5th ed.) Prentice Hall, Upper Saddle River, NJ, 1998.

Hall, H. "Borrowed theory: Applying exchange theories in information science research," Library \& Information Science Research (25:3) 2003, pp 287-306.

Hannan, M. "Competitive and Institutional Processes in Organizational Ecology," in: Technical 
report 86-13, Department of Sociology, Cornell University, Ithaca, NY, 1986.

Hannan, M.T., and Freeman, J. "The Population Ecology of Organizations," American Journal of Sociology (82:5) 1977, pp 929-964.

Hansen, M.T., and Haas, M.R. "Competing for Attention in Knowledge Markets: Electronic Document Dissemination in a Management Consulting Company," Administrative Science Quarterly (46:1) 2001, pp 1-28.

Healy, K., and Schussman, A. "The Ecology of Open-Source Software Development, Unpublished manuscript, University of Arizona," 2003.

Herring, S.C. "Computer-Mediated Discourse," in: Handbook of Discourse Analysis, D. Tannen, D. Schiffrin and H. Hamilton (eds.), Blackwell, Oxford, 2001.

Hertel, G., Niedner, S., and Herrmann, S. "Motivation of software developers in Open Source projects: an Internet-based survey of contributors to the Linux kernel," Research Policy (32) 2003, pp 1159-1177.

Hof, R. "Yahoo! Answers: Search with a Human Touch," in: BusinessWeek, 2005.

Homans, G.C. "Social Behavior as Exchange " The American Journal of Sociology (63:6), May 1958, pp 597-606.

Horrigan, J. "Online Communities: Networks that nurture long-distance relationships and local ties," in: Pew/Internet Reports, 2001.

Ingram, P., and Inman, C. "Institutions, Intergroup Competition, and the Evolution of Hotel Populations around Niagara Falls," Administrative Science Quarterly (41) 1996, pp 629-658.

Jeppesen, L.B., and Frederiksen, L. "Why Do Users Contribute to Firm-Hosted User Communities? The Case of Computer-Controlled Music Instruments," Organization Science (17:1), Jan/Feb 2006, pp 45-63.

Johnson, S.L., and Faraj, S. "Preferential Attachment and Mutuality in Electronic Knowledge Networks," International Conference on Information Systems (ICIS 2005), Las Vegas, NV, 2005.

Jones, Q., Rafaeli, S., and Ravid, G. "Information Overload and the Message Dynamics of Online Interaction Spaces: A Theoretical Model and Empirical Exploration," Information Systems Research (15:2) 2004, pp 194-210.

Joyce, E., and Kraut, R.E. " Loyalty: Predicting continued participation in newsgroups," Journal of Computer Mediated Communication (11:3) 2006.

Kankanhalli, A., Tan, B.C.Y., and Kwok-Kee, W. "Contributing Knowledge to Electronic Knowledge Repositories: An Empirical Investigation," MIS Quarterly (29:1) 2005, pp 
113-143.

Kern, E.-M., Hegering, H.-G., Brügge, B., and Mayrhofer, P. "Motives and Perception of Fairness in Commercial User Communities," in: Managing Development and Application of Digital Technologies, Springer Berlin Heidelberg, 2006, pp. 39-55.

Kim, A.J. Community Building on the Web: Secret Strategies for Successful Online Communities Peachpit Press, Berkeley, CA, 2000.

Kirkland, C. "Top Social Networks: Who's losing to MySpace," 2007.

Kollock, P. "The Emergence of Exchange Structures: An Experimental Study of Uncertainty, Commitment, and Trust," The American Journal of Sociology (100:2), Sept 1994, pp 313-345.

Kollock, P., and Smith, M. "Managing the virtual commons: Cooperation and conflict in computer communities," in: Computer-Mediated Communication: Linguistic, Social, and Cross-Cultural Perspectives, S.C. Herring (ed.), John Benjamin, Amsterdam, 1996, pp. 109-128.

Kraut, R. "Applying social psychological theory to the problems of group work," in: HCI Models, Theories and Frameworks: Toward A Multidisciplinary Science, J.M. Carroll (ed.), Morgan Kaufman, New York, 2003, pp. 325--356.

Lakhani, K.R., and Hippel, E.V. "How open source software works "free" user-to-user assistance," Research Policy (Special Issue on Open Source Software Development) (32) 2003, pp 923-943.

Lawler, E.J., and Jeongkoo, Y. "Commitment in Exchange Relations: Test of a Theory of Relational Cohesion," American Sociological Review (61:1) 1996, pp 89-108.

Lawler, E.J., and Yoon, J. "Power and the Emergence of Commitment Behavior in Negotiated Exchange," American Sociological Review (58:4) 1993, pp 465-481.

Lee, G.K., and Cole, R.E. "From a Firm-Based to a Community-Based Model of Knowledge Creation: The Case of the Linux Kernel Development," Organization Science (14:6), Nov-Dec 2003, pp 633-649.

Lerner, J., and Tirole, J. "Some Simple Economics of Open Source," Journal of Industrial Economics (46:2) 2002, pp 125-156.

Levine, J.M., and Choi, H.-S. "Impact of personnel turnover on team performance and cognition," in: Team cognition: Understanding the factors that drive process and performance E. Salas and S.M. Fiore (eds.), American Psychological Association, Washington, DC, 2004, pp. 153-177.

Levine, J.M., Choi, H.-S., and Moreland, R.L. "Newcomer innovation in work teams.," in: 
Group creativity: Innovation through collaboration, P. Paulus and B. Nijstad (eds.), Oxford University Press, New York, 2003, pp. 202-224.

Levine, J.M., and Moreland, R.L. "Progress in small group research," Annual Review of Psychology (41) 1990, pp 585-634.

Levine, J.M., and Moreland, R.L. "Small groups," in: Handbook of social psychology, D. Gilbert, S. Fiske and G. Lindzey (eds.), McGraw-Hill, Boston, 1998, pp. 415-469.

Levine, J.M., Moreland, R.L., and Ryan, C.S. "Group Socialization and Intergroup Relations," in: Intergroup cognition and intergroup behavior, C. Sedikides, J. Schopler and C. Insko (eds.), Erlbaum, Mahwah, N.J., 1998, pp. 283-308.

Levine, S., and White, P.E. "Exchange as a Conceptual Framework for the Study of Interorganizational Relationships," Administrative Science Quarterly (5:4) 1961, pp 583-601.

Levinthal, D.A. "Organizational Adaptation and Environmental Selection - Interrelated Processes of Change," Organization Science (2:1) 1991, pp 140-146.

Lickel, B., Hamilton, D.L., Wieczorkowska, G., Lewis, A., Sherman, S.J., and Uhles, A.N. "Varieties of Groups and the Perception of Group Entitativity," Journal of Personality and Social Psychology (78:2) 2000.

Ling, K., Beenen, G., Ludford, P.J., Wang, X., Chang, K., Li, X., Cosley, D., Frankowski, D., Terveen, L., Rashid, A.M., Resnick, P., and Kraut, R. "Using social psychology to motivate contributions to online communities," Journal of Computer Mediated Communication (10:4) 2005.

Lomi, A., and Larsen, E.R. "Interacting locally and evolving globally: A computational approach to the dynamics of organizational populations," Academy of Management Journal (39:5) 1996, p 1287.

Markus, L. "Towards a "critical mass" theory of interactive media: Universal access, interdepend-ence, and diffusion," Communication Research (14) 1987, pp 491-511.

McAfee, A. "Enterprise 2.0: The Dawn of Emergent Collaboration," MIT Sloan Management Review (47:3), Spring 2006, pp 21-28.

McGrath, J.E., Arrow, H., and Berdahl, J.L. "The Study of Groups: Past, Present, and Future," Personality \& Social Psychology Review (4:1) 2000, pp 95-105.

McPherson, J.M., Popielarz, P.A., and Drobnic, S. "Social Networks and Organizational Dynamics," American Sociological Review (57:2), Apr. 1992, pp 153-170.

McPherson, J.M., and Rotolo, T. "Testing a Dynamic Model of Social Composition: Diversity and Change in Voluntary Groups," American Sociological Review (61:2), Apr 1996, pp 
179-202.

McPherson, M. "An Ecology of Affiliation," American Sociological Review (48:4) 1983, pp 519-532.

McPherson, M., Smith-Lovin, L., and Cook, J.M. "Birds of a Feather: Homophily in Social Networks," Annual Review of Sociology (27:1) 2001, pp 415-444.

Messick, D.M., and Mackie, D.M. "Intergroup Relations," Annual Review of Psychology (40) 1989, pp 45-81.

Meyer, J., Stanley, D., Herscovich, L., and Topolnytsky, L. "Affective, continuance, and normative commitment to the organization: A meta-analysis of antecedents, correlates, and consequences," Journal of Vocational Behavior (61) 2002, pp 20-52.

Meyer, J.P., and Allen, N.J. "A three-component conceptualization of organizational commitment," Human Resource Management Review (1:1) 1991, pp 61-89.

Meyer, J.P., and Allen, N.J. Commitment in the workplace: Theory, research, and application. Sage, Newbury Park, CA, 1997.

Mockus, A., Fielding, R.T., and Herbsleb, J.D. "Two case studies of Open Source Software Development: Apache and Mozilla," ACM Transactions on Software Engineering and Methodology (11:3) 2002, pp 309--346.

Molm, L.D. "Theories of social exchange and exchange networks," in: Handbook of social theory, G. Ritzer and B. Smart (eds.), Sage, London, 2001, pp. 260-272.

Molm, L.D. "Theoretical Comparisons of Forms of Exchange," Sociological Theory (21:1) 2003, pp 1-17.

Molm, L.D., Takahashi, N., and Peterson, G. "Risk and Trust in Social Exchange: An Experimental Test of a Classical Proposition," The American Journal of Sociology (105:5), March 2000, pp 1396-1427.

Moon, J.Y., and Sproull, L. "Essence of Distributed Work: The Case of the Linux Kernel," First Monday (5:11), November 2000.

Moreland, R.L., and Levine, J.M. "Socialization in organizations and work groups," in: Groups at work: Theory and research, M.E. Turner (ed.), Lawrence Erlbaum As-sociates, Mahwah, NJ, 2000, pp. 69-112.

Moreland, R.L., and McMinn, J.G. "In and Out: Differentiation among Group Members through Social Network Ties,") 2002.

Ogawa, S., and Piller, F.T. "Collective Customer Commitment: Reducing the risks of new product development," MIT Sloan Management Review (47:2), Winter 2006, pp 65-72. 
Olsen, M. The Logic of Collective Action: Public Goods and the Theory of Groups, Cambridge, MA, 1965.

Ostrom, E. Governing the Commons: The Evolution of Institutions for Collective Action Cambridge University Press, New York, 1990.

P'eli, G., Bruggeman, J., Masuch, M., and 'O Nuall'ain, B. "A Logical Approach to Formalizing Organizational Ecology," American Sociological Review (59:4) 1994, p 571.

Pettigrew, T.F. "Social evaluation theory: Convergences and applications," Nebraska Symposium on Motivation (15) 1967, pp 241-311.

Podolny, J.M., Stuart, T.E., and Hannan, M.T. "Networks, Knowledge, and Niches: Competition in the Worldwide Semiconductor Industry, 1984-1991," American Journal of Sociology (102:3), Nov. 1996, p 659.

Popielarz, P.A., and McPherson, J.M. "On the Edge or In Between: Niche Position, Niche Overlap, and the Duration of Voluntary Association Memberships," American Journal of Sociology (101:3), Nov 1995, pp 698-720.

Preece, J. "What is an online community," in: Online Communities: Designing Usability and Supporting Sociability, J. Preece (ed.), John Wiley \& Sons, New York, NY, 2000, pp. 8-19.

Prentice, D.A., Dale T. Miller and Jenifer R. Lightdale "Asymmetries in Attachments to Groups and to their members: Distinguishing between Common-Identity and Common-Bond Groups," Personality \& Social Psychology Bulletin (20:5) 1994, pp 484-493.

Rabe-Hesketh, S., and Skrondal, A. Multilevel and Longitudinal Modeling Using Stata Stata Press 2005.

Ren, Y., Kraut, R.E., and Kiesler, S. "Applying Common Identity and Bond Theory to Design of Online Communities," Academy of Management Best Paper Proceedings, Atlanta, GA, 2006.

Resnick, P. "Beyond bowling together: Sociotechnical capital," in: HCI in the new millenium, J.M. Carroll (ed.), Addison-Wesley, 2001, pp. 647-672.

Rheingold, H. "The Virtual Community: Homesteading on the Electronic Frontier," 2000.

Ridings, C., and Gefen, D. "Virtual Community Attraction: Why People Hang Out Online," Journal of Computer-Mediated Communication (10:1) 2004.

Rusbult, C.E., and Buunk, B.P. "Commitment Processes in Close Relationships: An Interdependence Analysis," Journal of Social and Personal Relationships (10:2) 1993, p 175. 
Rusbult, C.E., and Farrell, D. "A Longitudinal Test of the Investment Model: The Impact on Job Satisfaction, Job Commitment, and Investments " Journal of Applied Psychology (68:3), Aug 1983, pp 429-438.

Rusbult, C.E., Farrell, D., Rogers, G., III, M., and G., A. "Impact of Exchange Variables on Exit, Voice, Loyalty and Neglect: An Integrative Model of Resposnes to Declining Job Status Satisfaction," Academy of Management Journal (31:3) 1988, pp 599-627.

Sassenberg, K. "Common bond and common identity groups on the Internet: Attachment and normative behavior in on-topic and off-topic chats," Group Dynamics: Theory and Practice (6:1) 2002, pp 27-37.

Schindler, E. "Return On Interaction," in: InformationWeek 2001.

Scott, W.R. Organizations: Rational, Natural and Open Systems (2rd ed.) Prentice Hall, 1987.

Sharf, B.F. "Communicating breast cancer on-line: Support and environment on the Internet," Women \& Health (26:1) 1997, pp 65-85.

Shaw, B.R., McTavish, F., Hawkins, R., Gustafson, D.H., and Pingree, S. "Experiences of women with breast cancer: Exchanging social support over the chess computer network.," Journal of Health Communication (5:2) 2000, pp 135-159.

Singer, J., and Willett, J. Applied Longitudinal Data Analysis University Press, Oxford, 2003.

Singh, J. "Review essay: Density dependence theory: Current issues, future promise," American Journal of Sociology (99) 1993, pp 464-473.

Singh, J.V. Organizational Evolution: New Directions Sage, Newbury Park, CA, 1990.

Smith, M.A. "Invisible crowds in cyberspace: Mapping the social structure of the Usenet.," in: Communities in cyberspace, M.A. Smith and P. Kollock. (eds.), Routledge, London, 1999, pp. 195-219.

Smith, M.A. "Netscan: A Social Accounting Search Engine (http://netscan.research.microsoft.com)," Community Technologies Group, Microsoft Corporation, 2005.

Sproull, L., Conley, C., and Moon, J.Y. "Pro-social behavior on the net," in: The Social Net: Understanding Human Behavior In Cyberspace, Y. Amichai-Hamburger (ed.), Oxford University Press, New York, 2005.

Stanoevska-Slabeva, K., and Schmid, B.F. "A typology of online communities and community supporting platforms," Proceedings of the 34th Annual Hawaii International Conference on System Sciences, 2001.

Staw, B.M., Sandelands, L.E., and Dutton, J.E. "Threat-Rigidity Effects in Organizational Behavior: A Multilevel Analysis," Administrative Science Quarterly (26) 1981, pp 
501-524.

Stewart, K.J., and Gosain, S. "An Exploratory Study of Ideology and Trust in Open Source Development Groups," The 22nd International Conference in Information Systems (ICIS 2001), New Orleans, Louisiana, 2001, pp. 507-512.

Stinchcombe, A.L. "Social Structure and Organizations," in: Handbook of Organizations, J.G. March (ed.), Rand McNally \& Company, Chicago, 1965, pp. 142-193.

Takahashi, N. "The Emergence of Generalized Exchange," American Journal of Sociology (105:4) 2000, p 1105.

Tedjamulia, S.J.J., Dean, D.L., Olsen, D.R., and Albrecht, C.C. "Motivating Content Contributions to Online Communities: Toward a More Comprehensive Theory," Proceedings of the 38th Annual Hawaii International Conference on System Sciences, HICSS '05. , 2005.

Tiwana, A., and Bush, A.A. "Continuance in expertise-sharing networks: a social perspective," Engineering Management, IEEE Transactions on (52:1) 2005, pp 85-101.

Torrey, C., Lee, M., Burke, M., Dey, A., Fussell, S., and Kiesler, S. "Connected Giving: Ordinary People Coordinating Disaster Relief on the Internet," CSCW 2006.

Turner, T.C., Smith, M.A., Fisher, D., and Welser, H.T. "Picturing Usenet: Mapping computer-mediated collective action," in: Journal of Computer-Mediated Communication, 2005.

Usher, J.M., and Evans, M.G. "Life and death along gasoline alley: Darwinian and Lamarckian processes in a differentiating," Academy of Management Journal (39:5) 1996, p 1428.

van Witteloostuijn, A. "Bridging Behavioral and Economic Theories of Decline:

Organizational Inertia, Strategic Competition, and Chronic Failure," Management Science (44:4) 1998, pp 501-519.

von Hippel, E. Democratizing Innovation The MIT Press, 2005.

von Hippel, E., and von Krogh, G. "Open Source Software and the Private-Collective Innovation Model," Organization Science (14:2) 2003, pp 209-223.

Wagner, M. "Using Second Life As A Business-To-Business Tool," in: InformationWeek, 2007.

Wang, X., Butler, B.S., and Joyce, L. "Competition - An Ecological Perspective of Online Communities," OCIS Division, Academy of Management Conference Best Paper Proceedings, AOM Annual Meeting 2006, Atlanta, Georgia, 2006.

Wasko, M.M., and Faraj, S. "'It is what one does": why people participate and help others in electronic communities of practice," Journal of Strategic Information Systems (9) 2000, pp 155-173. 
Wasko, M.M., and Faraj, S. "Why Should I Share? Examining Social Capital and Knowledge Contribution in Electronic Networks of Practice," MIS Quarterly (29:1) 2005, pp $35-57$.

Wasko, M.M., Faraj, S., and Teigland, R. "Collective Action and Knowledge Contribution in Electronic Netowrks of Practice," Journal of the Association for Information Systems (5:11-12), December 2004, pp 493-513.

Wellman, B. "Computer networks as social networks," Science:293(14 September)) 2001, pp 2031-2034.

Wylie, S. "The 2.0 Agenda: Transparency, Sharing, Access--Are You Ready For Enterprise 2.0?," in: InformationWeek, 2007.

Yamagishi, T., and Cook, K.S. "Generalized Exchange and Social Dilemmas" Social Psychology Quarterly (56) 1993, pp 235-248. 